\title{
AN ASSESSMENT OF STATISTICS ON ALCOHOL-RELATED PROBLEMS
}

\author{
MAY 5,1980 \\ Project Director \\ Eric Josephson, Ph.D. \\ Columbia University School of Public Health \\ Contributors \\ Norma Agatstein, M.Phil. \\ Columbia University School of Public Health \\ Julianne M. Byrne, M.S. \\ Columbia University School of Public Health \\ John J. Getzow, B.A. \\ New York City \\ Paul W. Haberman, M.B.A. \\ Columbia University School of Public Health \\ Thomas G. McGuire, Ph.D. \\ Boston University \\ Rita H. Neugut, M.P.H. \\ Columbia University School of Public Health
}

Prepared for the Distilled Spirits Council of the United States, Inc. 


\section{Table of Contents}

Summary. Prepared by Eric Josephson, Ph.D., Columbia School of Public Health

Ch. I. A Critical Review of the Literature on the Fetal Alcohol Syndrome in Humans. Prepared by Rita H. Neugut, M.P.H., Columbia University School of Public Health

Ch. II. Animal Models of the Fetal Alcohol Syndrome. Prepared by Julianne M. Byrne, M.S., Columbia University School of Public Health and John J. Getzow, B.A., New York City

Ch. III. Trends in Probiem Drinking. Prepared by Eric Josephson, Ph.D. and Paul Haberman, M.B.A., Columbia University School of Public Health

Ch. IV. Problem Drinking in Youth. Prepared by Eric Josephson, Ph.D., Columbia University School of Public Health

Ch. V. Problem Drinking Among Women. Prepared by Norma Agatstein, M. Phil., Columbia University School of Public Health

Ch. VI. Alcohol-Related Casualties. Prepared by Eric Josephson, Ph.D. and Paul W. Haberman, M.B.A., Columbia University School of Public Health

Ch. VII. Measuring the Costs of Alcohol Abuse. Prepared by Thomas G. McGuire, Ph.D., Boston University 
Prepared by Eric Josephson, Division of Sociomedical Sciences, Columbia University School of Public Health. 
An objective assessment of government statistics on alcoholrelated problems, many of them compiled in the Third Report to the U.S. Congress on Alcohol and Health in 1978, indicates that there is Iittle sound basis for clalms that there are upwards of 10 million problem drinkers (including alcoholics) in the adult population and that their number is increasing; that there are 1.5 to 2.25 million problem drinkers among women; that there are over 3 million problem drinkers among youth; that the heavy consumption of alcohol by pregnant women leads consistently to a cluster of birth defects -the so-called Fetal Alcohol Syndrome; that half of all motor vehicle accident fatalities are alcohol-related; and that the cost of alcohol abuse in 1975 was $\$ 43$ billion. These and other claims about the extent and consequences of alcohol use and abuse -- some of them fanciful, others as yet to be supported by research -- are part of the "numbers game" which besets discussion of alcohol-related problems and policy.

Concern about health and other problems related to the consumption of beverage alcohol has in recent years generated a substantial volume of epidemiological, psychosocial and biomedical research on the nature and extent of such problems and ways of dealing with them. Much although not all of this research has been conducted under the aegis of the National Institute on Alcohol Abuse and Alcoholism. But while a good deal has been learned about alcohol-related problems, much about them remains unknown. Why this is so has to do with the complexity of the problems, the lack of agreement among researchers themselves about the terms they use (e.g., "alcoholism" 
or "problem dinking"), inherent problems in measuring the extent of and trends in alcohol use, and perhaps above all, difficulties in determining just what problems can be attributed to the consumption of alcohol and what to other factors.

But these and other conceptual and methodological problems have not prevented public officials and some researchers themselves from issuing alarming statements about the prevalence of and trends in alcohol-related problems for which there is 1ittle basis in fact. The consumption of alcohol at certain levels may indeed have serious consequences nd be assoclated with a variety of health and other problems. The seriousness of those problems calls for equally serfous discussion of their nature and ways of coping with them.

This report is intended as a contribution to that discussion. Its aim is to provide a critical, objective assessment of government and other statistics regarding certain alcohol-related problems; further research will be suggested where needed and appropriate. The topics to be covered are: (1) human studies relating to the Fetal Alcohol Syndrome, (2) animal studies relating to the Fetal Alcohol Syndrome, (3) overall trends in the consumption of beverage alcohol and in problem drinking, (4) problem drinking among youth, (5) problem drinking among women, (6) alcohol-related casualties, and (7) the costs of alcohol abuse.

\section{(1) Human studies of the Fetal Alcohol Syndrome (Ch. 1)}

The Fetal Alcohol Syndrome, about which many alarming statements have been made, has been described as a cluster of birth defects in the 
offspring of women who consume heavy amounts of alcohol while pregnant. A review of the relevent research 1iterature indicates that the fetal alcohol syndrome has yet to be clearly established as a distinct entity; that investigators have so far been unable to Identify it consistent $1 y-1$, e. without prior knowledge of matexal: aleohol consumption; and that with the exception of a distinctive facial appearance all of the component abnormalities of the Fetal Alcohol Syndrome are known to be associated with various other antecedent factors. Nor are there data which would indicate just what amounts of alcohol consumed by pregnant women are associated with which effects. Although there are grounds for concern about the Fetal Alcohol Syndrome in particular and about fetal alcohol effects more generally, it is not possible to state with confidence whether, to what extent, or under what circumstances, heavy drinking during pregnancy is associated with a particular cluster of abnormalities or defects. There are no reliable national statistics on the extent of the phenomenon. Even less in known about the effects on offspring of lower levels of alcohol consumption.

(2) Antmal studies of the Fetal Alcohol Syndrome (Ch. II)

Animal studies relating to this phenomenon have been undertaken because of the opportunity they provide, missing in human studies, to examine the effects of dosage and timing in pregnancy and to control for the possible confounding influence of other factors, e.g., nutrition. Yet the applicability to humans of findings from animal studies of alcohol as well as other substances is Ifmited not only because of species differences, but also because they have their own methodological problems. 
Because these problems have not yet been satisfactorily resolved, issues relating to dosage (in some experiments the alcohol dose levels have been the equivalent of enormous amounts in human terms) and nutritional status have not as yet been clarified. Nevertheless, a review of the animal 1iterature indicates that alcohol ingestion during pregnancy acts in a dose-responsive manner to produce a wide valiety of changes ranging from impalred fertility to malformations, behavioral changes and lowered birthreight in the offspring. The malformations are variable, affecting many organ systems. However, alcohol has not yet produced in animals an identifiable constellation of anomalies, similar to that described by clinicians as the Fetal Alcohol Syndrome.

(3) Overall trends in problem drinking (Ch. III)

According to the 1978 NIAAA report, per capita consumption of beverage alcohol in the U.S. has since 1971 been higher than at any time since 1850. However, it is possible that consumption was considerably higher before 1850. In any case, the data available indicate that there were no major shifts in patterns and levels of consumption during the 1970s. Estimates regarding the prevalence of and trends in problem drinking (including alcoholism) -- NIAAA reported that there were 9.3 to 10 million problem drinkers (including alcoholics) -suffer from a number of difficultles: the surveys on which they are based vary in their definitions and in methods of data collection; there is the possibility, not necessarily equal, of over- as well as under-reporting in such surveys; and few of the surveys take into ac- 
count the reversibility of drinking problems. For these and other reasons, there are neither reliable nor valld data on the national prevalence of and trends in problem drinking.

(4) Problem drinking among youth (Ch. IV).

In its 1978 report NIAAA estimated that there were 3.3 milition problem drinkers among youth. Like some of the other estimates, this figure is based on an arbitrary definition of youthful problem drinkIng -- a phenomenon with a different context from that of adults -and very likely exaggerates the extent of the problem. A review of the 1iterature on youthful drinking behavior indicates that since the mid1960s there have apparently been no significant shifts in the age of initiation into drinking, the proportion of youth consuming beverage alcohol, the frequency with which they consume it, or the amounts consumed. Nor is there any evidence that the traditional gap between girls and boys in drinking practices has been closed, although it has apparently been narrowed. Young dinining drivers are generally regarded as disproportionately at risk of involvement in motor vehicle accidents and the reduction by some states of the legal drinking age has been linked to higher auto accident rates; but research has so far been unable to determine with any precision how many of these accidents are associated with drinking inexperience, driving inexperience or other factors and whether the reduction of the legal drinking age has contributed to higher auto accident rates. As for whether problem drinking in youth predicts problem drinking in adulthood, the data available provide no certain answer: some but by no means all young problem 
drinkers are likely to have problems with alcohol later in life many "mature out" of such problems which, as noted, have different contexts in youth and adulthood.

(5) Problem drinking among women (Ch. V).

Why concern has been expressed about problem drinking among women is not entirely clear; a prevailing assumption is that it is Increasing. It has been estimated by NIAAA that there are 1.5 to 2.25 million women with drinking problems, including alcoholics. And yet, whlle there is some evidence that more women consume alcoholic beverages today than several decades ago, during the 1970 s there was no apparent increase in the relative numbers of women who drink or in the frequency with which they drink. A review of the literature indicates that women continue to score lower than men by all measures of drinking and drinking problems; it also indicates that the problems women experience with alcohol tend to be different from those of men. Although there has been some speculation that women's drinking behavior is changing and will change further because of changing sex roles, this has yet to be demonstrated with any certainty.

\section{(6) Alcohol-related casulaties (Ch. VI).}

The heavy consumption of beverage alcohol, such consumption usually ill-defined, has been associated with a variety of casualties, notably motor vehicle accidents; NIAAA claims that half of all motor vehicle accident fatalities are alcohol-related. However, the 1978 NIAAA compilation of research findings on alcohol involvement in 
auto accidents makes it clear that there is a considerable range in the estimates regarding the implication of alcohol -- e.g., in the case of fatal traffic accidents Involving the driver the range is from 35 percent in one study to 59 percent in another, and in the case of fatal traffic accidents involving pedestrians the range is from 25 percent in one study to 83 percent in another; yet it is consistently the higher figure which is selected as the indicator of alcohol's contribution to such accidents. To be sure, those who abuse alcohol are at high risk of injuring themselves or of dying prematurely. And yet cirrhosis mortality rates in recent years have been declining in the U.S.; why this is so has not been determined.

(7) Measuring the costs of alcohol abuse (Ch. VII).

An authoritative economic study, commissioned by NIAAA, has it that alcohol abuse, which of course lends itself to various definitions, cost the U.S. $\$ 43$ billion in 1975 ; like the estimated number of alcoholics in the population, this figure keeps rising in official statements regarding the 1ssue. A critical review of the study from which this estimate is derived suggests that it may have overstated some of the costs (because of limitations in the data on the estimated number of alcohol abusers on which it is based, because it falled to include some of the benefits of alcohol consumption, and because certain costs associated with alcohol abuse are interpreted as due solely or primarily to such abuse). However, the study may also have understated some of the costs because of an incomplete accounting of all items which could concelvably be associated with alcohol abuse. 
I. A Critical Review of the Literature on the Fetal Alcohol Syndrome in Humans

Prepared by Rita H. Neugut, Division of Epidemiology, Columbia University School of Public Health 
Two regearch groups have independently observed a similar cluster of abnormalities in offspring born of alcoholic mothers. The Fetal Alcohol Syndrome (FAS), named in 1973, has been described as a cluster of pre- and postnatal growth deficlency, developmental delay, facial anomalies and vartous other malformations among those exposed in utero to maternal alcoholism. However, a review of the literature that deals with FAS in humans reveals that it has yet to be clearly established as a distinct entity.

While FAS cases reported in the 11terature since 1973 number in the hundreds, very few of them have been diagnosed without the potentially biasing foreknowledge of maternal alcoholism. Evidence is lacking of an ability to Identify FAS consistently in offspring of heavy drinkers without prior knowledge of maternal alcohol consumption. Similarly, without knowledge of maternal alcohol consumption, the syndrome should not be identified in offspring of non-drinkers or Ifght drinkers; this latter abllity also has not been demonstrated. The need for such "blind" demonstration is particularly strong because diagnosis of abnormal FAS-type factal characteristics has not been based on rigorous scientific criteria.

All of the component abnormalities of FAS, save the distinctive factal appearance, are known to be assocfated with various other antecedent factors. Thus, before heavy maternal alcohol consumption can be established as an additional cause of these abnormal outcomes, the contribution of other factors whlch are known to be assoctated with them must be assessed. For example, if an association between 
maternal alcohol consumption and birthweight is to be demonstrated, the roles of such factors as maternal size, maternal smoking, maternal welght gain during pregnancy, maternal age, and ethnicity -- factors which are known to affect birthwelght -- must also be assessed. This sort of analysis has not yet been done for efther component features of the syndrome or for the syndrome as a whole.

Four major prospective epidemiological studies have been undertaken where maternal alcohol consumption has been related to pregnancy outcome. in one study (Ouellette et al, 1978), no cases of FAS per se were found, though heavy maternal alcohol consumption during pregnancy did relate to a number of adverse pregnancy outcomes. In another study (Hanson et al., 1978), women were questioned about their alcohol consumption in the month prior to pregnancy and in the first four months of pregnancy. Self-report of alcohol consumption in the first four months of pregnancy, in general quite low, did not relate to blind diagnosis of FAS or "partial FAS," though self-report of consumption in the month prior to pregnancy did relate to such a diagnosis. In a third study (Kaminski et al, 1976) largely carried out before FAS had been described, heavy maternal alcohol consumption during pregnancy was related in a limfted fashion to a few adverse pregnancy outcomes. Subsequently, the researchers became aware of FAS but emphasize that they did not find an excess of congenital malformations among the offspring of their heavier drinkers as compared to their lighter drinkers. In a fourth study (Olegard et al, 1979), possibly the most supportive of the existence of the syndrome, all or most infants born in one clty during 
a specified time period were assessed for FAS. FAS was diagnosed in the offspring of some women who were known from earlier in pregnancy to be alcohol abusers. More significantly, FAS was also diagnosed in a few infants without a priori information regarding maternal alcohol consumption during pregnancy. In those cases where information was subsequently obtained regarding alcohol consumption, it was found to have been excessive. However, in this study no criterla were given for the diagnosis of FAS and only very 1 Imited information was given regarding Identification of maternal alcohol abuse.

Although the evidence to date justifies serlous concern, it is still not possible to state with confidence whether, to what extent, and under what circumstances, heavy drinking during pregnancy is associated with a particular cluster of factal and other congenttal anomalies. To answer such questions, further investigation should be strongly encouraged. 
INTRODUCTION

This evaluation of the evidence regarding the association between heavy maternal alcohol intake during pregnancy and pregnancy outcome is undertaken from an epidemiological perspective. The claim has been made that in utero exposure to heavy maternal alcohol consumption causes a specific cluster of abnormalities in the offspring, named Fetal Alcohol Syndrome (FAS). The cluster of FAS abnormalities includes:

(1) prenatal growth deficiency as measured by birth weight, birth length and head circumference

(2) certain congenftal malformations

(3) postnatal faflure to thrive

(4) developmental delay

(5) a distinctive abnormal-1ooking facial appearance

Much concern has been expressed (Third Spectal Report to the U.S. Congress on Alcohol and Health, 1978; Fabro, 1979) regarding the public health significance of the syndrome. There are two underlying characteristics of the syndrome which should be made explicit:

(1) Of the five features of the syndrome enumerated above, each of the first four has been associated with various other antecedent factors (e.g., prenatal growth deficiency is associated with inter alia, maternal age, maternal size, maternal welght gain during pregnancy, maternal smoking and ethnicity). Each of these four is therefore non-spectfic, and in order to discover a causal connection between maternal drinking and these outcomes, appropriate comparison groups or statistical controls are needed. 
(2) On the other hand, the unusual faclal characteristics noted in FAS are a sine qua non for diagnosis of the syndrome. Unfortunately, the abnormal facial appearance assoctated with FAS is not one which is readily subject to rigorous measurement criteria.

To establish a causal assoclation, and to evaluate the relative risk of heavy drinking for FAS, systematic study must therefore be undertaken. Case reports arouse suspicion, but do not establish a relationship. Thus to report series of cases in which all individuals In the series share both the exposure and the outcome tells one nothing about the frequency of the exposure or about the frequency of the outcome in the general population. Hence the need for a comparison group.

If systematic study is done prospectively, it requires followup of pregnant women both with and without the risk factor: high levels of alcohol consumption during pregnancy. If the study is prospective, infants born to study women must be examined using a standard and systematic schedule. Examinations must be made without foreknowledge of maternal alcohol consumption, 1.e., "blindly."

If the study is retrospective, systematic criteria for case definftion are still required, but in this design mothers of individuals both with and without the syndrome are assessed for alcohol consumption during pregnancy; it is essential that this assessment of the mothers' consumpton be done without knowledge of the status of the infants.

Maternal alcohol consumption, both heavy and light, must be documented by means of a systematic and chronological history of maternal drinking, gathered without knowledge of the outcome in the offspring, 
i.e., blindly. The range of alcohol consumption among study mothers must be adequate to the task of relating amounts of alcohol consumed to outcome. Therefore, women with a range of alcohol consumption patterns must be included for study.

The syndrome should be diagnosed in the offspring of women consuming defined "large amounts" of alcohol during pregnancy and in no others; i.e., it should not be diagnosed in women consuming lesser amounts during pregnancy. Interpretation of occurrence of partial expression of FAS awaits better understanding of the full syndrome.

Establishment of an association between heavy maternal alcohol consumption during pregnancy and the particular abnormal FAS-type face would imply causality if no other equally suspicious factor can be suggested. Establishment of a causal association between maternal alcohol consumption during pregnancy and one or more of the non-spectflc FAS features (whether in conjunction with the abnormal face or separately) requires more careful analysis. In the latter case, controlled assessment of the role of the known antecedent factors which could explain an observed correlation is requisite.

W1th this brief discussion of epidemiological principles, the 11terature will be reviewed. Areas of concern include the objectivity with which the drinking history was obtained, the systematic nature of the infant examination, the presence or absence of a comparison group and, perhaps most important of all, whether the identification of a case was made blind to knowledge of the maternal drinking history. 
II. IDENTIFICATION AND DESCRIPTION OF THE FETAL ALCOHOL SYNDROME

\section{A. Identification of The Syndrome}

In 1972, Ulleland in Seattle, Washington published her findings of an association between intrauterine growth fallure (IUGF), fallure-to-thrive postnatally, and maternal alcoholism. After observIng six children who shared these three features between October 1968 and June 1969, she went back to review the records of a total population of births (1500+) for recognized maternal alcoholism and low birthweight. Studying a population which included the six cases who had brought the association to her attention, she found that 10 of the 12 offspring of recognized alcoholics had low birthweight as compared to 2.3 percent with similarly low birthweight in the other $1500+$ children born between January 1968 and June 1969. The criteria for diagnosing alcoholism was given as a modification of the WHO definition. U1leland also noted high rates of postnatal fallure-to-thrive and developmental delay in the alcoholics' offspring. She quite rightly pointed out that even if 90 percent of alcoholic women in the study population went unrecognlzed, the association between birthweight and maternal alcoholism would still exist.

A problem with Ulleland's population study should be noted. By selecting as the time period for the birth of the study subjects one which included the dates of birth of the six cases of low birthweight which she had observed previously, Ulleland biased her population data in favor of a positive association. Put more simply, the six cases of recognized maternal alcoholism and low birthwelght (a) were known before undertaking systematic investigation; (b) promo- 
ted the further study, and (c) contributed substantially to the results of that further study.

In 1973, Jones et al., researchers at the same Seattle location, assessed elght offspring of chronic alcoholic mothers using criteria issued by the $\mathrm{N}$ ational Council on Alcoholism. Possibly some, perhaps all, of these elght had also been included in U1leland's series. In these eight they observed and described a pattern of craniofacial, 1imb and cardiovascular malformations, developmental delay and pre- and postnatal growth deficiency. The physical ard mental assessments were made with foreknowledge of the mother's alcohol abuse, 1.e., the evalutations were not performed blindly. A few months later, describing three additional cases with similar findings where maternal alcohol abuse was known before the diagnosis was made, Jones and Smith (1973) dubbed the cluster of anomaIles they observed "fetal alcohol syndrome" (FAS). Furthermore, though they did not specify a mechanism, they implicated in utero exposure to excessive maternal alcohol intake as the cause of the clinical outcome.

It was only after their identification of FAS that the group of Jones et al. became aware of a French paper published in 1968 (Lemoine et al.) which described the offspring born of chronic alcoholic mothers and/or fathers. The discovery of this earlier paper was heralded as providing strong corroboration of the existence of FAS. The paper by Lemoine et al. reports in anecdotal fashion on the "high1y distinctive appearance" of 127 children born of alcoholic parents. No information whatsoever is given regarding the basis for the diagnosis of alcoholism. The 127 children came from a total of 69 fami- 
lies - 29 where both parents were alcoholic, 25 with only an alcoholic mother, and 15 with only an alcoholic father. The anecdotal descriptions of particular features of these children did not differentiate the children according to parentage though the authors comment that they had reservations about the comparability between those children whose fathers only were alcoholic and the others. Lemoine et al. found the 127 children outstanding with respect to four characteristics: distinctive faclal features -- very similar indeed to those described by Jones et al. (1973), growth retardation, high frequency of malformations and psychomotor disturbances.

\section{B. Description of The Syndrome}

It is appropriate now to look more closely at the prevailing defintion of fetal alcohol syndrome. Firstly, the term 'syndrome' may be defined as a concurrence or clustering of symptoms in one individual. Indeed, only the unusual faclal appearanee: associated with FAS is considered distinctive to affected individuals (although whether it is exclusively limited to alcoholics' offspring has not been established). It is the clustering of the various features in the individual case which allows for Identification of the syndrome.

A 1976 paper by Hanson, Jones \& Smlth consolidates the work of the Seattle group on FAS. They reported on 41 FAS cases - the 11 they had previously described (Jones et al, 1973; Jones and Smith, 1973) and 30 others -- gathered in a varlety of ways. The 30 new FAS cases reported on in the article, once again, were assessed with the evaluators being aware beforehand of maternal alcohol abuse. Without giving a precise definition, they provided the following table of common abnormalities found in FAS. 


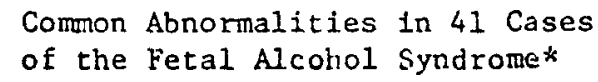

Abnormality

Number Observed

Number Affected

Percent Affected

\begin{tabular}{|c|c|c|c|}
\hline Prenatal growth deficiency $(1)$ & 39 & 38 & 97 \\
\hline Postnatal growth deficiency(1) & 38 & 37 & 97 \\
\hline Microcephaly (i) & 41 & 38 & 93 \\
\hline $\begin{array}{l}\text { Development delay or } \\
\text { mental deflclency }(i)\end{array}$ & 35 & 31 & 89 \\
\hline Fine motor dysfunction & 35 & 28 & 80 \\
\hline \multicolumn{4}{|l|}{ Cranlofacial } \\
\hline ++Short palpebral fissures (ii) & 38 & 35 & 92 \\
\hline M1dfacial hypoplasia & 40 & 26 & 65 \\
\hline Eplcanthic folds & 41 & 20 & 49 \\
\hline \multicolumn{4}{|l|}{ L1mb } \\
\hline Abnormal palmar creases & 41 & 20 & 49 \\
\hline Joint anomalies (mostly minor) & 41 & 17 & 41 \\
\hline \multicolumn{4}{|l|}{ other } \\
\hline $\begin{array}{r}\text { Cardiac defect (mostly septal } \\
\text { defects) }\end{array}$ & 41 & 20 & 49 \\
\hline External genital anomalies (minor) & 41 & 13 & 32 \\
\hline $\begin{array}{l}\text { Hemanglomas (most ly small, } \\
\text { raised, strawberry angiomas) }\end{array}$ & 41 & 12 & 29 \\
\hline Ear anomalies (minor) & 41. & 9 & 22 \\
\hline
\end{tabular}

(i) 2 SDs or more below the normal for age, equivalent to below the 2.5 percentile.

(i1) Judging from standards of Chouke.

NOTE: See page I- 11 for definition of terms used in ahove tablè.

SOURCE: Hanson, J.W.; Jones, K.L., and Smith, D.W. : Fetal Alcohol Syndrome Experience with 41 patients. Journal of The Anerican Medical Association 235: $1458-1460,1976$.

+ This feature has been emphasized as especially common in and distinczive of FAS. 
Non-technical definitions (Stedman's Medical Dictionary, 1972)

of the terms used in the previous table are given below:

palpebral flssure - eye slit

hypoplasia - defective formation or Incomplete development

epicanthic (or epicanthal) folds - a fold of skin extending from the root of the nose to the inner end of the eyebrow overlapping the inner comer of the eye; it is normal in the Mongolian race

hemangiomas - a benign cluster of blood vessels

Hanson et al mention other abnormalities noted in two to five of the cases:

microphthalmos (p1. - thalmia) - abnormally small eyeballs

strabismus - cross-eyed

ptosis - droopy eyelid

cleft palate - a congenital fissure down the middle of the palate

pectus excavatum - a hollow at the lower part of the chest

In a subsequent description (Clarren \& Smith, 1978, where 245 FAS

cases reported in the literature to date were reviewed, albeit somewhat misleadingly, for frequency of occurrence of particular symptoms)* of the facial anomalies associated with FAS, the mid-facial hypoplasia has been described more specifically to include:

hypoplastic philtrum - diminished or absent groove in the midline of the upper lip

thinned upper vermilion - thinned external upper lip

short upturned nose

hypoplastic maxilla (upper jaw) and micrognathia/retrognathia smallness or underdevelopment of one or both the upper and lower Jaws

* See Appendix for a discussion of some of the serious problems In this article. 
There is a strong though ifmited concurrence between the description of the FAS features given by Jones et al. and those described by Lemoine et al. Lemoine et $\underline{\text { al }}$. also described prenatal and postnatal growth deficiency though they were more optimistic than Jones' group with regard to catch-up growth in adolescence. They differed from Jones' group in that nearly all of their subjects were born prematurely (though small even when corrocted for gestational age). Both groups mention that length was often more deficient than weight at birth. Lemoine et al. mention, without elaboration, psychomotor anomalies and an average I.Q. of about 70 in their subjects. Jones et al. usually found mild to moderate mental retardation in their cases. The French group reported on malformations observed for 25 of their subjects and they are not inconsistent with Jones' findings. The reader is told, however, that the manner in which they collected their sample probably increased the likelihood of malformations among its members. Probably most impressive, though, is the similarity between the two groups in their descriptions of the face. The mid-face hypoplasia is quite similarly described; the short upturned nose, hypoplastic philtrum, and retrognathia are specifically referred to by the French. The ocular anomalies, and especially the short palpebral fissures, were not, however, described in the French study.

While the anecdotal nature of the French report, as well as Iimitations of the American work must be remembered, the independent 
confirmation which the Americans and French works provide must also be emphasized. 1

It Is not a coincidence that Hanson et al (1976) (and Clarren and Smith (1978) as well) do not give a precise definition but rather identify common features when describing FAS. Indeed, if one defines a syndrome as a cluster of symptoms or features with many of the symptoms occurring in each case, then what is the meaning of subsequently reviewing a series of cases and reporting on the percentages with each feature?

It is certainly appropriate now for those researchers who feel confident that FAS exists as a distinct entity to provide a rather specific definition of the disorder---in particular, stating which features are requisite for the diagnosis and which are individually optional though some minimal number of them must occur. If a definition of this sort were developed a priori and subsequently a series of cases were collected, it would then be a real contribution (a) to report, along with the definition of FAS that was employed, the frequency of each optional feature in a serles of cases so defined, and (b) to discuss cases which the researchers intuitively feel should be considered FAS cases but which do not quite fit the definition. Thus, if a particular neonate does not sat1sfy the established low birthwelght criterion but does have the other FAS characteristics, one would want to know whether or not that infant is below average

1 It is also noteworthy that Lemoine et al. refer to a 1957 thesis of J. Rouquette which, they state, reports very similar facial and personality features in 100 other offspring of alcoholics. 
in weight.

The problem of the empirical basis for the identification of the fetal alcohol syndrome as a distinct entity is a pressing one. Recently, the claim has been made that the FAS facial appearance is as distinctive as that found with Down's Syndrome (Streissguth, 1978). And yet, the contrast between the routes to discovery of these two syndromes is instructive. Down's Syndrose was described clinically in the mid $1800^{\prime} s$. It was only a ter about: a hundred years that the cause of the clinical outcome was recognized. Thus, for nearly a century clinicians had to make their diagnoses of Down's Syndrome without knowing the causative mechanism. After the etiology of Down's Syndrome was discovered, by successfully going back and revlewing previously identified cases of the disorder to verify the presence of the causative factor, clearcut proof that the syndrome was indeed a distinct entity was provided.

The circumstances surrounding the discovery of FAS are by no means comparable. Rather, in the case of FAS, both the effect (i.e., the pre- and postnatal abnormalities) and the purported cause (1.e., maternal alcoholism during pregnancy) were recognized simultaneously. But it should be quite obvious that foreknowledge of mothers' alcoholism certainly could bias the expectations of a pediatrician or other evaluator observing a group of their offspring and hence his assessments. ${ }^{2}$ This is especially true in the case of FAS

2 The possibility for unwitting biased interpretation of observation becomes all the greater once a particular syndrome has already been described. 
because so many of the particular facial anomalies associated with it are not subject to diagnosis by standardized criteria.

There is also a major problem with accepting the discovery of the purported cause. Maternal alcoholism is often associated with various other behaviors and circumstances which themselves may contribute to adverse pregnancy outcome. Thus, J. Mendelson has stated: "Although no one would encourage alcohol abuse by pregnant women, to emphasize the teratogenic role of ethanol per se without adequate delineation of other factors in the causation of birth defects is scientifically unsound." (NEJM, 1978, p.556)

\section{REVIEW OF THE RESEARCH ON FAS IN HUMANS}

When studying disease processes in humans two types of data collection are common. One data-gathering method, that of the case report or case series, is informative, especially in the early stages of confirming and understanding a disease process. Case reports allow for: a detalled description and probing of the circumstances of the individual case or serles of cases. However, by its very nature, the case report method cannot provide a picture of the broader pattern of ocisurence of the disease elther among the population at large or anong the exposed population. If one wants to understand the determinants and the distribution of the occurrence of a particular disorder, then systematic study of populations or population sub-groups is necessary.

\section{A. Case Reports}

Following the initial reports of the discovery of the fetal alcohol syndrome, case reports began to proliferate in the literature 
(see footnote $e^{3}$ below for a partial 11sting). What is the significance of these numerous case reports? On the one hand, they suggest that others seemed to be seelng what Jones et al. had described. And yet, the knowledge (on the part of the various researchers) of maternal alcohollsm before the diagnosis of FAS was made, once again, reduces the objectivity of the diagnosis in such instances.

There is a further problem in interpreting the significance of the case reports. Alcohol consumption varies on a continuum among women. Throughout the world numerous offspring are born to women consumIng high levels of alcohol. Individual observations or groups of observations cannot be related to appropriate denominators. Even if none of the FAS characteristics were related to matemal alcohol consumption, the frequent occurrence of heavy maternal alcohol use would, by chance, produce some infants who would exhibit enough of the specific FAS anomalies to be so diagnosed. This is particuiarly true since women who are heavy consumers of alcohol may be at increased risk of adverse pregnancy outcome because of other behaviors.

Once a new syndrome, e.g. FAS, is described, confirmatory case reports become worthy of publication and appear in the literature. On the other hand, findings of other anomalous characteristics in newborns with in utero exposure to varying levels of maternal alcohol consumption and, of course, births of healthy neonates to alcoholic mothers

3 Case reports include: Barry \& O'Naullain, 1975; Bierich et al, 1975; Christoffel et al, 1975; Ferrier et al, 1973; Hall \& Orenstein, 1974; Lolodice et al, 1975; Manzke and Grosse, 1975; Mulvihill et al, 1976; Noonan, 1976; Palmer et a1, 1974; Reinhold et al, 1975; Root et al, 1975; and Tenbrinck et al, 1975. 
are not as likely to be published since they do not represent reports of some specific syndrome.

Large serles of cases not gathered systematically are more informative than reports of one or a handful of cases. Nonetheless, limitations to inference deriving from the method of data collection remain. The series of cases collected by Majewski, Bierich et al. In Germany, while apparently not gathered systematically, is one such large series. Their sertes grew from 12 cases (Blerich et al., 1975) to 24 (Bierich et al., 1976) to 68 (Majewski et al., 1976) (and there is a report of 76 cases in their series in Clarren \& Smith, 1978a). It is reported that in most cases the diagnosis of FAS was made before maternal alcohol abuse was known. The description of the serles of cases does closely resemble the earlier descriptions of Lemolne et al. and Jones et al. with two exceptlons. Majewskl et al. found small palpebral fissures, a hallmark FAS characteristic according to Jones et al., in less than $10 \%$ of his cases (see Clarren \& Smlth, 1978). Another rather odd finding of the German group is that among their patients the severity of FAS (in three grades) seemed to relate inversely to amount of alcohol consumed dally.

A third point and a major criticism of their work relates to the fact that about one-third of their cases, those experiencing only the lightest grade of FAS, had as the1r only symptoms at birth small 
size and microcephaly (Loser \& Majewski, 1977). How could FAS possibly have been identified blindly in these children since these particular symptoms can have multiple causes? When these infants were identified, did the researchers then Investigate various possible causes for the growth retardation or did they only check for heavy maternal alcoholism consumption? It is inconcelvable that every low birthweight infant born with microcephaly who came to their attention had an alcoholic mother, though information on this point is lacking.

Another large case series which should be cited, a northern French series of over 50 cases published in 1977 (Dupuis et al.) is considerably more problematic than the German serfes. The cases, though possibly gathered more systematically, were not gathered blind1y. In fact, it seems that in some instances recognition of maternal alcoholism was overtly used to assist in the diagnostic process! While the authors mention that not every offspring born of an alcoholic mother had FAS, they give no further information in this regard.

\section{B. Epidemiologic Data}

1. Chart review study. Jones et al, $1974 a$.

In an attempt to assess the effects of maternal alcoholism prospectively (i.e., by following up a group of children first identified while in utero as being exposed to maternal alcoholism), Jones et al. (1974a) undertook a chart review study. They used an enormous data set which contained information on about 55,000 pregnancies from the time of maternal registration for prenatal care until the offspring either died, reached seven years of age, or were lost to follow-up. 
Though very extensive, this data set did not include systematic inquiry about maternal alcohol consumption. A diagnosis of maternal alcoholIsm seemed 'reasonably secure" in 23 cases; rigid criterta for the diagnosis could not be met since the chart information was largely anecdotal. Matching each of these 23 women closely to two other women without chart mention of maternal alcoholism (e.g. matching for socioeconomic: group, age, race, etc.), the pregnancy outcomes of the two groups were contrasted. Among the 23 alcoholics' offspring, four died perinatally vs. one among the comparison group of 46 . While the data set had been collected before FAS had been described, the researchers felt that the chart reviews indicated enough abnormal features in six of the remaining 19 exposed offspring to suggest a posstb1lity of FAS but not in any of the controls. In fact, the authors went so far as to suggest that induced abortion be considered in pregnant alcoholics.

There are numerous problems with this study. As Rosett (1974) pointed out, based on a national survey of drinking practices, one would have expected about 2750 heavy-drinking pregnant women in the total study population rather than only 23 alcoholic women as Jones et al. identified. The 23 identifled might very well represent a high1y unusual sub-group of alcoholics. Sturdevant (1974), also critical of the study, ascertalned by questloning the authors (Jones \& Smith, 1974b) that the offspring were not assessed blindly. There are other problems with the study: (a) Whereas six of 19 alcoholics' offspring were lost-to-follow-up before seven years of age, it seems that none of: the comparison group were; this suggests that the two groups were 
perhaps not well-matched; (b) The reduced intellectual performance Identified among the alcoholics' offspring as compared to the comparison group could well be due to postnatal rather than prenatal environmental effects. The gap between the two groups' I.Q.'s was larger at the testing at age 7 than at age 4 . Further implicating the home environment (though the numbers are too small for statistical significance to be obtained), rearing by the mother through seven years of age was associated with a lower mean I.Q. as compared to rearing by others.

\section{Loma Linda University Study}

Four research groups have published or presented preliminary findings of studies aimed at systematically investigating the nature of FAS. At the Loma Linda University in San Diego, California, there is a large prospective study underway of nearly 6,000 women using the prenatal clinics. Thus far the only information avallable from this study provides characteristics of the mothers by average amount of alcohol consumption. The profile of the woman who drinks heavily during her pregnancy (i.e., more than $1.0 \mathrm{oz}$. absolute alcohol/day) is distinct from that of other women. Inter alia, heavy drinking correlates with heavy smoking, use of hard drugs (past or present), and heavy use of caffeine, sugar, and refined food (as reported in Fabro 1979, pp.5859).

3. Boston study. Ouellette, Rosett et al, 1977.

In Boston, at the Boston City Hospital, Ouellette, Rosett, and others (1977) have been conducting a prospective study of the pregnan- 
if some 633 inner-city women with differing alcohol consumption erns.

A questionnaire which sought information regarding past and present use of alcohol, tobacco and various drugs as well as diet on the previous day, was administered to the women when they registered for prenatal care. A reliable measure of heavy alcohol use was associated with heavy smoking during pregnancy and prior psychoactive drug use. Nutritional status did not vary significantly between groups but was poor in general. A total of 322 women had delfvered by the termination of the study and their offspring had undergone detalled pediatric, neurologic and developmental examination. of these 322 , $13 \%$ were heavy drinkers consuming on occasion more than 5 drinks and on average more than $45 \mathrm{ml}$. (approximately 1.6 ounces). absolute alcohol per day. Without controlling for the above-noted associations in their data, the researchers report a doubling of risk of abnormality among the offspring of heavy drinkers as compared to moderate drinkers and abstainers. They found a marked excess of ( 1 ) infants small for gestational age; (2) infants with congenital anomalies, and (3) infants with microcephaly and multiple congenital anomalies, among the offspring of the heavy drinkers. However, "no specific pattern of anomalies," 1.e., wo cases with the particular FAS cluster of abnormalities, was found. The researchers also found that reducing alcohol consumption during pregnancy decreased the risks to the fetus (Rosett et al., 1978). 
4. Seattle study. Hanson, Streissguth \& Smith, 1978.

A third prospective epidemiologic investigation of the offspring of women consuming varlous amounts of alcohol is being carried out in Seattle, Washington, at the same site from which the first American descriptions of FAS emanated (Streissguth et al., 1978a). S11ghtly over 1500 women receiving their prenatal care at two Seattle hospitals, one providing private care and the othes serving a more varied population, wera enrolled in a study of pregnancy and health. A questionnaire was administered during the fifth month of pregnancy. Detailed Information was gathered on beverage consumption (i.e. wine, beer, and liquor separately, coffee, and tea) as well as diet, tobacco, and medicine use during pregnancy. A number of scales were used to score the beverage consumption. The overall study was aimed at assessing the effect of "socia1" drinking on pregnancy outcome and only secondarily at studying FAS, per se. Varying sub-groups of the $1500+$ study women enrolled in the overall study participated in, or were evaluated in, different sub-studies.

In one of the sub-studies (Hanson et al, 1978) the attempt was made at blind identification of FAs. A criterion for making the diagnosis of FAS was established at the outset. One hundred and sixty three newborns were matched according to date of birth and hospital of b1rth in such a way that the mother of one in each pair reported drinking heavily in the month prior to recognition of pregnancy and the mother of the other abstained or drank infrequently. ${ }^{4}$ The 163

4 When such a match was not possible the second mother was the lightest drinking mother available. 
newborns were then examined in palrs without prior knowledge of the mother's alcohol consumption by the examiners. Heavy drinking was defined as an average daily absolute alcohol consumption of one or more oz. or intoxications during pregnancy on five or more drinks per occasion. Matching was done only by date of birth and hospital af b1rth. Infants were assessed on four criteria:

1) small for gestational age (weight or height or both less than $3 r d$ percent1le)

2) microcephaly (head circumference less than the 3rd percentile)

3) short palpebral fissure (width 1.8 or less $\mathrm{cm}$. in infants 36 or more weeks gestation)

4) two or more dysmorphic features of the FAS type out of a list of nine fudged by clinical observation

Infants were classified into three categories:
A) features compatible with FAS and suggestive of a prenatal effect of alcohol - rated abnormal on at least two of the four above criteria and including elther or both criteria three and four
B) minor abnormalities not indicative of FAS
C) normal

The researchers identified 11 infants in category $A$, nine of whose mothers in reporting their alcohol intake prior to recognition of pregnancy belonged to the group of heavy drinkers. The mothers of the other two averaged less than $1 \mathrm{oz}$. of absolute alcohol per day during the same time period. Of the 11 infants in class $A$, two were considered to clearly exhibit FAS. The mothers of these two infants 
were alcoholics by their medical records; how many others were alcoholic is not given though 19 of the heavy drinkers in this subsample had average dally absolute alcohol consumption scores in the month prior to pregnancy recognition of 2 or more oz. Both mothers of the two FAS cases were non-w'. Ite though non-whites represented only nine percent of the study population. While heavy use of alcohol, caffeine and tobscco were correlated, neither of the other two substances was as strongly related to neonatal abnormality as was alcohol consumption; small numbers in the study did not allow for statistical assessment of these other factors.

There is one very serious problem with the reported measurement of alcohol consumption in this study. Inquiry regarding wine, beer and liquor consumption was done separately through questioning about consumption of each beverage during two time periods. In another paper where the questionnaire technique is outlined in detall the two time periods are described thus: "the five months since the onset of pregnancy 5 , referred to as 'during pregnancy' and the month prior to pregnancy, referred to as 'pre-pregnancy'" (Streissguth et al., 1977a, p.398). And yet, somehow, when Hanson et al. (1978) use these same data to classify their study women, they no longer refer to the prepregnancy time period as "pre-pregnancy" but rather they refer to it as "the month prior to recognition of pregnancy"(p.457). And indeed it is only heavy maternal alcoholism consumption as reported for the pre-pregnancy month and not that reported for the first half of pregnancy that relates to presence of FAS symetoms. What can be made of

5 Elsewhere this second time period is usually described as the first four months of pregnancy. 
this? It is possible that some of the study women did not think precisely about the pre-conception month when reporting their prepregnancy alcohol consumption. Though reported alcohol consumption dropped considerably between the two time periods, it is admittedly hard to conceive of a frequent reason why there would be a marked change in ) consumption patterns around the time of pregnancy but not related to the pregnancy. However, this might relate either to pregnancy recognition or to inftiating attempts to become pregnant or to some unknown factor. Even though women are not aware they are pregnant until after the first missed period, the study women were asked in their fifth month of pregnancy to report beverage consumption in the pre-pregnancy month. By then, aware of her due date, a woman would likely be aware of when she conceived. Which of the women erred in their reporting. for the prepregnancy time period, and by how much, is unclear and could lead to improper inference.

There is another problem with the study. Socioeconomic status and ethnicity relate to each other and to birthweight. It is possible that in the Seattle study population, non-Caucasian ethnicity is related to both lower socioeconomic status and heavier alcohol consumption. It may be that when pairs of infants were selected at the study hospital serving a population of a wide socioeconomic range, that the members of pairs were not the same with regard to ethnicity and/or socloeconomic status. Presented with a smaller non-white baby and a larger Caucasian baby, the dysmorphologist performing blind evaluations actually might be recelving clues unwittingly and thus surmise, beyond what chance would predict, the probable alcohol consumption pattern 
of each of the two mothers. In this regard, it should be reiterated that both of the cases of FAS which the investigators identified were non-white though non-whites composed only nine percent of the sample. 6

5. Goteburg, Sweden study. Olegard et al., 1979.

A fourth group which has attempted epidemiologic investigation of FAS carried out their work in Goteburg, Sweden (Olegard et al., 1979). They carried out both retrospective and prospective studies. It is not clear whether or not the researchers had a working definition of FAS for either of their studies.

a. Retrospective study.

In the retrospective study of alcoholics' offspring, subjects were not gathered systematically. The researchers found a high rate of those features included in the FAS symptomatology using record reviews and/or interviews with social workers, etc. Furthermore, some of the children were born prior to the onset of maternal alcoholism and they fared better, on average, than their younger stblings. It should be remembered though that the assessments of the children were made (1) with the foreknowledge of maternal alcohol abuse, and (2) without assessment of the role of other environmental factors.

b. Prospective study.

In a prospective study by the same investigators, a structured interview was administered to about one-third of the $7600+$ pregnant women In Goteburg between May, 1977 and November, 1978 and 28 alco-

6 Other substudies of the Seattle-based Pregnancy and Health study will be discussed later. 
holic women were identifled at varying stages of pregnancy. These 28 women were followed prospectively while being encouraged to cut down their consumption. Of the 28, five women had induced abortions and two of their infants died during b1rth. Of the remaining 21 , seven infants were judged to have the full FAS and seven others to be damaged by alcohol butwith only partial FAS. To reiterate, no criteria for diagnoses of FAS is given. The likelthood of developing FAS seemed to decrease if the woman decreased her alcohol consumption during pregnancy. It should be noted that in this study, too, the diagnosis of FAS was not made blindly and there is no information gfven about other environmental circumstances of the alcoholic women. Espectally curious is why the researchers were confident it was appropriate to attribute the limited damage in seven of the babies to maternal alcoholism.

There is one further aspect to this propsective study which is, I believe, actually its most signflcant finding. Since all neonates born in Goteburg pass through one or two neonatal units with which the researchers are associated, all infants were evaluated for FAS. Among the offspring born to the two-thirds of the Goteburg women not interviewed prospectively about alcohol consumption, the researchers believe they identified seven FAS babies and two partially affected neonates. In five of the seven full cases as well as in the two partial cases, maternal alcohol abuse was confirmed. In the other two cases, alcohol abuse by the mother has not yet been proved. No further information is given, but it does seem that five blind 
diagnoses of FAS were made in a population of about 5000 . The significance of the partial and unconfirmed cases is less clear.

While this prospective study as a whole is quite interesting, st111 there seems to be something awry in the numbers of FAS cases found in the various sub-groups of the population. Since it is reasonable to assume that the 28 alcoholics identified in the interviewed one-third of the Goteburg maternity prpulation are not all the alcoholics among that group (some must have been overlooked, especially since ti.e percentage of of alcoholics in the group seems 1ow; cf. Rosett, 1974) It is rather surprising that all the FAS cases recognized in this one-third of the population were born to only those 28 women whose heavy alcohol consumption was known a priori.

Probing a little further it seems odd, once again, that about two-thirds of the FAS or FAS-11ke cases (seven FAS and seven with more limited alcohol damage) were found in the offspring born of the interviewed one-third of the Goteburg materntty population while about one-third of the cases were identified in the uninterviewed two-thirds. Stated otherwlse, if the interviewed third of the matemity population was selected randomly, and if unbiased evaluations for FAS were made, then the percent of alcoholic mothers and the percent of FAS cases should be about equal in both the interviewed and non-interviewed groups.

6. Paris, France study. Kaminski et al., 1976.

One other large prospective study of pregnancy factors and 
outcomes from France, included material on maternal alcohol consumption and pregnancy outcome (Kaminski et al., 1976). The research, however, was largely performed prior to the description of FAS. Approximately 9000 women of $18,000+$ who used any of 12 maternity hospitals in Paris (the vast majority of the others delivered elsewhere, aborted, or were excluded from the analysis because they were not native born) were followed to term. The researchers feel that the data they gathered on alcohol consumption were underestimates, especially since alcohol consumption was not the primary interest of the research. Using reported daily consumption of over $40 \mathrm{cl}$. of $11 \%$ alcohol wine (about $1.6 \mathrm{oz}$. of absolute alcohol and almost identical to the criterion of Ouellette et al., 1977) as the cutoff point'for heavy drinkers, slightly over 500 women were in the heavy drinking group. Heavy drinking was associated with an excess of stillbirths ${ }^{7}, 2.6$ percent vs. 1.0 percent, and with an excess of small-for-date-births, 4.8 percent vs. 2.5 percent. The mean birthwelght of the offspring of the heavier drinkers was 58 gms. lower (3255 vs. 3313) than that of the lighter drinkers and the mean placental welght 22 gms. lower (589 vs. 611). These associations were found by neonatal assessment without knowledge of maternal alcohol consumption and remained constant when various other factors were taken into account, e.g. maternal age or smoking, though only one other factor at a time. It deserves mention that the excess risk, with respect especially to intrauterine growth retardation and stillbirths, was associated only with heavy beer consumption, and not with heavy wine consumption. In French

7 In a personal communication, Kline et al. (as yet unpublished data) have informed me that in thelr case-control data set, frequency of maternal alcohol consumption related to risk of spontaneous abortion at less than 28 weeks gestation. 
society, where wine is the standard form of alcoholic beverage, this finding suggests that it may not be the alcohol per se which leads to the low birthweight and other findings. Also, the birthweight differences are not large. No association was found between maternal alcohol consumption and congenital malformations (though at the time of the publication of their paper Kaminski et al, were aware of the discovery of FAS).

\section{Other Information.}

Three other bits of information ought to be mentioned. First, much of the literature which reports on cases of FAS Includes, as well, photographs of the affected children. Looking at a group of such pictures the similarities are impressive. And yet, one must wonder (1) how frequent such physiognomy is found in a more general pepulation, and (2) what the parents of these individuals look like.

Many researchers, when reporting their findings on matemal alcohol consumption and pregnancy outcome, refer to the lengthy history of suspicion of an adverse association and provide biblical and Greco-Roman sources with citations dating back to those times. While it is seemly to refer to these, it should also be emphasized that the body of ancient literature, as well as more recent Iiterature; is large enough to find suspicious references to almost anything (cf. Preuss, 1978 for numerous substantiated and unsubstantiated ancient references).

Thirdly, a distinct lack of case reports from the United Kingdom has been remarked upon (Smithel1s, R.W., 1979). As well, in a recent brief conversation which this writer had 
with Sir Richard Doll of Great Britain, he mentioned that to date there had been no reports of FAS made to the congenital malformations registry of England and Wales. But neither has there been a special nationwide effort in Great Britain to inform pediatriclans of what to look for in terms of FAS.

\section{Discussion}

What can be inferred from the case reports, the various prospective studies, and the other items? of the numerous reports on FAS, in only a very small proportion of them was the diagnosis made with any scientific rigor. But, there have been a few instances where that cluster of symptoms called FAS has been identifled and then, going back, the researcher has determined that the mother consumed heavy quantities of alcohol during pregnancy (e.g. 0legard, 1979; presumably some of the cases of Majewsk1 et al., 1976). Does this mean that it is appropriate to attribute a distinct disorder of major public health significance to in utero exposure to heavy maternal alcohol consumption? Probably not. There has not yet been a study adequate to the task of blindly evaluating infants or others for FAS where other potentially confounding factors are kept at least modestly controlled. Data which are suggestive of both the existence of FAS as a distinct syndrome and of the association of the syndrome with maternal alcoholism include:

(1) The congruence between the Initial case reports of Jones et al. and the anecdotal description of Lemoine et al. 
which, though 1imited, is impressive.

(2) The scattered few instances of blind diagnosis of FAS.

(3) The photographic similarities of FAS children.

(4) The results of the study of Hanson et a1 (section 4 above) and of the prospective study of 0legard et al. (section $5 \mathrm{~b}$ above) which, however, are not rigorous, as discussed above.

Specific inference beyond recognition of the suggestive nature of some of the reszarch is unwarranted. The criteria set out in the introduction to this paper have not yet been satisfied.

Well-controlled investigation which would clearly implicate In utero exposure to heavy maternal alcohol consumption may be extreme1y difficult to obtain. Nonetheless, a sustained and systematic demonstration of the ability to blindly diagnose the syndrome in a group including exposed and unexposed individuals, but without foreknowledge of exposure in particular cases, is a sine qua non for clearcut acceptance of the existence of the syndrome as a distinct entity. Solid establishment of the syndrome as a distinct entity ought to precede expounding about its cause.

Though it has been claimed that full-blown FAS has never been diagnosed in an infant not born of an alcoholic mother (Third special Report to the U.S Congress on Alcohol and Health, 1978) there is no way of knowing how numerous the instances are where a neontologist, or psychologist, or some other examiner, entertained a diagnosis of FAS only to reject it because heavy maternal alcohol consumption could not be documented. 
Having made the above statements, it should be added that the consistent finding of association between heavy maternal alcohol consumption and sundry untoward pregnancy outcomes is somewhat more impressive. The work of Ouellette's group In Boston (discussed in section 3 above) is probably the most significant in this direction. Though heavier and lighter drinkers were not matched on various factors (e.g. smoking) which would tend to be associated with adverse pregnancy outcome, and though the heavier drinkers were probably at greater risk by virtue of these other factors, nonetheless their entire study population must have shared many equalizing disadvantages. To relterate, they found the offispring of the heavier drinkers to have more untoward pregnancy outcomes, including comparative excesses of intrauterine growth retardation, congenital anomalies, prematurity and microcephaly (no cases of ful.1-blown FAS per se were found in this very high risk population). The findings of Kaminski et al. (section 6 above) of a limited association between maternal alcohol consumption and intra-uterine growth retardation, birthweight, and stillbirth rate, though not of an association with congenital anomalies, is also supportive in this direction. Furthermore, in many instances where a diagnosis of FAS was made, the specificity of the diagnosis is questionable. For example, it seems quite unjustiflable to describe a child of an alcoholic with mild mental retardation and who is small for age but with no other abnormality, as a child with partial expression of a distinct syndrome resulting from in utero alcohol exposure. 
As set out in the introduction, finding an assoclation between maternal alcohol consumption during pregnancy and some non-specific undesirable pregnancy outcome cannot be taken to imply causality unless the roles of all other factors known to increase risk for the particular unfavorable outcome have been assessed.

\section{E. Estimation of Rates.}

A number of authors have taken it upon themselves to estimate the population frequency of the syndrome among alcoholics' offspring. These seem quite inappropriate. The first instance of an FAS rate being derived relled on the results of the chart review study of 23 pregnant alcoholics of Jones et al. (1974a, as described in section 1 above). In that and subsequent papers (e.g. Jones et al. 1974c; Jones \& Smith, 1975) the authors emphasize that in six of 19 (32\%) surviving offspring born to the alcoholic mothers in that study, the diagnosis of FAS was a distinct possibility. Based on this high rate of occurrence of FAS as well as other untoward findings in the alcoholics' offspring the authors recomend serious consideration of induced abortion. To reiterate: the highly problematic nature of this study, especially the unrecognizable biases most likely associated with the identification of alcoholism in the study women makes such inferences un founded.

Others have provided estimates of population rates of the occurrence of FAS (Majewski et a1., 1976, Dehaene et al., 1977, 01egard et a1., 1979). The information given by both Majewski and Dupius (the rates given by Dehaene relate to the data in Dupius, 1977) do not seem 
sufficient, however, for such calculations. In particular, the case series on which their estimates are based are in themselves problematic (see earlier discussion, section A). The prospective data of Olegard et al. (section 5) also seem inadequate for the calculation of rates. The fluctuation in the number of cases identiffed in varfous of their population subgroups discourages the calculation of rates. Another estimate of FAS rates among women consuming various levels of alcohol was provided by Hanson et al. (study discussed in section 4 above). An overriding problem with the estimate, once again, relates to the fact that FAS symptomatology was correlated with alcohoIic consumption as reported by the women for the month prior to pregnancy and not during pregnancy. It seems particularly inappropriate using this severely limited data base for the authors to attempt to extrapolate downward and predict. rates of partial. FAS expression at lower consumption levels. As well, if any further comment is needed, in only two of their cases did they diagnose the full syndrome; in the other cases there was only partial expression, though this point is not clearly stated in the article and subsequent references to it.

IV. RELATED ISSUES.

A. Review of the Literature Regarding Maternal Alcohol Consumption during Pregnancy and Three Particular FAS Features.

1. Birthweight.

It is not surprising that birthwelght is one of the most-studied 
parameters by which neonates are assessed; Information on birthweight is very widely and easily obtainable and clearly relates to future outcome in the neonate. Size for gestational age relates, or more specifically standardizes, birthwelght for the length of in utero gestation. This latter measure is more precise since, e.g., the significance of a birthwelght of say 2000 gms. differs substantially in a full-term newborn as compared to a prematurely born infant.

Two of the prospective studies discussed above provide information aboul birthweight variables in particular. Both Ouellette et al. (1977) and Kaminiski et al. (1978), as mentioned previously, found a significant increase in the proportion of infants born small for gestational age among the heavier drinkers as compared to the moderate or lighter drinkers. :Kanfinskl et al. also found a mean reduction of $58 \mathrm{gms}$. In the birthweight of the offspring of the heavier drinkers as compared to the lighter, although there were not differences in rates of prematurity. Ouellette did find an excess of prematurity in the births of the heavier drinkers. To reiterate, the assoclation found by Kaminski et al. existed only when the alcoholic beverage which the mother consumed was beer and not when it was wine -- the more standard national beverage. Moreover, neither of these groups performed analyses which controlled simultaneously for risk factors already known to be associated with reduced birthweight.

Two other studies focused exclusively on maternal alcohol consumption and birthweight. Little (1977) studied moderate alcohol con- 
sumption measured in dally ounces of absolute alcohol (AA units) and its relation to birthweight in a subgroup of private patients enrolled in the Seattle-based study. Information was available regarding maternal alcoholic consumption for three time perfods: the six months before pregnancy and the first four and second four months of pregnancy. The 263 women in the study were chosen in such a way as to rule out confounding an alcohol-birthweight association with clgarette smoking and the analytic technique controlled some though not all other recognized potential confounders. Using multiple regression analysis, Little found consumption in the six months pre-pregnancy and in the second four months of pregnancy to be related to reduced birthweight. Possibly the very low levels of alcohol consumption reported by the women in the study during the flrst four months of pregnancy precluded the finding of an association between birthweight and alcohol consumption during that time period. Use of regression analysis allowed Little to estimate that an average daily alcohol consumption of one AA unit in the six months pre-pregnancy related to a 91 gram reduction in birthwelght and in the second four months of pregnancy, to a 161 gram reduction.

Russell, employing an unụsual study design, used available records and compared the birthwelght of offspring born to mothers with alcohol-related psychiatric diagnoses (I) and 'offspring of women with other psychiatric diagnoses (II). A third matched group of offspring born to mothers without psychiatric diagnoses (III) were also included. Infants were matched by maternal age, race and education. Average 
birthwelght between groups I and II differed by 302 gms. but did not differ between groups II and III. There was an excess among the alcoholics' offspring of both premature infants and infants small for gestational age. It seems as if the birthwelght difference was more striking for black infants than for white. The 1onger the mother had been an alcoholic before she gave birth, the greater was the birthwelght differential between her infant and its matched pair. Potential confounding factors were not controlled.

Two earlier epidemiologic studies of factors associated with birthweight did not show a relationship between maternal alcohol consumption and birthweight. However, both of these used the overly crude grouping of women as abstainers vs. non-abstainers (Mau \& Netter, 1974; Pettersson et a1., 1975). In the yet unpublished data of K1ine et al., maternal alcohol consumption has been assessed carefully and confounding factors have been controlled. No association with birthweight of offspring has been found; however, the level of consumption was low.

To summarize these results regarding birthwelght, certainly the data published thus far would tend to support an association between maternal alcohol consumption and birthweight of offspring. The question of "maternal consumption when?" is less easily answered given Little's puzzling results (and her study design is the best of those published so far). Furthermore, whether the association, if it exists, is a causal one cannot be answered, since the role of associated risk factors has hardly been assessed (cf. Yerushalmy, 1971 on the problem of in- 
fering causality in the much more well-established association between maternal cigarette smoking and birthweight of offspring).

\section{Palpebral Fissure Length}

Short palpebral fissure length comes as close as does any single FAS feature to being a hallmark feature of the syndrome. 8 Thus, for example, in the one prospective study (Hanson et al., 1978) where a ciriterion for FAS was established a priori, short palpebral fissures or multiple dysmorphic features of the FAS type was requisite for the diagnosis. Relying even partially for the diagnosis of a syndrome on such an imprecisely defined abnormality may be criticized as unsclent1fic. Indeed, when short palpebral fissure length has been diagnosed, the basis for the diagnosis is usually impressionistic. Until 1978, the only standards for measurements of palpebral fissure length were outdated ones from 1929. In 1978, Jones et al. published data on palpebral fissure length in 200 white term infants and 600 others born between 32 and 38 weeks gestation. In 1980, Fuchs et al. reported palpebral fissure size in over 100 infants of each the white, black and Hispanic ethnic groups between 37 and 42 weeks gestation. While Jones et al. presented curves of normative size for 32 to 40 weeks gestation, Fuchs et al. gave only a mean for each ethnic group stating that palpebral fissure size did not vary by gestation in the range they studied.

It is noteworthy that mean palpebral fissure length seems to be longer for non-whites than for whites. There is a 11mited inconsistency between the two findings regarding whether or not palpebral fissures

8. A research group that would probably take exception to this is the German group of Majewsk1 et al. who found short palpebral fissures to be present in 1 ess than $10 \%$ of their case series (see Clarren \& Silth, 1978a). 
increase in size late in gestation. Nonetheless, it is this sort of material which provides a scientific basis for the diagnosis of an abnormality, that is requisite. Only the Hanson et a1. (1978) study, after giving their criterion for diagnosis of FAS, included, as well, a specific criterion for diagnosis of of short palpebral fissure length. (Unfortunately, the palpebral fissure length criterion given in the text of that article is presumably a misprint, since about $20 \%$ of newborns would satisfy the published criteria). It is certainly reasonable tn expect future reports on FAS to include information of actual measurements of palpebral fissure length.

Development of standards of palpebral fissure length is essentially a first step toward the establishment of systematic criteria for the diagnosis of the distinctive FAS facles Identification of short palpebral fissures is probably considerably simpler than identification of, e.g., a short upturned nose.

Thus far, the need for systematic evaluation of neonates for FAS features has been greatly stressed. However, with regard to the distinctive facies associated with the syndrome, it is possible that the development of a standardized criterion for the diagnosis of each unusual facial feature is unachlevable. Reading the literature, one comes away with the strong sense that diagnosis of the FAS facies relies on an overall clinical impression and not on specific measurements. Such impressionistic diagnosis should not be problematic if part of a well-designed study. 
3. Mental Retardation

As Abel (1980) Inter alia has pointed out, mental retardation is by far the most intrinsically significant of the various anomalles that have been attributed to in utero exposure to excessive maternal alcohol consumption. And yet, a direct connection between in utero exposure and mental disability is not established. The task of singling out alcohol as the causative factor is enormousiy complex and has by no means been accomplished. The human data that bear on this issue are quite limited. Going back to the chart review study of Jones et al. (1974) the data, if anything, are suggestive of external environment influencing the I.Q.'s of the in utero exposed offspring. As noted previously, though small numbers precluded finding statistical significance, the I.Q.'s of the alcoholics' children seemed to decline between testing at ages four and seven, and as well, the mean I.Q. of those reared away from the mother was higher than of those reared only with her. Both these circumstances are consistent with an environmental effect rather than an in utero one.

Deroover et al. surveyed the inmates of a Belglan mental inst1tution and felt they identified four cases of FAS among the 500 inmates. The reader is told that subsequent to FAS diagnosis, maternal alcoholism before and during pregnancy was confirmed. No information regardIng how maternal alcoholism was confirmed in these individuals, aged $15,16,19$ and 21 at time of diagnosis, is given. No information is given regarding any other suspected causes for the mental retardation or any substant1al background of these individuals. 
Streissguth et al. (1978b\&c) gathered a series of 20 FAS cases aged nine months to 21 years and evaluated their mental deficiency in several ways. Presumably, the sample was not gathered blindly. In one report (Strelssguth et al., 1978b) the authors believe they showed a statistically significant correlation between severity of the physical FAS anomalies and I.Q. score. They did not achieve this, however, since their methods were inappropriate.9 In another paper (Streissguth et al., 1978c) the authors show that the I.Q. of 17 subjects is rather stable over testing intervals varying from one to four years. They indicate that none of the 17 is being reared by an alcoholic mother; either the mother has reformed or the child lives elsewhere. This information is possibly suggestive, though inconclusive. Without extensive information on other aspects of the preand postnatal experiences of these FAS cases, it is inappropriate to attribute their mental retardation to in utero alcohol exposure. 10

9 For example, one child with only mild physical anomalies was recognized as a case of mild FAS and included in the study only because he had a more severely affected sibling. Since the I.Q. of this child was also high, he raised the mean I.Q. of his class of FAS cases with mild physical anomalies.

10 Work in related areas can be briefly mentioned. In subsamples from the Seattle-based Pregnancy and Health Study, newborn conditioning (Martin et al., 1977a) and sucking frequency (Martin et al., 1977b) have been assessed in relation to maternal drinking and smoking, and as well naturalistic observations of neonatal behaviors have been systematically recorded in relation to maternal alcohol intake and smoking (Landesman-Dwyer et al., 1978). Neonatal state regulation has been studied systematically in Infants born of mothers with varying levels of alcohol consumption by Rosett et al. (1979) and by Havlicek et a1. (1977). Brain pathology on a few aborted fetuses or neonates with heavy in utero alcohol exposure has been described (Clarren et al., 1978 and Pfeiffer et al., 1979). Some of these data are suggestive though inference to causes of mental retardation is not yet appropriate. 


\section{B. Measurement of Maternal Alcohol Intake During Pregnancy.}

All but two papers dealing with measurement of alcohol consumption specifically in pregnant women have derived from the large prospective study in Seattle. In six different papers, those researchers have described results of their investigations of various aspects of consumption patterns, rellability of scales, and usefulness of differing measurement devices. Different subsamples of the overall study population participated in particular substudies.

Two of the substudies dealt with reliability of reporting in women who were essentlally social drinkers (Little et al., 1976; Strelssguth et al., 1976). Strelssguth et al. assessed reliability on Calahan $^{\text {"s }}$ Q-F-V (Quantity-Frequency-Variability) scale over a one week time interval. Little et al. evaluated the rellability of three scales, the Q-F-V scale, Jessor's V-V (Volume-Variabllity) scale and average daily A-A (Absolute Alcohol) scores in five categories with a 4-month lag between the time of the two interviews. At both interviews, women in this study of Little et al. were asked about the same time periods (plus a query about an additional time perfod at the later date). As one might expect, reliability over the shorter time interval, almost $90 \%$, is higher than that over the 4-month interval, around $70 \%$, varying a bit for the different scales.

Rellability, 1.e. repeatability of reported information, is much more easily assessed than validfty, 1.e., the accuracy of the re- 
port. There is no work dealing with validity of reported maternal alcohol consumption specifically during pregnancy.

Three other papers dealing with measurement focus on the types of information provided by different scales. In an interesting brief report, Little et al. (1976a) demonstrated the limited information gathered by two physicians who routinely ask their obstetrics patients whether they drink and, if so, what and how much as compared to information gatiered by the formal, more comprehensive, study questionnaire. In another report, Little et al. (1977b) compared three scales for measurement of alcohol consumption: the $Q-F-V$ scale, the $V-V$ scale, and the A-A scale, and propose a fourth two-pronged scale which they constder more comprehensive. Another paper by the group (Streissguth et al., 1977a) compared the usefulness of elght different scales in identifying heavy drinkers. And, indeed, if one wants to differentiate the woman who averages six drinks per occasion from the one who averages ten, the interview must be appropriately designed. The cholce of a measure relates to the observed outcome.

Two other papers published by the Seattle group, one based on data from their. prospective study and the other on a previously gathered sample of alcoholics, dealt with changing consumption patterns during pregnancy. In one paper, Little and Streissguth (1978) report retrospectively gathered data on drinking habits of 41 alcoholic women before and during pregnancy. Whereas the drinking habits of the women In the year prior to pregnancy remained fairly constant, about one- 
fourth reported drinking an average of less than 2.0 AA ounces per day, their habits changed quite a bit during pregnancy. The one-fourth figure cited above approximately doubled during pregnancy while, on the other hand, the frequency of binge drinking during pregnancy increased for 20 percent of the women and decreased for five percent. The main reason cited for the decreased average consumption was fetal welfare.

Two other studies report on changing patterns of maternal alcoholl consumption during pregnancy. In both studies the subjects represented a cross-section of women, and tn both, a considerable percent decreased consumption. In the study sample of Little (1976), twothirds of over 150 women decreased their consumption between the six months pre- and the early pregnancy time periods. In Hook's (1976) population, between one-third and one-half of over 100 women consumIng various alcoholic beverages at the start of pregnancy decreased consumption during the first trimester. While Iittle found the main reason given by the women was adverse physlological effects and did not find decrease assoclated with reported nausea and vomiting of pregnancy, Hook found that nausea and vomiting of pregnancy was a reason often given to account for decreased consumption. Little found a similar pattern of decreased coffee consumption during pregnancy and Hook found such a pattern for tobacco use and consumption of colas as well; he found no pattern for tea consumption and an inverse pattern for milk consumption. Hook speculates that the nausea and vomiting of pregnancy may be the consequence of a feto-protective mechanism which 
limits intake of substances which might be noxious to the fetus.

\section{Brief Enumeration of Confounding Factors}

A number of risk factors are associated with alcohol consumption and, unless controlled, can confound attempts to assess the specific association between in utero exposure to maternal alcohol consumption and birth outcome. Rosett (1979) enumerates the associated risk factors as follows: nutrition, smoking, other drugs, caffeine, disulfiram, paternal drinking and maternal psychological stress. There are other risk factors more specifically associated with birthweight (including ethnicity; SES, pre-pregnant weight, and weight gain during pregnancy). As should be obvious, none of the studies of FAS has been of sufficient size or scope to control for these factors though information at least is starting to be gathered on some of them. All of the studies (Loma Linda, Seattle, Boston) of FAS which sought information on maternal smoking have confirmed the association with maternal alcohol consumption. Furthermore, two of the the three criterlaffor neonatal assessment employed by the Seattle group mentioned in footnote 10 differentiated neonates only when mothers ranked high on both alcohol consumption and tobacco use. Both of the two studies (Loma Linda and Seattle) seeking information on caffeine consumption found that it was associated with alcohol consumption. In the Loma Linda study, diet has been monftored. In the Boston study, limited information on this same factor was gathered. Regarding nutritional factors interrelated with alcohol consumption, Hurley (1977) discusses at some 
length three particular nutritional deficlencles associated with alcoholism: those of magnesium, zinc and folate, which might, in fact, acicount for an observed association between maternal alcohol consumption and birth outcome.

In sum, much work remains to be done to identify the relationshlp between, and the roles of, alcohol consumption and varfous other factors with which 1 is is associated with respect to pregnancy outcome. 
APPENDIX

The 1978 review article on FAS by Clarren \& Smith which appeared in the Medical Progress section of the New England Journal of Medicine is one of the most widely referenced papers in the field. A few critical comments regarding its accuracy seein appropriate:

In the paper, the authors identify and describe features of FAS. Two tables are presented in which FAS features are dubbed either "principle" or "assoclated," based reported ${ }^{\text {t }}$ on observation of 245 persons affected with the syndrome. On closely reviewing the article it becomes obvious that the following tables are misleading.

The authors refer to a great many articles reporting FAS cases known to them and they indicate that the total number of cases reported In these articles is somewhat over 250. Nonetheless, they do not 1dentify specifically the 245 cases on which their tables are based.

However, the lack of specific identification of the cases on whose evaluation the tables are based is actually the result of a more serious underlying problem. Based on the discussion in the text it is clear that the prevalence rates calculated for particular FAS features In the tables are not consistently derived from the assessment of 245 cases; rather it would seem that in many instances the number of cases evaluated was considerably less than 245 .

In both of the two Instances where the text discusses the prevalence rate of a specific FAS feature (among FAS cases), the number of cases evaluated was less than 245 . With regard to mental retardation: "Of 126 patients described (in the literature) with specific mention of 
Table 1. Principal Features of the Fetal Alcohol Syndrome Observed in 245 Persons Affected.

FEATURE

Central-nervous-system dysfunction:

Intellectual

Neurologic

Behavioral

Growth deficiency:

Prenatal

Postnatal

\section{MANIFESTATION}

Mild to moderate mental retardation* Microcephaly*

Poor co-ordination, hypotonia**

Irritability in infancy*

Hyperactivity in childhood**

Facial characteristics:

Eyes

Short palpebral fissures*

Nose

Short, upturned**

Hypoplastic philtrum*

Maxilla

Hypoplastic**

Mouth

Thinned upper vermillion*

Retrognathia in infancy*

Micrognathia or relative prognathia in adolescence**

*Feature seen in more than $80 \%$ of patients.

**Feature seen in more than $50 \%$ of patients. 
Table 2. Associated Features of the Fetal Alcohol Syndrome Observed in 245 Persons Affected.

$\underline{\text { AREA }}$

Eyes

Ears

Mouth

Cardiac

Renogenital

Cutaneous

Skeletal

Muscular

\section{FREQUENT*}

Ptosis, strabismus, epicanthal folds

Posterior rotation

Prominent lateral

- palatine ridges

Murmurs, especially in early childhood, usually atrial septal defect

Labial hypoplasia

Hemangiomas

Aberrant palmar creases, pectus excavatum
OCCASIONAI**

Myopia, clinical microphthalmia, blepharophimosis

Poorly formed concha

Cleft 1ip or cleft palate small teeth with faulty enamel

Ventricular septal defect, great-vessel anomalies, tetralogy of Fallot

Hypospadias, small rotated kidney's, hydronephrosis

Hirsutism in infancy

Limited joint movements, especially fingers \& elbows, nail hypoplasia, especially 5 th, polydactyly, radioulnar synostosi pectus carinatum, bifid xiphoid, Klippe1-Feil anomaly, scoliosis

Hernias of diaphragm, umbilicus or groin, diastasis recti

* Reported in between 26 and $50 \%$ of patients

$* *$ Reported in between 1 and $25 \%$ of patients

standardized testing of performance, 107 ( 85 per cent) scored more than 2 standard deviations below the mean." (p. 1064). This statement indicates that some type of IQ testing, presumably a necessary though not a sufficient basis for a diagnosis of mental retardation, had been performed at the time of the writing of the article on 126 and not 245 persons identified as affected with FAS. 
The other FAS feature regarding which the text of the article provides a discussion of frequency is palpebral fissure length. ConcernIng palpebral fissures it seems there is a compound error in the table. The table indicates that short palpebral fissures were found in more than 80 percent of 245 FAS cases. The textual discussion of the subject is as follows: "We have viewed short palpebral fissures as one of the most important findings in making the diagnosis (of FAS), and 59 of our (65) patients with the fetal alcohol syndrome (91 percent) have had this facial feature. Twelve other authors have described short palpebral fissures in 54 of 74 patients ( 73 percent). Only Majewsik did not find this abnormality to be a frequent feature. He reports short palpebral fissures in less than 10 per cent of 76 patients." (p. 1066). In this discussion, Clarren and Smith refer to 215 FAS cases and not to 245 cases. Among these 215 cases, 120 had short palpebral fissures: 59 of their own cases, 54 of others' cases and, at most, seven of Majewski's cases. Thus 56 percent of 215 cases exhibited short palpebral fissures, and not 80 percent of 245 cases. Did Clarren and Smith, Inter alla, just disregard Majewski's series when they compiled the table?

In sum, as regards each FAS feature listed in the tables, the number of FAS cases evaluated for that feature must be considered to be unknown. As well, the authors may have summarily excluded certain cases or case series from particular calculations because the observations in those instances did not concur with their own findings. 


\section{REFERENCES}

1. Abel, E.: Fetal Alcohol Syndrome. Psychol. Bull. 87:29-50, 1980 .

2. Barry, R.G.G., and O'Naullain, S.: Foetal alcoholism.Ir. J. Med. Sc: $144: 286-288,1975$.

3. Bierich, J.R., Majewski, F., Michaelis, R.: Fetal alcohol syndrome. Pediat. Res. 9:62, 1975.

4. Blerich, J.R., Majewski, F., Michaelis, R., and Tillner, I.: Uber das embryo-fetal Alkoholsyndrom. (On the embryo-fetal alcohol syndrome) Eur. J. Pediat. 121:155-177, 1976.

5. Christoffel, K.K., and Salafsky, I.: Fetal alcohol syndrome in dizygotic twins. J.Pedlatr: 87:963-967, 1975 .

6. Clarren, S.K. and Smith, D.W.: The Fetal Alcohol Syndrome NEJM 198: $1063-1067,1978$.

7. Clarren, S.K. and Alvord, E.C., Jr., Sumi, S.M., Streissguth, A.P. and Smith, D.W.: Brain malformations related to prenatal exposure to ethanol. J. Peds. 92:64-67, 1978.

8. Dupuis, C., Dehaene, P., Deroubalx-Tella, P., Blanc-Garin, A.P., Rey, C., \& Carpentier-Courault, C.: Les cardiopathies des enfants nes de mere alcoolique. Arch Mal Coeur 71:565-572, 1977.

9. e1-Guebaly, N. \& Offord, D.R.: On being the offspring of an alcohollc: An update Alcoholism: Clin \& Experimental Res. 3:148$157,1979$.

10. Fabro, S.: The Fabro Report in The Fetal Alcohol syndrome Public Awareness Campaign, Dep't. of the Treasury \& The Bureau of Alcohol, Tobacco and Firearms, 1979.

11. Ferrler, P.E., Nicod, I., and Ferrler, S.: Fetal alcohol syndrome. Lancet $2: 1496,1973$.

12. Fryns, J.P., Deroover, J., Parloir, C., Goffaux, P., Lebas, E. and Van den Berghe, H.: The Foetal Alcohol Syndrome. Acta Paediatr. Belg. 30:117-121, 1977.

13. Fuchs, M., Iosub, S., Bingol, N. and Gromisch, D.S.: Palpebral fissure size revisited. J. Peds. 96:77-78, 1980.

14. Hall, B.D., and Orenstein, W.A.: Noonan's phenotype in an offspring of an alcoholic mother. Lancet 1:680-681, 1974.

15. Hanson, J.W., Jones, K.L., and Smith, D.W.: Fetal Alcohol Syndrome Experience with 41 patients. JAMA 235; 1458-1460, 1976. 
16. Hanson, J.W., Stretssguth, A.P. and Smith, D.W.: The effects of moderate alcohol consumption during pregnancy on fetal growth and morphogenesis. J. Peds. 92:457-460, 1978.

17. Havlicek, V., Jhildiaeva, R. and Chernick, V.: EEG frequency spectrum characteristics of sleep states in infants of alcoholic mothers. Neuropadiatria 8:360-373, 1977.

18. Hook, E.B.: Changes in tobacco smoking and ingestion of alcohol and caffelnated beverages during early pregnancy: Are these consequences, in part, of feto-protective mechanisms diminishing maternal exposure to embryotoxins? : Birth Defects: Risks and Consequences. Pp. 173-184, Academic Press, N.Y., 1976. (S. Kelly, E.B. Hook and P. Janerlch, eds.)

19. Hurley, L.: The Fetal Alcohol Syndrome: Possible implications of nutrient deficiencles. Research Monograph \#2 Alcohol \& Nutrition, Proceedings of a workshop 9/26-27/77, Indianapolis, Indiana.

20. Jones, K.L.; Smith, D.W.; and Ulleland, C.N.; Streissguth, A.P. Patterns of malformation in offspring of chronic alcoholic mothers. Lancet 1:1267-1271, 1973.

21. Jones, K.L. and Smith, D.W.: Recognition of the Fetal Alcohol Syndrome in early infancy. Lancet i:999-1001, 1973.

22. Jones, K.L.; Smtth, D.W.; Strelssguth, A.P.; and Myrianthopoulos, N.C.: Outcome in Offspring of Chronic Alcohollc Women. Lancet $1: 1076-1078,1974 a$.

23. Jones, K.L. and Smith, D.W.: Offspring of chronic alcoholic women. Lancet 11:349, 1974b.

24. Jones, K.L.; Smith, D.W.; Streissguth, A.P. and Myrianthopoulos, N.C.: Incidence of Fetal Alcohol Syndrome in offspring of chronically alcoholic women. Ped. Res. 8, 440, 1974c.

25. Jones, K.L. and Smith, D.W.: The Fetal Alcohol Syndrome. Teratology $12: 1-10,1975$.

26. Jones, K.L.; Hanson, J.W. and Smith, D.W.: Palpebral Fissure size in newbom infants. J. Peds. $92: 787,1978$.

27. Kaminsk1, M., Rumeau-Roquette, C. and Schwartz, D.: Rev. Epidemiol. Sante Publique 24:27-40, 1976; translated by R. Little, Alcohol Consumption in pregnant women and the outcome of prgenancy: Alcoholism: Clin. and Experimental Res. 2:155-163, 1978.

28. Lausecker, C; Withofs, L.: Ritz, N. and Pennrath, A.: A propos du syndrome dit "D'alcoolisme Foetal" Pedlatrie 31:741-747, 1976. 
29. Leiber, B. Olbrich G.: Embryopath1sches Alkoholismus-Syndrom (Embryopathia alchoholica). Msch. Kinderheilk, 124: 43-46, 1976.

30. Lemolne, P.; Harousseau; H.; Borteyru, J.P.; and Menuet, J.C.. Les enfants de parents alcooliques. Anomalles observees. A propos de 127 cas Ouest Medical 21:476-482, 1968. English translation of Lemolne et al from the Nat' 1 . Clearing-house for Alcohol Info. - STIAR (Selected Translations of Int'1. Alcoholism Res.).

31. L1ttle, R.E.: Alcohol consumption during pregnancy as reported to the obstetrician and to an independent interviewer. Ann. N.Y. Acad. Sc1. 273:588-592, 1976.

32. Little, R.E., Schultz, F.A. and Mandell, W.: Drinking during pregnancy; J. Stud. Alc. 37:375-379, 1976.

33. Little, R.E.: Moderate alcohol use during pregnancy and decreased infant birthweight. AJPH $67: 1154-1156,1977$.

34. Little, R.E., Mandell, W., and Schultz, F.A.: Consequences of retrospective measurement of alcohol consumption. J. Stud. Alc. 38:1777-1780, 1977a.

35. Little, R.E., Schultz, F.A. and Mandell, W.: Describing alcohol consumption. A comparison of three methods and a new approach. J. Stud. Alc. 38:554-562, $1977 \mathrm{~b}$.

36. L1ttle, R.E. \& Streissguth, A.P.: Drinking during pregnancy in alcoholic women. Alcoholism: Clin. \& Experimental Res. 2:179$183,1978$.

37. Lolodice, G., Fortuna, G., Guidetti, A., Ria, N., and D'El1a, R.: Considerazioni cliniche intorno a due casi di malformazioni congenite in bambini nati da madri affette da alcolismo cronico. (Clinical notes on two cases of congenttal deformity in children born of chronic alcoholic mothers) Minerva Pediatr. 27:1891$1893,1975$.

38. Loser, H. and Majewski, F.: Type \& Frequency of cardiac defects in embryofetal alcohol syndrome. Brit. Heart J.39:1374-1379, 1977.

39. Majewsk1, F., Bierich, J.R., Loser, H., Michaelis, R., Lieber, B. and Bettacken, F.: Zur Klinik und Pathogenese der AlkoholEmbryopathie. Munch, med. Wochenschr. 118:1635-1642, 1976.

40. Manzke, H., and Grosse, F.R.: Inkomplettes und komplettes fetales Alkoholsyndrom: Bel d=ei Kindern einer Trinkerin. (incomplete and complete alcohol syndrome: Three children of a drinker.) Med. Welt 26:709-712, 1975 . 
41. Mart1n, J.C., Mart1n, D.C., Lund, C.A. and Streissguth, A.P.: The effects of maternal alcohol ingestion and cigarette smoking upon newborn conditioning. Alcoholism: Clinical \& Experimental Res. 1:243-247, 1977a.

42. Martin, D.C., Martin, J.C., Steissguth, A.P. and Lund, C.A.: Sucking frequency and amplitude in newborns as a function of maternal drinking and smoking, in Currents in Alcoholism (F.A. Selxas, ed.) v.II, PP. 359-366, Grune \& Stratton, Inc., New York, $1977 b$.

43. Mau, G. and Netter, P.: Kaffee und Alkoholkonsumriskofaktoren in der Schwangerschaft? Geburtsch U Frauenhe11k 34:1018-1022, 1974 .

44. Mendelson, J.H.: The fetal alcohol syndrome: NEJM 299:556, 1978.

45. Mulvihill, J.J., Klimas, J.T., Stokes, D.C., and Risemberg, H.M.: Fetal alcohol syndrome: Seven new cases. Am. J. Obstet. Gynecol. $125: 937-941$, 1976.

46. Noonan, J.A.: Congenital heart disease in the fetal alcohol syndrome. Am. J. Cardiol, $37: 160,1976$.

47. Olegard, R., Sabe1, K.G., Aronsson, M., Sanden, B., Johansson, P.R., Carlsson, C., Kyllerman, M., Iverson, K. and Hrbek, A.: Effects on the child of alcohol abuse during pregnancy. Acta Paedr. Scand. Supply. 275:112-127, 1979.

48. Ouellettee, E.M., Rosett, H.L., Rosman, N.P. and Weiner, L.: Adverse effects on offspring of maternal alcohol abuse during pregnancy NEJM 297:528-530, 1977.

49. Palmer, H.P., Ouellette, E.M., Warner, L., and Leichtman, S.R.: Congenital malformations in offspring of a chronic alcoholic mother. Pediatrics 53(4):490-494, 1974.

50. Pettersson, F., Melander, S.: Prediction of birthweight: Results of a multiple regression analysis. Ups. J. Med. Sc1. 80:135$140,1975$.

51. Pfeiffer, J., Majewsk1, F., Fishbach, H., Blerich, J.R., and Volk, B.: Alcohol Embryo and Fetopathy Neuropathology of 3 Children and 3 Fetuses. J. of the Neurol. Sclences 41:125137, 1979.

52. Preuss, J. Biblical and Talmudic Mediclne. Translated by F. Rosner, Sanhedrin Press, New York, 1978. 
53. Reinhold, L., Hutterroth, H., and Schulte-Wissermann, H.: Das fetale Alkohol-Syndrom: Fallbericht uber 2 Geschwister. (The fetal alcohol syndrom: Case of two siblings) Munch med Wochenschr $117: 1731-1734,1975$.

54. Root, W.W., Reiter, E.0., Andriola, M., and Duckett, G.: Hypothalamicpitultary function in the fetal alcohol syndrome. J. Pediatr. $87: 585-588,1975$.

55. Rosett, H.L. Maternal alcoholism and intellectual development of offspring. Lancet $11: 218,1974$.

56. Rosett, H.L., Ouellette, E.M., Welner, L., and Owens, E.: Therapy of heavy drinking during pregnancy. Ob. \& Gyn. 51:41-46, 1978.

57. Rosett, H.L.: Clintcal pharmacolog,y of the Fetal Alcohol Syndrome in E. Majchrowicz and E.P. Noble, Eds., Biochemistry and Pharmacology of Ethano1 V.2, Pp.485-509, Plenum, N.Y., 1979.

58. Rosett, H.L., Snyder, P., Sander, L.W., Lee, A., Cook, P., Weiner, L., and Gould, J.: Effects of maternal drinking on neonate state regulation. Deve1. Med. Child Neurol. 21:464-473, 1979.

59. Russe11, M.: Intrauterine growth in infants born to women with alcohol-related psychiatric diagnosis. Alcoholism: Clinical and Experimental Res. 1:225-231, 1977.

60. Smithells, R.W. Fetal Alcohol Syndrome. Deve1. Med. \& Child Neurol. $21: 244-248$, 1979 .

61. Stedman's Medical Dictionary, 22nd edition, Williams and Wilkins Co., Balt. Md. 1972.

62. Streissguth, A.P., Martin, D.C. and Buffington, V.E.: Testretest rellability of three scales derived from a quantityfrequency-varlability assessment of self-reported alcohol consumption. Ann. N.Y. Acad. Sci. 273:458-466, 1976.

63. Streissguth, A.P., Martin, D.C. and Buffington, V.E.: Identifying heavy drinkers: A comparison of eight alcohol scores obtained on the same sample, in Currents in Alcoholism (F.A. Seixas, ed.) v. II, pp.395-420, Grune \& Stratton, Inc., New York, 1977.

64. Streissguth, A.P. Fetal alcohol syndrome: An epidemiologic perspective. Amer. J. Epid. 107:467-478, 1978.

65. Streissguth, A.P., Martin, J.C. \& Martin, D.C.: Experimental design considerations and methodological problems in the study of the effects of social drinking on the outcome of pregnancy. ADAI Technical Report 非8-01, 1978a. 
66. Streissguth, A.P., Herman, C.S. and Smlth, D.W.: Intelligence behavior, and dysmorphogenests in the fetal alcohol syndrome: A report on 20 patients. J. Peds. 92:363-367, 1978b.

67. Streissguth, A.P., Herman, C.S. and Smtth, D.W.: Stability of Intelligence in the Fetal Alcohol Syndrome: A preliminary report. Alcoholism Clinical and Experimental Res. 2:165$170,1978 \mathrm{c}$.

68. Sturdevant, R. Offspring of chronic alcoholic women. Lancet 1i:349, 1974 .

69. Techntcal Support Document, 3rd Spectal Report to Congress on Alcohol and Health, NIAAA, ADAMHA, PHS, June, 1978.

70. Tenbrinck, M.S., and Buchin, S.Y.: Fetal Alcohol syndrome: Report of a case. JAMA 232:1144-1147, 1975.

71. Ulleland, C.N. The offspring of alcoholic mothers. Ann. N.Y. Acad. Sc1. 197:167-169, 1972.

72. Yerushalmy, J.: The relationshtp of parents' cigarette smoking to outcome of pregnancy -- implications as to the problem of inferring causation from observed assoclations. Amer. J. Epid. 93:443-456, 1971 . 
Assessinent of Stat stics on Alcohol-Related Problems

II. Animal Models of the Fetal Alcohol Syndrome

Prepared by Tulianne M. : ne, Division of Epidemiology, Columbia University schuol of Pubii. Health and John J. Getzow, New York City 
Criticism of the clinical and epidemiological evaluation of the Fetal Alcohol Syndrome has centered on the failure of most studies to control for possible confounding variables (see previous chapter). Animal studies are particularly useful in this regard because they provide the opportunity to manipulate the test conditions. Animal studies are thus a necessary companion to human investigations of malformations. As Mendelson aptly staites, "Alcohol abuse may have a role in the 'fetal alcohol syndrome' but the syndrome may eventually prove to be a 'polydrug-abuse fetal syndrome' or conceivably a polydrug-abuse-nutritional-deficit-stress-induced fetal syndrome'" (1978). Factors such as these which relate to alcoholism could account for the syndrome as observed by clintclans (Hanson et al, 1976). There is therefore considerable reason to take Mendelson's warning seriously.

It is important to note also that alcohol is associated with other adverse reproductive outcomes besides FAS. Thus in humans low birthwelght and stilibirths are reported-(Kaminski et al, 1978). Spontaneous abortion has been shown to be associated with alcohol in two separate studies (Harlap and Shiono, 1979; Kline et al, 1979). We shall see that these outcomes are an important part of the effects of alcohol reported from animal studies.

\section{Relevence of animal studies to FAS.}

Studies in animals provide the opportunity to examine the separate and interacting influences of confounding variables in ways which are imposstble in humans. 
Models of the Fetal Alcohol Syndrome in animals can address the following questions:

(1) Are the malformations described as typical of FAS in humans also seen in animals as a result of intrauterine exposure?

(2) Are these malformations the direct result of ethanol ingestion or are they produced by changes secondary to alcoholism?

(3) Does a woman who has stopped drinking have a smaller risk of bearing a child with FAS than one who continues drinking?

(4) Is binge drinking more or less important during pregnancy than continuous drinking?

(b) Is there a maximal safe level of drinking beyond which adverse effects on reproduction appear?

(6) Is there a particular time in pregnancy when the fetus is perticularly vulnerable to alcohol?

(7) Do other factors such as smoking, stress, other drug use, malnutrition and poverty contribute to the syndrome?

(8) Are effects in animals achieved at doses greatly exceeding that usually observed in humans?

Unfortunately, answers to these questions cannot necessarily be extrapolated from animals to humans bacause of inter-species differences. For example, ordinary animal studies prior to its marketing failed to reveal the teratogenicity of thalidomide. Only in primates have the characteristic limb and facial anomalies been produced. Thalidomide is not a teratogen* in rodents, and in rabbits causes a wide spectrum of anomalies (Wilson, 1973).

* Some explanatory terms: teratogen, a substance causing malformations or functional deficit in the developing organism; teratogenicity, the ability of a substance to behave as a teratogen (from the Greek, terato, a monster). 


\section{Animal studies - General Considerations.}

When evaluating the teratogenicity of a substance not only is the dose and the timing important, but the method of administration and secondary effects on the mother must be taken into account. Most drugs have fairly non-specific effects, which are dependent to some degree on the dose and stage of pregnancy. Early in pregnancy a teratogen usually kills the embryo; later, whlle the organs are being formed (organogenesis) it will cause specific malformations, depending on which organ is undergoing differentlation at that moment - the socalled critical period. After the organs have been fully formed and the fetus is undergoing growth and maturation, administration of a teratogen will usually cause growth retardation.

For the most part, variation in drug dosage will produce similar effects. A very large dose may kill all or a proportion of the embryos, which is shown in antmals by decreased litter size resulting in an increase in resorptions, which are probably analogous to spontaneous abortions in humans. Malformations in animals delivered at term result from lower doses while decreased size and weight may be borderline effects seen with small doses (Wilson, 1973).

\section{Antmal Studies of FAS - Methodological Problems.}

a. Inter-species differences. Even strains of the same genus can respond differently to alcohol (see Chernoff below) and racial differences in the ability of humans to metabolize alcohol have been reported (Hollstedt et al, 1977). In alcohol research rodents are 
used almost exclusively; ferrets and rabbits are used occasionally. One researciner has developed a beagle model of the FAS, and only one study report has used primates.

b. Route of administration. This should mimic the human situation as closely as possible. Studies where alcohol was injected or intubated are not as valid as continuous administration of alcohol via a liquid diet. Blood alcohol levels are probably the best measure of alcohol, rather than dose administered as a function of body weight, because $c i$ differing metabolic rates.

\section{c. Controls. Because alcoholics may eat less and because}

alcohol interferes with absorption of some essential nutrients, animal controls must be pair-fed, i.e., they must be given the same as their matches ate the previous day. This was not appreciated by some early investigators. The control animals must also receive the same volume of calories, 1.e., the doses must be isocaloric. This, too, is a recent methodological improvement. Since alcoholics commonly derive a substantial proportion of daily caloric intake from ethanol, administering ethanol as a fixed percentage of the diet yields higher continuous bloce alcohol levels. Also a relatively recent development in animal alcohol studies, this procedure -- maintaining a constant level of ethanol-derived calories (EDC) in the bloud -- exposes test animals to conditions more closely resembling the experience of alcoholics. Finally, to test the effects of dietary restrictions on pairfed control animals, a third control is maintained on an ad libitum diet. Likewise, to evaluate behavioral effects of prenatal exposure 
to alcohol, Abel (1980) recomends that the animals be cross-fostered to normal mothers immediately after birth in order to control for the envilronmental influences of alcohollc mothers. All such measures control for the dietary intake, but not for alcohol-induced metabolic disturbances. Satisfactory procedures remain to be devised that will measure differences between test animals and controls due to nutritional deficiencies secondary to alcoholic intake.

\section{Reports of Animal Studies.}

The following two studies report generally negative findings perhaps as a result of low blood alcohol levels. Schretz et a1 (1978) adminfstered $15 \%$ ethanol in drinking water to pregnant mice, rats and rabbits during organogenesis. Blood alcohol levels fluctuated widely In all species but seemed to be generally lower than $20 \mathrm{mg} / \mathrm{dl}$. Maternal food and water intake decreased when ethanol was available and mothers gafined less weight than controls. No effect of alcohol was noted on the number of litters or the number of resorptions. Mice and rats weighed slightly less at delivery and showed only minor bony anomalles, attributed by the authors to growth retardation. Although the authors claim that these effects are not teratogen induced, by the criteria of Wilson (1973) they may represent borderline effects of alcohol.

Hood et al (1979) administered ethanol as a $10 \%$ solution in water to pregnant mice on days 7-10 of gestation, and as a $20 \%$ solution on days $7-11,6-11$ or $1-11$. They failed to note any effect of alcohol on litter size, fetal weight or malformations. Blood alcohol levels 
were not measured in this study.

In an attempt to assess the effect of ethanol on the post-natal brain Bauer-Moffett and Altman (1975) exposed newborn rats to ethanol vapor inhalation from day 3 to day 20, thereby achieving high blood alcohol levels (averaging $268 \mathrm{mg} / \mathrm{d} 1$ ). They described reductions in cerebellar and remaining brain weight in the exposed animals and these differences persisted when the animals were examined at 90 days of age (Bauer-Moffett and Altman, 1977). Since brain growth spurt occurs mainly prstnatally in rats these treatments are meant to mimic 3rd trimester effects of alcohol in the developing human.

Plck et al (1976) developed a beagle model for FAS and reported dose-responsive effects ranging from complete suppression of development to stillbirths and malformations.

Kronick gave mice an intraperitoneal injection of $25 \%$ ethanol on days 8 and 9 or days 9 and 10 of development or single treatments on days $9,10,11$ and 12 . Fetal mortality increased following injection on days 9 through 12 . The commonest malformations seen were of the eyes and forepaws and were significantly increased following treatments on days 8,9 or 10 . The on 1 y weight difference noted followed injection on day 12. Blood alcohol levels were not mentioned.

The effects of chronic alcohol use were assessed in the following two studies where female animals were kept on an ethanol diet prior to and during pregnancy.

Two strains of mice were maintained on a diet containing $15-35 \%$ ethanol-derived calorle (EDC) by Chernoff (1977) resulting in blood al- 
cohol levels of $73-398 \mathrm{mg} / \mathrm{dl}$ for at least 30 days prior to conception and throughout gestation. The rate of resorptions increased dramatically from zero at $15 \%$ EDC to $100 \%$ on a diet of $35 \%$ EDC. Fetal weight was also affected, though less strikingly. Malformations were noted at all levels of alcohol intake and consisted of brain and cardiac anomalies, with exencephaly and gastroschisis noted in animals on the higher EDC diet. Quantitative differences in the rate of production of fetal anomalies and in resorption rates and fetal weight were noted between the two strains.

Tze and Lee (1975) accustomed female rats to $30 \%$ ethanol in water for 5 weeks before mating and malntained them on this diet during their pregnancies. While test rats became pregnant at the same rate as controls, only half delivered 1itters, and these were significantly smaller in number than controls. Birthweight of test animals was significantly lower and they exhibited microcephaly,'cracked, dry loose skin' and 'a generally shrivelled appearance'. No other specific anomalles were noted. The mean blood alcohol of these animals was $61 \mathrm{mg} / \mathrm{dl}$.

Chernoff found no effect on malformations at the lowest dose used and concluded that a blood alcohol level of at least $100 \mathrm{mg} / \mathrm{dl}$ was necessary to produce them. This might explain why Tze and Lee failed to find speciftc malformations at the doses they used.

Two carefully controlled experiments of Randall and co-workers measured an acute effect of ethanol in animals exposed during pregnancy. Randal1 and Taylor (1979, and Randall et al, 1977) administered 3 levels of EDC to mice from day 5 to day 10 of development. The diet 
containing $17 \%$ ethanol-derived calories (EDC) resulted in a mean blood alcohol level of $19 \mathrm{mg} / \mathrm{dl}$ on day 7 and resulted in more implantations and resorptions but not malformations. Two other diets (25\% EDC and $30 \%$ EDC) resulted in maximal blood alcohol levels of $261 \mathrm{mg} / \mathrm{dl}$ and $384 \mathrm{mg} / \mathrm{dl}$ respectively. Resorptions and malformations increased in a dose-response fashion. The malformations included limb, cranial, eye, urogenital defects and gastroschisis.

The following work of Henderson et al (1979) includes both chronic and acis'e, effects in the research design. Rats received a liquid diet containing $6 \%$ ethanol for 30 days prior to impregnation and throughout pregnancy. Acute exposure to $30 \%$ ethanol was achieved in 2 groups for 3 days each (days $11-13$ and 14-16). Maternal weight gain was less than controls in the chronic group, and unchanged in the acutely exposed on days 11-13. Fetal weights of survivors were reduced for all 3 test groups. In this study the authors state that no overt malformations were noted, but it is not clear that anatomic defects were one of the endpoints of the experiment. Organ weights were less than controls in all groups. Blood alcohol levels were varlable, reaching about $400 \mathrm{mg} / \mathrm{dl}$ in the acute groups on the last day of exposure. In the chronic group it was $70 \mathrm{mg} / \mathrm{dl}$. These investigators found zinc levels, an :index of nutrition, unchanged in the test animals compared to controls.

Brown et al (1979) in an attempt to circumvent the confounding due to impaired absorption of nutrients in the presence of alcohol, grew rat embryos in tissue culture medium containing 150 or $300 \mathrm{mg} / \mathrm{d} 1$ of ethanol for 2 days. The embryos grown in the lower dose were smaller 
and less differentlated than controls, and these effects were even more pronounced at the higher dose. These authors state that the growth of these control embryos was indistinguishable from that of embryos left in situ. Alcohol apparently causes reduced embryonic growth and differentlation in this system.

Behavioral studies seek to identify neurological damage resulting from intrauterine exposure to alcohol. Since these tests are affected by size and growth rates as well as the postnatal environment appropriate controls are necessary.

A series of rat experiments by Abel (1978) and $\Lambda$ bel and Dintcheff (1978) included pairfed isocaloric controls, as well as ad libitum fed controls and the offspring fostered at birth to normal mothers. These experiments taken together demonstrated in a dose-responsive manner progressive neurological impalment as a function of ethanol dose to the mother. At lower levels -- 1-2 $\mathrm{g} / \mathrm{kg} /$ day ethanol throughout pregnancy -there were no differences in behavioral responses to silmuli, despite reduced sizes and weights in the test group. At higher levels $(4-6 \mathrm{~g} / \mathrm{kg} /$ day) motor activity was impalred and postnatal mortality increased.

The single experiment which tested alcohol effects during pregnancy in primates (Elton and Wilson, 1977) stated that one offspring out of 4 macaque mothers exposed was hyperactive.

\section{Studies on Males.}

Offspring of male mice mated after ingestion of $1.24 \mathrm{~g} / \mathrm{kg}$ alcohol once a day for 3 days were more often resorbed when the mating occurred 
7-14 days after treatment (Badr and Badr, 1975). Klassen and Persaud (1976) found that male rats had fewer successful matings if fed a $10 \%$ alcohol diet for 35 days. Their litters were smaller and the pups smaller and lighter. These results suggest a role for the male alcoholic in pregnancy loss, where the effect must be mediated through the sperm.

\section{Dosage}

Dose equivalents in animals are difficult to establish because of varying metabolic rates across species. Mice, for instance, metabolize alcohol about six times faster than man and about three times faster than chronic drinkers. Rats metabolize alcohol about 30 percent faster than chronic drinkers (Kalant, 1971). In humans a blood alcohol level of $100 \mathrm{mg} / \mathrm{d} 1$ is considered intoxicated, 200-300 mg/dl is considered severe intoxication with lack of consciousness at the higher levels, and $400-500 \mathrm{mg} / \mathrm{d} 1$ is considered a toxic dose likely to be fatal. Chronic drinkers can sustain higher doses than moderate drinkers without functlonal impairment. Studies In alcoholic volunteers reported by Isbell (1966) indicate that habituated drinkers can tolerate doses of more than $200 \mathrm{mg} / \mathrm{dl}$. Animal studies have been criticized for reporting reproductive effects at blood alcohol levels which would be toxic for humans; but even at lower levels, $100-200 \mathrm{mg} / \mathrm{dl}$, animal reproduction has been consistently and adversely affected.

\section{7a. Conclusions.}

These experiments can answer some, but by no means a11, of the questions posed on page 2 . 
(1) This reviewer is not satisfled that those specific stigmata comprising FAS are reproduced in the animal studies so far reported. In these studies nearly all organ systems are affected, and a wide range of anomalies is reported.

(2) Comparing studies of chronic exposure with those of acute exposure the evidence does not clearly suggest that long-term alcoholism In animals has any more deleterfous effects than exposure solely during pregnancy. Untoward outcomes -- fetal deaths, malformations and weight loss -- seem to result from both conditions. Therefore it is possible that: secondary changes due to alcohol abuse, whether hormonal or nutritlonal, play little part.

(3) No experiment so far has addressed the question of former alcoholism directly. It would not seem that damage resulting from prior alcoholism bodes 111 for a pregnancy, although animal models may not be comparable in this respect.

(4) Binge drinking does not seem to be any more or less deleterlous for pregnancy than is chronic drinking.

(5) Variation in the methods and results of animal studies are too great to allow recommendation of a maximal safe dosage at this time.

(6) Studies conducted in animals so far have not delineated any particular vulnerable period in pregnancy beyond that established by general teratological principles.

(7) Nutrition is the only potentlally confounding factor which has been investigated in animal studies and while not every aspect has been controlled, the bulk of the evidence from the most carefully conducted studies seems to indicate that impaired nutrition is not the 
mechanism producing fetal death, malformation and growth retardation. The effect seems to be a direct embryotoxic effect of ethanol. It still remains for human and animal studies to investigate the possible role of other agents, e.g., stress, drug use and smoking, in mediating this effect.

(8) Because metabolic rates and possibly also metabolic pathways are quite different for animals and humans, it is not clear what equivalent doses of alcohol, and the effects associated with them, might mean. Nevertheless it can be salj that at blood alcohol levels comparable to that seen in humans all aspects of reproduction are adversely affected in experimental animals. 
REFERENCES

Abel, E.L. (1980) "Fetal Alcohol Syndrome: Behavioral Teratology," Psychological Bulletin, 87, pp. 29-50.

Abel, E.L. (1978) "Effects of ethanol on pregnant rats and their offspring," Psychopharmacology 57:5-11.

Abel, E.L. and Dintcheff, B.A. (1978) "Effects of prenatal alcohol exposure on growth and development In rats," J. Pharmacol. Exp. Ther., 207, 916-921.

Badr, F.M., Badr R.S. (1975) "Induction of dominant lethal mutation in male mice by ethyl alcohol," Nature 253, 134-135.

Bauer-Moffett, C. and Altman, J. (1975) "Ethanol injuced reductions

- in cerebellar growth of infant rats," Exp. Neurol: 48: 378-382.

Bauer-Moffett, C. and Altman J. (1977) "The effect of ethanol chronically administered to pre-weanling rats on cerebellar development: A morphological study," Brain Re search 119, 249-268.

Brown, N.A., Goulding, E.H. and Fabro, S. (1979) "Ethanol embryotoxicity: direct effects on mammalian embryos in vitro," Sclence 206, 573-575.

Chernoff, G.F. (1977) "The Fetal Alcohol Syndrome in mice: an animal model," Teratology, Vol. 15: pp. 223-230.

Elton, Robert H., and Wilson Mark E.: "Changes in ethanol consumption by pregnant pigtailed macaques," Journal of Studies on Alcohol 38(11): 2181-2183 (1977).

Hanson, J.W.; Jones, K.L., and Smith, D.W.: 'Fetal Alcohol Syndrome Experience with 41 patients," Journal of the American Medical Association 235:1458-1460 (1976).

Harlap, G., and Shiono, P.H.: "Alcohol, Smoking and the Incidence of Spontaneous First and Second Trimester Abortions." (Paper presented at Symposium on Reproductive Loss -- Human Embryonic and Fetal Death. Albany, NY. October 1979).

Henderson, G.I., Hoyumpa, A.M., McClain, C., and Schenker, S. (1979): "The effects of chronic and acute alcohol administration on fetal development in the rat," Alcoholism: C1Inical and Experimental

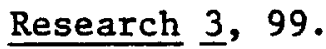

Hollstedt, C., 01sson, 0. and Rydberg, V., (1977): "The Effect of Alcohol on the developing organism," Medical Blology, 55:1-14.

Hood, R.D., Lary, J.M., Blacklock, J.B. (1979): "Lack of prenatal effects of maternal ethanol consumption in CD-1 mice," Toxicol Lett(AMST) 4(2), 79-82. 
Isbell, H. (1966): "Experimental Physical Dependence on Alcohol in Humans," in Alcohol and Alcoholism, Popham, R.E., ed. The Addiction Research Foundation, University of Toronto Press, Toronto, Canada.

Kalant, H. (1971): "Effects on Blological Membranes," in The Biology of Alcoholism, Vol. 1. Biochemistry, Kissin, B. and Begleiter, H. eds. Plenum Press, N.Y.

Kaminski, M., Rumeau-Rouquette, C., Schwartz, D.: "Consommation d'alcool chez les femmes encelntes et issue de la grossesse," La Revue d'Epidemiologie, Medecine Soclale et Sante Publique 24:27-40, 1976. (English translation by Little R.E., Schinzel, A.: "Alcohol consumption in pregnant women and the outcome of pregnancy," Alcoholism: Clinical and Experimental Research 2:155-163, 1978.

Rlassen, R.W. and Persaud, T.V.N. Exp. Pathol. 12:38 (1976).

Kline, J., Stein, Z., Susser, M. and Warburton, D.: "Environmenta1 Influences on early reproductive loss in a current New York City Study," (Paper presented at Symposium on Reproductive Loss Human Embryonic and Fetal Death. Albany, NY. October, 1979).

Kronick, J.B. (1976) "Teratogenic effects of ethyl alcohol administered to pregnant mice," Am. J. Obstet. Gynecol. 124:676-680.

Mendelson, J.H.: "The Fetal Alcohol Syndrome," NEJM 299(10), p. 556. (1978).

Pick, J.R., Ellis, F.W. and Dieh1, W.J. (1978): "Ethanol exposure during organogenesis in the beagle model of the fetal alcohol syndrome," The Pharmacologist, Vo1 20(3), 194. (Abstract).

Randall, C.L. and Taylor, W.J. (1979): "Prenatal ethanol exposure in mice: teratogenic effects," Teratology 19, 305-312.

Randa11, C.L., Taylor, W.J., Walker, D.W. (1977): "Ethanol-induced malformations in mice," Alcoholism: Clinical and Exper. Research 1: $219-224$.

Schwetz, B.A., Smith, F.A., and Staples, R.E. (1978): "Teratogenic potential of ethanol in mice, rats, and rabbits," Teratology 18, 385-392.

Tze, W.J. and Lee, M. (1975): "Adverse effects of maternal alcohol consumption on pregnancy and fetal growth in rats," Nature, Vo1. 257, p. 479-480.

Wilson, J.G.: Environment and Birth Defects. Academic Press, NY. 1973. 
Assessment of Statistics on Alcohol-Related Problems

III. Trends in Problem Drinking

Prepared by Eric Josephson and Paul W. Haberman, Division of Sociomedical Sciences, Columbia University School of Public Health 
We deai here with overall trends in the consumption of beverage alcohol and in problem drinking, some of the meth/fological issues which present themselves in measuring such behavior, ald a controversial model for interpreting consurntion patterns which has received much attention because of its implichtions for alcohol policy. Subsequent chapters of the report deal with religted topics: problem drinking among youth and among women, alcohol-re]ated casualties, and the costs of alcoho1 abuse.

1. Overa11 :rends.

Trend data on the "apparent per capita" consumption of alcoholic beverages in the U.S. presented in the Third Special Report to the U.S. Congress on Alcohol and Health indicate a levelling off during the 1970s, by which time it was higher than at any time since 1850 , the earliest year for which data are shown (Technical Support Document, 1978). However, a more recent study suggests that per capita consumption may have been considerably higher before 1850 (Rorabaugh, 1979:... It is also worth noting that international comparisons of per capita alcohol consumption place the U.S. In the middle of a group of 26 countries for which data are available; in the U.S. consumption is considerably 10wer than in such countries as Portugal and France and considerably higher than in such countries as Iceland and Israel (Technical Support Document, 1978). The reliability and validity of these consumption estimates, based on "indirect" or sales measures, are not known; error may result from not being able to take into account illicitly obtained or homemade beverages (Kreitman, 1977). 
But whatever their reliability and validity, such consumption estimates do not indicate who in the general population may be exper1encing problems with drinking. The definition and measurement of such problems face enormous difficulties (Room, 1977); some of these difficulties are discussed below. Here it is important to recognize the distinction between problem drinking as uncovered in surveys of the general population and alcoholism as clinically defined; they are not the same. Thus Room (1977) found that it was only a subgroup of the general population reporting the most severe drinking problems, less than one percent of that population, who reported problems comparable with those of alcoholics in clinical samples; in another study, only three percent of a nationwide sample of "problem drinkers" had an average alcohol consumption level half that of clinical samples of alcoholics. As a result, Room concludes "that there is a wide gulf between reality in the context of the general population and clinical reality. General population measures as they have been used do not define a population which is equivalent in its alcohol-related behavior to clinical populations. Measuring behavior which is equivalent would require sample sizes far beyond any that have yet been contemplated." In other words, surveys of drinking behavior in the general population have so far been unable to provide data on the prevalence of or trends in alcoholism as it is defined clintcally and attempts to come up with such estimates, using different methods, yleld widely varying rates (Celentano and McQueen, 1978). It is for these and other reasons that statements regarding the number of alcoholfcs in the population at large and claims that they have been 
Increasing - e.g., the doubling of the number from five to ten million within less than a decade -- have little if any basis in fact. What do surveys of adult drinking behavior show as regards trends in consumption? A serles of such national surveys was conducted for NIAAA from 1971 to 1976 (Armor et al, 1977). Based on a measure of the frequency with which respondents consumed alcoholic beverages and the amount consumed, these surveys reveal no significant shift in the proportion of drinkers or in their consumption at least during this five-year perfod; in 1976, the 1sit year for which data are reported, one third of adults described themselves as abstainers, neariy two-fifths were categorized as "light" drinkers, one-fifth as "moderate" drinkers, and one in ten as "heavy" drinkers.* Neither among men nor among women (see Section $V$ in this report) were there any major shifts in reported consumption of alcohol. There were also no significant changes in overall adult consumption by age. Data from another serles of national surveys conducted for NIDA from 1974 to 1977 also show no highly significant change in "current" drinking -- defined as drinking during the past month -- among men or women or by age during this shorter period of time (Abelson et al, 1977)

As for trends in problem drirking, data are so far available for only a two-year period, 1973 to 1975 . In the surveys conducted for NIAAA, drfiking respondents were asked to indlcate how often they had experienced each of 16 symptoms presumably 1ndicative of *Iight drinkers were those who consumed one drink a year up to 3 drinks/week (or 12 drinks/month); moderate drinkers consumed 4 to 13 drinks/week (or 13 to 58 drinks/month; and heavy drinkers consumed 2 or more drinks/day (or 14 or more drinks/week). 
drinking problems -- e.g., "taking a drink to feel better," "drinking in the morning to relieve a hangover," and "gulping drinks." The 16 symptoms were combined into a single problem index and respondents with frequent symptoms were defined as those who answered "frequently" on four or more of the symptoms, "sometimes" on eight or more items (but: none frequently), or combinations of one, two, or three items "frequently"with six, four and two items "sometimes" respectively. Further, "potential" symptoms were defined as those drinkers reporting two or three symptoms "frequently," four to seven symptoms "sometimes" (but: none frequently), or a combination of one symptom "frequently" and two or three symptoms "sometimes." So derived, the problem drinking index ylelded 63 percent of the 1975. survey respondents with no symptoms, 26 percent with potential symptoms, and 10 percent with frequent symptoms; the flgures for 1973 were almost identical (Arinor et al, 1977). The rate of problem drinking was substantially less for women (see Section $V$ ) than for men: about five percent of the drinking women reported frequent symptoms, but among men the figure was about 14 percent (Armor et al, 1977).

About these data on problem drinking, which provided NIAAA with the basis for its 1978 estimate that there were 9.3 to 10 million problem drinkers (Including alcoholics) in the U.S. adult population, several things can be sald. One has to do with the arbitrary nature of the definition of problem drinking -- e.g., including an 1tem such as "taking a driak to feel better" in the Index. Equally arbitrary is the "cutting point" or criterfa for distinguishing between persons with "frequent" and those with "potential" symptoms. 
A more liberal definition of problem drinking would have yielded a larger proportion of problem drinking; a more stringent definition would have produced a smaller proportion. But the rationale for selectIng the cutting point is not provided. Still another question has to do with the small size of the national sample from which the 1975 data were derived; there were only 454 drinkers in the total sample, of whom 45 apparently were 1dentified as problem drinkers. This is a sma1l number indeed on whlch to base a national estimate regarding the number of problem drinkers -- 9.3 to $10 \mathrm{mfllion}$, according to NIAAA. Stiil cther problems with the estimate are discussed at the end of this section.

In short, the 11mited data available indicate no general increase in problem drinking; but they are also imprecise regarding the extent of such problems. As a leading figure in alcohol studies has sald about such numbers games (Cisin, 1979), "Granted that problems arlsing from alcohol consumption are unsightly, unpleasant, disgraceful and numerous; should anyone really care exactly how many of these problems there are? I was a reluctant midwife at the creation of the by-now-famous 9 million problem drinkers (who have now grown to 10 militon alcoholics in the popular press). Can one seriously contemplate development of a new discipline in such an atmosphere of game-playing?"

2. A note cn the distribution of consumption model.

It has been argued by a number of Investigators iSchmidt, 1977; Schmidt and Popham, 1978) that the rate of liver cirrhosis - for which see Section VI of this report -- varies directly with the level of per captta alcohol consumption, which in turn varies in- 
versely with the relative price of alcoholic beverages. Put otherwise, the lower the price of alcohol, the higher the general level of alcohol consumption in the population and the greater the number of deaths attributed to clrrhosis. Most of the research undertaken to test this so-called distrtbution of consumption model has been done in Europe and Canada. The Implication for alcohol control pollcy is that an increase in the price of alcoholic beverages would reduce the rate of alcohol-related health problems.

Critics of the model (Kreitman, 1977; Parker and Harman, 1978; Taussig, 1978) have attacked 1 t on conceptual and methodological grounds. Thus, two critics (Parker and Harman, 1978) write: "The empirical support for the...proposition that there is a constant relationship between mean consumption and the dispersion of the distribution, and for the avallability proposition that the mean consumption can be lowered by raising the price of alcohol relative to disposable income, is weak, inconclusive and even negative. And the conceptual range of variables is overly restrictive." The distribution of consumption model has also been criticized on policy grounds -- 1.e., for Its implication that all who purchase and consume alcoholic beverages, light or moderate as well as heavy drinkers, should be made to pay for abuse by some. There has been further criticism of the model for not recognizing that those who abuse alcohol might sacrifice other interests, such as the welfare of their famllies, or suffer in a varlety of ways when forced to purchase it at a higher price, but these and other possible social costs of the polfcy that the model Implies have not been calculated. 
The distribution of consumption model has aroused a considerable amount of controversy and that controversy cannot be resolved here. But since the model's advocates have apparently won a certain degree of officlal support, it may be appropriate to end this note with a statement by one who is skeptical about it (Cisin, 1979). Appealing for "liberation from snake oil salesmen," Cisin said: "The frustration we all feel at our fallure to show striking success in coping with alcohol problems makes us particularly vurnerable to those who offer panaccas. All you have to do is increase the price sufficiently and everyone will cut his consumption in half, says the purveyor of the magic curve, and if everyone cuts his consumption in half, all the excessive drinkers will cut their consumption in half and, voila, alcoholism goes down. You would be amazed at how many responslble people, lesperate for easy solutions to hard problems, have swallowed this snake o11 in splte of clear demonstration that the magic curve does not fit alcohol consumption because it does not embrace zero; that the curve can be made to appear to fit any distribution containing outliers, no matter where the outliers are located; that the counterexamples outnumbered the confirming examples; and that the nution, even if it did work, would punish the many tc get at the few."

3. Definitions and prevalence estimation of alcoholism or problem drinking.

\section{a. Definitions}

The two najor issues in attempting to estimate the prevalence of alcoholism and alcohol-related problems are first, the lack of agreement on a completely adequate and generally accepted definition 
(or definitions) of the phenomend (Jones, 1977), and second the Is 1 reporting of drinking difficulties -- which may include overreporting but is more I1kely to include underreporting of such difficulties (Haberman and Baden, 1978).

The definitional problem is perhaps a result of the complexities Inherent in the nature of alcohol-related problems (Promisel, 1979). To start, there have been many different labels for persons reportedly having alcohol-related problems, such as alcoholics, alcohol abusers, problem drinkers, deviant drinkers, implicative drinkers, or probable alcoholics. Some of these labels reflect the tentative nature of the Identification. Others distinguish alcohol-related problems involving excesstve use by non-alcoholics. Nonetheless, a person described as an alcoholic by one "expert" may be described as a problem drinker by another "expert." Thus, compounding the definitional issues, there is a lack of agreement on what to call that which is being defined or perhaps who are being defined. NIAAA in its Technical Support Document for the Third Speclal Report on Alcohol and Health (1978) presents a small sample of a dozen definitions of alcoholism. For the purposes of prevalence estimation, Knupfer (1967), however, has made the important observation that the definition (of problem drinkers) must be adaptable to the methods used. Clark (:966) has demonstrated the marked susceptibility of alcoholism rates to relatively minor changes in severity or definitions. b. Related 1ssues

One related 1ssue described by Balley (1967) and Knupfer (1967) Is the question of severity or intensity. In the usually gradual development of alcoholism when has a case become severe enough to be counted in prevalence estimates (or defined as an alcoholic)? 
The location of a cutting point along the continuum of normal-abnormal drinking behevior should be done on the basis of content or face value by an operational or working definition.

A second related issue, also described by Bailey (1967) and. Knupfer (1967) is the question of recency. Should a rase reporting previous, but no current, problems with drinking be counted in prevalence estimates (or defined as an alcoholic)? If not, how long an interval without drinking-related problems should be required?

A third related issue is reversability (Bailey, 1967). Should a case reporting previous problems with drinking but currently able to drink mocierately without any damage to social functioning be counted or defined as an alcoholic? Once again, if not, how long an interval without drinking-related problems would be required? A number of carefully documented studies have found that a small minority (less than 10 percent) of previously identifled alcoholics, were able to drink moderately (Davies, 1963; Balley and Stewart, 1967; Polich, Armor, and Bralker, 1980). On the other hand, the traditional position, that alcoholics can never return to normal drinking, has been stated by many in the fleld, e.g., Lemere (1963). Cahalan (1970) has also vaised the issue of which came first for different persons, the 1mplicative drinking or the associated problems. This question perhaps suggests some explanation regarding reversability: when long-standing problems assoctated with excessive drinking are resolved, a small minority of cases may be able to revert to moderate drinking patterns.

These issues are related not only to definitions but to prevalence rates and trends as well. For example, if one accepts the NIAAA 
estimate of $" 9.3$ to 10 million problem drinkers (including alcoholics) in the adult population, or 7 percent of 145 million persons 18 years and older" (Technical Support Document, op. c1t., 1978), are the unknown minorities of alcohollcs who are abstaining and/or who have reverted to moderate drinking included in this estimate? c. Underreporting

The second major 1ssue with regard to prevalence estimation in this field is the serious underreporting of alcoholism and alcoholrelated problems by respondents, informants, and in medical records, such as death certificates, due primarily to conscious or unconscious dental (Haberman and Baden, 1978). Consumption is also underreported, particularly among heavy drinkers and alcoholics (Bailey et al., 196.5; Popham, 1970). Among the reasons for this denial are the soctal stigma associated with alcohol abuse, economic protection, lack of awareness or recognition of drinking-related problems, and the episodic nature of related problems (and drinking) for some persons. Evidence of this serfous underreporting of drinking-related problems have been shown in test-retest inconsistency, false negatives identified by more criterion measures, and non-response bias, with a greater likelihood of problem drinkers being non-respondents (Bailey et al., 1966; Cahalan, 1976; Haberman, 1969). On the other hand, a few drinkers may be falsely labelled as problem drinkers or alcoholics because of Identification by abstainers, or because of heavy arinking as a temporary crisis response.

offsetting the serlous underestimate to an unknown extent, alcoholism prevelance estimates, as with other statistics in the field, are invartably rounded up and the higher flgure in the range 
is most often cited. For example, with regard to the NIAAA estimate of 9.3 to 10 million problem drinkers (Technical Support Document, op. c1t., 1978), 10 million is now the most often cited official figure (Cisin, 1977; Pattison, 1977).

d. Summary.

Relating the previous discussion to official estimates of the number of problem drinkers or alcoholics, in conclusion, there are some major omissions in the supporting documentation. No mention is made of the definition or definitions used, whether or not problematic sijgroups, e.g., abstalning or moderate-drinking alcoholics, are included in the estimates, and what adjustments or modifications, If any, were made for such problems as denial, under (and over) reporting and non-response bias. There are, in brief, a very insufficlent description of the prevalence estimation methods used and virtually no description of how the reported figures were derived. 
D.J. Armor, P. Johnson, S. Pollch, and H. Stambul. Trends in U.S. Adult Drinking Practices: Summary Report. Prepared for NIAAA. Santa Monica, CA: Rand, December 1977.

M.B. Bafley, "Some Issues in Epldemfologlc Surveys of Alcoholism," American Journal of Public Health, 57: 987-991, 1967.

M.B. Bailey, et al, "The Epidemiology of Alcohollsm in an Urban Restdential Area," Quarterly Journal of Studies on Alcohol, 26:19-40, 1965 .

M.B. Bafley, et al, "Identifying Alcoholics in Population Surveys: A Report on Rellability," Quarterly Journal of Studies on Alcohol, $27: 300-315,1966$.

M.B. Bailey \& J. Stewart, "Normal Drinking in Persons Reporting Previous Alcohol Problems," Quarterly Journal of Studies on Alcohol, $28: 305-315,1967$.

D. Cahalan, Problem Drinkers: A National Survey, San Francisco: Jersey Bass, 1970.

D. Cahalan, "Some Background Considerations in Estimating Needs for States' Services dealing with Alcohol-Related Problems," Presentation at Conference on "Need" Methodology for Formula Grants, HEW, 1976.

D.D. Celentano and D.V. McQueen. Comparison of Alcoholism Prevelence Rates Obtained by Survey and Indirect Estimators. Journal of Studies on Alcohol, Vol. 39, No. 3, March 1978, pp. 420-434.

I.H. Cisin, Response to S.D. Bacon: From Morass to Discipline in One Grand Leap, Journal of Studies on Alcohol, Supplement 8, Nov. 1979.

W. Clark, "Operational Definitions of Drinking Problems and Associated Prevelence Rates," Quarterly Journal of Studies on Alcohol, $27: 648$ $668,1966$.

D.L. Davies, "Normal Drinking in Recovered Alcohol Addicts," Quarterly Journal of Studies on Alcohol, 23:94-104, 1962 .

P.W. Haberman, "The Rellability and Validity of the Data," in Poverty and Health: A Soc1ological Analysis, J. Kosa et a1, eds., Cambridge, Mass: Harvard Uriversity Press, 1969.

P.W. Haberman \& M.M. Baden, Alcohol, Other Drugs and Viclent Death, New York: Oxford University Press, 1978.

B.M. Jones, op. cit., Journal of Studies on Alcohol, Supplement 8, Nov. 1979.

G. Knupfer, "The Epidemiology of Problem Drinking," American Journal of Public Health, 57:973-986, 1967. 
N. Kreitman, Three Themes in the Epidemiology of Alcoholism. In: G. Edwards and M. Grant, eds., Alcoholism: New Knowledge and New Responses. London: Croum Helm, 1977.

F. Lemere, "Normal Drinking in Recovered Alcohol Addicts: Further Comment on Article by D.C. Davies, Quarterly Journal of Studies on Alcohol, $24: 727-728,1963$.

D.A. Parker and M.S. Harman, The Distribution of Consumption Model of Prevention of Alcohol Problems; a Critical Assessment. Journal of Studies or Alcohol, Vol. 39, No. 3, March 1978, pp. 377-399.

E.M. Pattison, op. cit., Journal of Studies on Alcohol, Supplement 8 , Nov., 1973.

J.M. Polich et al, The course of Alcohollsm: Four Years after Treatment, Santa Monica, Cal.: Rand Corp., 1980.

R.E. Popham, "Indirect Methods of Alcoholism Prevelence Estimation: A Critical Evaluation," in: Alcohol and Alcoholism, R.E. Popham, ed., Toronto: Toronto University Press, 1970.

D.M. Promisel, "Applications of Synthetic Estimates to Alcoholism and Problem Vrinking," in: Synthetic Estimates for Small Areas NIDA Research Monograph 24, ADAMHA, PHS, Feb. 1979.

R. Room, Measurement and Distribution of Drinking Patterns and Problems in General Populations. In: G. Edwards, M.M. Gross, M. Keller, J. Moser and R. Room. Alcohol-Related Disabilities. World Health Organization, Geneva, 1977.

W.J. Rorabaugh, The Alcoholic Republic: An American Tradition. New York: Oxford University Press, 1979.

W. Schmidt, Cirrhosis and Alcohol Consumption: an Epidemiological Perspective. In G. Edwards and M. Grant, eds., Alcoholism: New Knowledge ard New Responses. London: Croon Helm, 1977.

W. Schmidt and R.E. Popham, The Single Distribution Theory of Alcohol Consumption; a Rejoinder to the Critique of Parker and Harman. Journal of Studies on Alcohol, Vo1. 39, No. 3, March 1978, pp. 400-419.

Technical Support Document, 3rd Special Report to Congress on Alcohol and Health, E.P. Noble, Ed., PHS, NIAAA, ADAMHA, PHS, June, 1978. 
Assessment of Statistics on Alcohol-Related Problems

IV. Problem Drinking Among Youth

Prepared by Erlc Josephson, Division of Soclomedical Sclences, Columbla University School of Public Health. 


\section{The problem.}

In 1 ts 1978 Report to the U.S. Congress on Alcohol and Health, NIAAA est1mated that there were 3.3 problem drinkers among youth 14 to 17 years of age. As has recently been observed, current concerns about youthful drinking "center on the question of whether more young people, especially girls, are drinking now than before, whether they are beginning to drink at a younger age, and whether they are consuming more and w1th more problems" (Chafetz and Blane, 1979). These problems can take various forms; but concern has focused particularly on what is reportad to be the high proportion of alcohol-related automobile accidents involving youthful drivers and on the claim that the reduction of the minimum drinking age laws in some states has resulted in an increase in such accidents. Another concern has to do with the notion that problem drinking early in life is predictive of problem drinking later in life. In this review of the 1iterature, we will focus chiefly although not exclusively on the drinking behavior of adolescents, here defined to inciude those 12 to 18 years of age.

A few words are in order about the context of youthful drinking; It is not the same as for adults. Adolescence is for many, perhaps most, of those who are ever going to drink the age of inftiation into drinking; what is at issue is a learning experience. It seems appropriate therefore to regard initiation into drinking as part of normal adolescent development, one of a number of experiences which mark the transition between childhood and adulthood (Jessor and Jessor, 1975; Margulies et 21,1977$)$. What is deviant or precocious is not drinking per se but rather starting to do so considerably earlier than one's peers, consuming heavy amounts, and experiencing an unusually 
large number of problems associated with such consumpticn; but such behavior also needs to be viewed in the broader context of adolescent development and nct necessarily as a harbinger of problems to come later, in adult life.

2. Overall trends.

Although many surveys of teenage or adolescent drinking behavior have been conducted during the past four decades, deriving trends from them is fraught with difficulties because of differences between the populations belng studfed and in the ways they were studied. According to a review of more than 100 such studies condusted in juntor and senfor high schools since 1941, (Blane and Hewitt, 1977), the perlod before 1966 witnessed an increase in the proportion of teenagers drinking; for the perlod 1966-75 the prevalence of alcohol use by teenagers remained stable. As regards the age of initiation, the'stidies reviewed indicated no significant shift from 1940 to 1965 in the age at which adolescents took their first drink, although there was " a slight but statistically insignificant trend observable in the last five years for adolescents to have had their first drink at a slightly younger age than in the previous 20 years." Nor do the studies reviewed provide any stong evidence that young people are drinking more frequently now than before or drinking to intoxication more now than before. The authors of the review conclude: "there hasn't been a great deal of change in teenage drinking behaviors over the past 10 years, although the averages for this period are generally much higher than those for previous periods. For the most part, we have been witnessing a plateau in adolescent drinking, with steady rates of prevalence for use...1ittle change in the age at which drinking begins, 
no shifts in how often drinking occurs, and no clearly demonstrable changes in intoxication experience. The lack of change reported here for most of the variables studied cannot be entirely attributed to sampling bias and other method varlance. The consistency across varlables is toogreat for the pattern of stability over time... in the drinking characteristics examined to be a function solely of cumulative errors or chance..." (1bid). In other words, there appears to be little justification for public con arn about recent increases In youthful arinking; apparently there have been no such increases. Trend data from more recent surveys indicate that overall youthful drinking levels continue to be fairly stable. One such nationwide surrey, based on repeated household rather than school classruom samples of 12-i7 year-olds, has been conducted for NIDA throughout the 1970's (Abelson et al, 1977). According to this survey, the proportion of "current" drinkers among 12-17 year-olds, i.e., those who had drunk alcoholic beverages during the past month, was 34 percent in 1974 and then showed little change in 1976 and 1977 by which time 1 was 31 percent. Youngsters in this age group were half as likeiy to be current drinkers as persons 18 and over. Among youngsters 12-13 years old, the proportion of current drinkers was 19 percent in 1974 and 13 percent in 1977; among 16-17 year olds the corresponding figures were 51 percent in 1974 and 52 percent in 1977 . Another rationwide trend study of high school sentors (i.e., 17 and 18 year-ulds), conducted each year from 1975 to 1979 for NIDA, also founo ilttle change in overall drinking levels (Johnston et al, 1979). The proportion who had consumed alcohollc beverages during the past 30 days remained close to 70 percent for each of the five survey 
years; dally use also remained relatively steady at between 5.7 percent and 6.9 percent, the figure for 1979. However, there was some increase in the reported frequency of heavy drinking. Thus, when asked whether they had taken five or more drinks in a row during the frior two weeks, 37 percent of the seniors in 1975 sald they had and this proportion rose gradually but steadily to 41 percent by 1979 . On the other hand, the curves for lifetime prevalence of alcohol use at earlier grade levels were very flat, suggesting very little change In the age of inftiation during the years covered by the survey.

\section{Sex differences.}

Traditionally, girls have been less likely than boys to consume alcohollc beverages and less frequent in their use. Are the girls catching up with boys as regards drinking? Data from sevaral high school drinking surveys conducted in selected areas during the 1970 's do Indeed suggest a narrowing of the difference between tize proportions of girls and boys with drinking experlences (Summary Report - Surveys of Student Drug Use, San Mateo County, California, 1977; Wechsler and McFadden, 1976). However, according to the review of more than 100 high school drinking surveys cited earlier, "sex differences in prevalence (were) remarkably stable during (the 1965-75) period, with annual difference rates varying between 7 percent and 8 percent... Prior to 1966 , sex differences were much greater" (Blane and Hewitt, 1977). Furthermore, data from the nationwide trend study of 12-17 year-olds conducted for NIDA during the 1970's show little change in the relative proportions of boys and girls with drinkfng experfences; among boys the proportion of "current" drinkers was 39 percent in 1974 and 34 percent in 1977, among g1rls the corresponding figures 
were 29 percent and 25 percent (Abelson et al, 1977). Nationwide trend data on daily use of alcohol among high school seniors from 1975 to 1979 also show relatively unchanged sex differences, with boys consistently five percentage points higher than girls in reporting such behavior. (Johnston et al, 1977). In short, if girls began to close the gap between them and boys in drinking up to the mid-1960's, data collected on a nationwide basis since then indicate that a gap still remains.

4. Problem drinking.

Defining problem drinking as four or more eplsodes of drunkenness in the past year and/or two or more areas of negative consequences of drinking (trouble with teachers, friends or police because of drinking, driving when having"a good bit to drink"), a nationwide sample survey of high school students in grades 7 to 12 conducted by the Research Triangle Institute for NIAAA in 1974 , identified 28 percent of the total sample and 34 percent of the drinkers as problem drinkers (Rachal et al, 1975; Kachal et al, 1976). This survey has been criticlzed on conceptual and methodological grounds, particularly as regards its operational definition of problem drinking (Marden et al, 1976). The critics observed: "In the study under review, the operational definitions of 'moderate drinking,' 'problem drinking' and drinking in 'illicit contexts' dc noc appear to be valid, and they apparently resulted in 'research findings' which proved widespread 'problem drinking' when much of the behavior behind this label not have been problem behavior at all, but behavior well within the normal non-problem range." Crucial in the Identification of problem drinkers among youth as among adults are the "cutting points" or criteria selected for making identification; different cutting points will of course 
yleld different estimates of the numbers with problems. This is illustrated by another classification of problem drinkers in the same RTI survey (Donovan and Jessor, 1978); according to one cefinttion, 19 percent of the adolescent respondents were classified as problem drinkers. Just how many adolescent problem drinkers there are remains uncertain; even more uncertain is whether there has been any increase in their relative numbers.

In their analysis of the correlates of adolescent problem drinking, Donovan and Jessor (1978) suggest that what distinguishes problem and non-problem drinkers is a greater proneness to problem behavior more generally, less conventionality, more personal autonomy, a greater orientation toward peers, looser tles with parents, and lass involvement in or comitment to conventional activities. But they "found no discontinuity -- no sharp hiatus--- between the psycosoclal patterns of problem and non-problem dirinkers. No special or qualitatively unique explanatory concepts have to be involved to account for problem drinking. Instead of recourse to pathology or maladjustment or even physiology, the stance that is supported by the data is that a common set of psychosocial dimensions accounts for both problem and nonproblem drinking, and that varlation on those dimensions characterizes adolescents who engage in one or the other kind of drinking. It is worth noting that the same dimensions also discriminate the abstainers from the drinkers." (emphasis added)

5. Motor vehicle accidents and drinking age laws

Elsewhere in this report there is a general discussion of alcohol-related casualties, including motor vehicle accldents, and some of the problems that present themselves. In determining the role of alcohol. Here our concern is with young drfvers; also with the Impact 
of reducing the legal age for drinking and purchasing alcoholic beverages on youthful drinking generally and on alcohol-related auto accidents more particularly.

As regards alcohol-related motor vehicle accidents and young drivers, a recent review of the 11terature (Aarons et al, 1978) Indicates that drinking drivers are a relatively small proportion of all acciden:-involved drivers in the lower age groups but that a larger proportion of alcohol-related crashes involve more drivers under the age of 25 tian older ones. However, although only a small proportion of young drivers have been found to be drinking at the time of the crash, the number of young drivers involved in accidents is so large that even a small proportion of this number accounts for a large proportion of all drivers involved in alcohol-related crashes. The large number of young drivers involved in accidents Is reflected in the fact that this group accounts for more non-alcoholrelated crashes as well as more alcohol-related crashes than older drivers. More specifically, the largest proportions of alcoholrelated crastes involve drivers in the $20-24$ year age group, with young men far more likely than young women to be involved. The compllers of this review note: "The most common explanation offered by researchers for the consistently high accident-involvement of young drivers is the inexperience of this group with driving and with drinking and driving. The large proportion on non-alcoholrelated accidenis that involve young drivers are attributed to inexperience in driving, while the large proportion of alcoholrelated crashes in this age group are attributed to inexperience with driving after drinking." 
Much remains to be learned about alcohol-related motor vehicle accldents and youthful drivers -- e.g., controlling fo: the alcohol consumed, who among them are most I1kely to become Involved in accidents? Much also remains to be learned about the effect of reducing the minimum drinking age upon youthful drinking and alcoholrelated auto accidents among young drivers. It is by no means certain that lowering the minimum drinking age -- achieved in 26 states between 1970 and 1975 -- has resulted in an Increase in youthful drinking or in problems associated with drinking (Smar: and Goodstadt, 1977). Indeed, trend data from surveys of teenage drinking in Massachusetts conducted between 1965 and 1974 suggest that an increase in drinking preceded passage of the law reducing the drinking age from 21 to 18 (McFadden and Wechsler, 1979). As for the impact of such lawis on alcohol-related auto accidents, the data ava1lable lead to conflicting interpretations. In some states which passed such laws, research has shown an increase in alcohol-related motor vehicle accidents after passage of the laws (Douglass, 1979/80); but in others there was either only a very small increase in such accidents or no increase at all (Aarons et al, 1978). The need for systematic research on the Impact of such laws on youthful drinking and problems associated with drinking is self-evident; also needed is research on the effect of still more recent reversals of state mintmum drinking age laws -- 1.e., in those states which have raised the minfmum age after lowering $1 t$.

6. Youthful problem drinking as a predictor of adult problems. Apart from the issue of the prevalence of problem drinking among youth, there remains the question whether such, behavior is a strong 
predictor of problem drinking in adult life. A number of surveys show that ar least half of those who were 'problem drinkers' during thelr late teens and early twenties no longer experience any drinking problems afrer age 30 or 35 (Bacon, 1978). One of the few prospective longltudinal studies, a follow-up of adults who had originally been questioned as college students 20 years earlier, found that "problems which tend to characterize young problem drinkers are not necessarily those which serve as good predictive tools for later problems" (Fillmore, 1975). More specifically, "young men who have accidents or are arrested becaus of a drinking-related offense, who are belligerent, or report that drinking has interfered with their schoolwork are not necessar1ly tomorrow's problem drinkers." Put otherwise, some of those who experience drinking problems early in 11 fe w111 continue to do so as adults; but others among them will "mature out" of such problems. For others in adult life who have drinking problems it is not youtr.ful drinking behavior which predicts such problems but the circumstances of adulthood itself. In research on drinking behavior, there are perhaps few more urgent or difficult tasks than undertaking systematic follow-ups in the adult years of adolescents as well as college students studied earlier. A number of such prospective longttudinal studies currently under way offer the promise of new light being shed on the relationship between youthful and adult drinking behavior; however, little as yet has been reported from these studies. 


\section{REFERENCES}

IV-10

-1. M. Azrons, T. Cameron, J. Roizen, R. Roizen, R. Room, D. Schneberk and D. Wingard. Alcohol Casualties and Crime. Special Report prepared for NIAAA. Berkely, CA.: Soclal Research Group, University of California. 1978.

2. H.I. Abelson, P.M. Fishburne and I. Cisin. National Survey on Drug Abuse: 1977. Vol. 1: Main Findings. Princeton, N.J.: Response Analysis, 1.977 .

3. S.D. Bacon. On the Prevention of Alcohol Problems and Alcoholism. Journal of Studies on Alcohol. Vol. 39, No. 7, July 1978. pp. 1125-47.

4. L. Blackford. Summary Report. Surveys of Student Drug Use, San Maleo County, California. San Mateo County Department of Public Health and Welfare, 1977.

5. H.T. Blane and L.E. Hewltt. Alcohol and Youth: An Analys is of the Literature, 1960-1975. Prepared for NIAAA, March 1977.

6. M.M. Chafetz and H.T. Blane. High School Drinking Practices and Problems. Psychiatric Opinion, Vol. 16, No. 3, March 1979. pp.17-19.

7. J.E. Donovan and R. Jessor. Adolescent Problem Drinking: Psyciosocial Correlates in a National Sample Study. Journal of Studies on Alcohol. Vol. 39, No. 9, Sept. 1978, pp. 1506-1524.

8. R.L. Douglass. The Legal Drinking Age and Traffic Casualties. Alcohol Health and Researeh World, Vo1. 4, No. 2, Winter 1979/80, pp. 19-25.

9. K.M. Fillmore. Relationships between Specific Drinking Protlems in Early Adulthood and Middle Age; an Exploratory 20-year Follow-Up Study. Journal of Studies on Alcohol, Vol. 36, No. 7, July 1976, pp. 882-907.

10. R. Jessor and S.L. Jessor. Adolescent Development and the Onset of Drinking: A Longitudinal Study. Journal of Studies on 1lcohol, Vol. 36, No. 1, Jan. 1975, pp. 27-51.

11. L.D. Johnston, J.G. Bachman and P.M. O'Malley. 1979 Highlights. Drugs and the Nation's High School Students. Five Year National Trends: NUDA, 1979.

12. M. McFadden and H. Wechsler. Minimum Drinking Age Laws and Teenage Drinking. Psychiatric Opinion, 16:(3), March, 1979. pp. 22-8.

13. P. Marden, R. Zylman, K.M. Fillmore and S.D. Bacon. Comment on "A National Study of Adolescent Drinking Behavior, Attitudes and Correlates." Journal of Studies on Alcohol. Vo1. 3\%, No. 9, Sept. 1976, pp. 1346-58. 
14. R.Z. Margulies, R.C. Kessler and D.B. Kandel. A Longitudinal Study of Onset of Drinking among High-School Students. Journal of Studies on Alcohol, Vol. 38, No. 5, May 1977, pp. 1506-1524.

15. J.V. Rachal, J.R. Williams, M.L. Brehm, B. Cavanaugh, R.P. Moore, W.C. Eclierman. A National Study of Adolescent Drinking Behavior, Attitudes and Correlates: Final Report. Research Triangle Institute, April 19?5.

16. R.G. Swirt and M.S. Goodstadt, Effects of Reducing the Legal AlcoholPurchasing Age on Drinking and Drinking Problems; a Review of Empirical Studies. Journal of Studies on Alcohol, Vol. 38, No. 7, July 1977, pp. 1274 93.

17. H. Wechsler and M. McFadden. Sex Differences in Adolescent Alcohol and Drug Use; a Disappearing Phenomenon. Journal of Studies on Alcohol, Vo1. 37, No, 9, Sept. 1976, pp. 1291-1301.

18. H. Wechsler and M. McFadden. Drinking among College Students in New England: Extent, Social Correlates and Consequences of Alcohol Use. Journal of Studies on Alcohol, 40 (11), Nov. 1979, 969-996. 
Assessment of Statistics on Alcohol-Related Problems

V. Problem Drinking Among Women

Prepared by Norma Agatstein, Division of Sociomedical Sciences, Columbia University School of Public Health 


\section{Introduction.}

In its 1978 Report to the U.S. Congress on Alcohol and Health, NIAAA estimates that the number of women with alcohol-related problems ranges from 1.5 to 2.25 million and suggests further that this figure may be an under-estimate. The belief that more women are drinking now than in the past, coupled with the claim that there has been a relative increase in the number of young women drinkers, has led to speculation that this has raised the risk of alcohol abuse and could be a precursor to an increase in women's drinking problems in the future (Tec: ical Support Document, 1978; Armor et al, 1977; Schuckit and Morrissey, 1976).

Despite concern about the issue of women's drinking, there is surprisingly little reliable and valid data on women's use and abuse of alcohol in general; thus it is not known whether measures of alcohol consumption (due to differences between the sexes in body welght) and of alcohol-related problems currently being used are applicable to women (Technical Support Document, 1978). Bourne (1979) has otserved that although there has been much research on physical disoroers related to alcohol abuse, most of the information here, too, is hased on male problem drinkers or alcoholics; even in anfmal studies of pathological conditions implicating alcohol as a primary or causal factor, female research animals have often been exluded. It may be that the rates of problem driniking for women are under-estimations and that there are a considerable number of 'hidden' cases, or that certain alcohol problems specific to women have not been r.easured at all (for example, troubles with family, such as marital disruptions, or drinking problems related to the 
menstrual cycle) (Technfcal Support Document, 1978; Gomberg, 1977; Gomberg, 1976; Schuckit and Morrissey, 1976; Corrigan, 1974); but these remain speculations.

It has been suggested that there is an association hetween recent changes in women's societal and sex roles and drinking practices and behavior (Technical Support Document, 1978). The question has been ralsed as to whether the expansion of women's roles to include traditional male role functions, particularly employment outside the home, will increase alcohol-related problems among women. It has also been suggested that exposure to the male-dominated environment in the work place, where there is a more permissive attitude towards alcohol use and peer pressure to drink, may cause an increase In women's drinking and thus increase the risk of alcohcl-related problems as well. An alternative explanation is that elevated rates, if they occur, may be due to increased use of alcohol to cope with conflicts and pressures resulting from the dual demands of fulfilling both traditional (wife, mother) and non-traditional employee roles (Technical Support Document, 1978; Johnson, 1978; Wilsnack, 1976; Beckman, 1975; Corrigan, 1974; Schuckit, 1972). 2. Sex Differences in Alcohol Consumption

\section{A. Consumption Patterns:}

That there are sex differences in alcohol consumption has been well established. Fewer women than men drink alcohol; woten who do drink usually drink less frequently, in smaller quantiłles, and report fewer alcohol-related problems. Recent studies indicate that, in Eact, the majority of women (approximately 80 percent) do not drink at all or are light drinkers, while considerably more men are 
moderate or heavy drinkers (approximately 45 percent). The proportion of problem drinkers is also substantially less amorg women (approximately 5 percent) than among men (approximately 16 percent) (Technical Support Document, 1978; Armor et a1, 1977).

B. Trends in Consumption Patterns

The question has been raised as to whether sex differences in alcohol consumption patterns are decreasing; that is, whether the gap is narrowing and women are becoming simflar to men in aicohol use and thus at risk for increased and/or similar alcohol-related problems. Trud data available from national surveys for the periods 1946 through 1965 (Riley and Marden, 1947; Mulford, 1963; Cahalan et al, 1969), and 1971 through 1976 (Technical Support Document, 1978; Armor et al; 1977) indicate an increase in the proportion of women who drink prior to 1970 but no change during the 1970 's.* For men there has been essentially no change in the proportion drinking since the 1940's. There was no increase for either sex in the proportion of problen drinkers** (among drinkers) during the 1970 's***. Unfortunately, differences in the definition of problem drinking and In the age groups included in the surveys do not allow comparison with the studies prior to 1971 .

\footnotetext{
*inere are differences in the ages Included in the surveys; the early surveys included ages 21 or over, the recent ones, ages 18 and over. **The measurement of problem drinking used in the surveys was based on responses to a checklist containing 16 symptoms indicative of drinking problems which were conbined with an alcohol consumption index (which was called Blood Alcohol Content (BAC) Index and was created by adjusting for body weight the responses to questions about consumption asked during the interview). The 16 symptoms were combined into an index defining a problem drinker as one who experienced four or more of the symptoms frequently or elght or more sometimes. A potential problem drinker was defined as one who reports two or three symptoms frequently or four to seven of them sometimes (Technical Support Document, 1978). $* * * 0 n l y$ a two-year trend was avallable for problem drinking:
} 
C. Changes in Drinking Patterns: Generational and/or life span.

The proportion of both men and women who drink drops considerably with increasing age. This raises the question of whether this is a generational difference or whether consumption falls over the life span. Longitudinal or cohort data are needed to decide this issue. Mulford (1964) comared the proportion of drinkers in several age groups in his 1963 survey with comparable age groups reported 17 years earlier by Riley and Marden (1947). For example, Mulford compared the proportion of drinkers in the age group 38-42 in 1963 with that for ages 21-25 in 1946 (17 years earlier), etc. The proportion drinking decreased over the years in the age cohorts where comparisons were possible, lending support to the theory that individual consumption levels are inversely related to age over the life span. Mulford pointed out, however, that probably both generational and life span changes are occuring.

Longltudinal data from a sample of college students who were surveyed regarding drinking practices while in college (from 1949 through 1952) and who were contacted again 25 years later are of interest (Technical Support Document, 1978; F1llmore, 1975). Some consistency in drinking status was found for individuals between these two widely separated time periods. Women (and men) who were abstinent in college were most likely to be abstinent 25 years later and some of those who were problem drinkers in college were likely to be problem drinkers at the later time. However, what is especlally interesting is that the majority of the respondents 25 years later were non-problem drinkers regardless of their drinking status during college. 
There is some additional evidence to indicate that both men and women drink less and have fewer problems with drinking as they grow older Calahan (1970) found that even during a three-year period individuals moved in and out of the problem drinking category.* Why this is so is not clear; reasons suggested include: 1) learning how to 'handle' 11quor, 2) changes in life situations, 3) the maturing process of aging, and 4) social influences. Thus it may be that drinking patterns over time are dependent on a vilety of factors in current Iffe experiences which affect both sexes.

For women, changes in consumption level or in alcohol-related problems are especially important when considering drinking during pregnancy and possible negative effects for the unborn child. (The consequences for the infants of women who drink heavily during pregnancy are covered in the first section of this report). Not much data are avallable on drinking patterns of pregnant women and what exists was seldom collected systematically or prospectively. Some women have reported cutting down on drinking during pregnancy; when asked why, responses have included: 1) being asked to by their physician, 2) adverse physical reactions, 3) other physical reasons, and 4) Increased concern over health (both for self and unborn child) (Little, Schultz, and Mande11, 1976). One of the few prospective studies on the fetal alcohol syndrome currently in progress (Rosett, Ouelette, Weiner, and Owens, 1978) reports that when pregnant, heavy-drinking women were advised to reduce drinking during pregnancy, slightly less than one-third were able to do so.

Problem drinking was based on a checklist of 11 alcohol-related problem areas and included a level of alcohol consumption component. 


\section{Drinking Practices Among Women}

\section{A. Recent trends.}

As already mentioned, the proportion of women who drink increased durfing the perfod prior to the 1970 's but remained about the same from 1971 through 1976. Based on the five-year average from 1971-1976, Armor et al (1977) report that the proportion of women drinking rose from 61 percent for 18-20 year olds to 68 percent for those ages $21-34$ and then tapered off to 33 percent for those 65 and over. Although there were no significant changes in the proportion of women drinkers and the proportions in the light and heavy drinking categories for each age group during these years, a statistically significant increase was found in the proportion of moderate drinkers for women ages 35-49 (Technical Support Document, 1978). However, the number of women involved is falrly small and caution should be used in interpreting this finding. If future research confirms an increase in the moderate drinker category for this age group, it is at least occurring past the peak childbearing years.

\section{B. Estimates.}

Using the definition of 'problem drinker' and 'potential problem drinker' (as already described) and based on the population survey carried out in June, 1975 (Armor et al, 1977), NIAAA estimates that 27 percent of the women drinkers were problem drinkers ( 6 percent) or potential problem drinkers (21 percent) (Technical Support Document, 1978). Elsewhere in the Technical Support Document, NIAAA estimates that three percent of the adult female population are problem drinkers and that 24 percent of the adult problem-drinking population are women; that is, a male/female ratio of 3 to 1 . Although sources 
for these estimates and the definition of problem drinkers in the latter estimate are not given, it is pointed out by NIAAA that these are probably low estimates because prevalence estimation methodology historically has not accounted for the somewhat different manifestations of alcohollc problems in women. As noted earlier, it is estimated by NIAAA that there are 1.5 million to 2.25 million adult women with alcohol-related problems. They point out that the latter number may be an underestimate because of the use of nale-orfented problem drinking moasures in the national household surveys on which this estimate is based.

As already mentioned, many of the studies on alcohol use and abuse have dealt primarily with male populations and their drinking practices and behaviors. Most of the alcohol consumption measures are based on standards for male body weight and many of the items included in indices for identifying problem drinkers are based on problems and symptoms reported by men (Technical Support Document, 1978). (However, Armor et al (1977) do adjust consumption level for sex differences.) It has been noted that until recent1y information about women problem drinkers was often presented in comparison to men and not as a primary study of women's problems with alcohol (Corrigan, 1974; Schuckit and Morrissey, 1976).

It seems that the most usual measures of problem drinking are welghted towards external activities that bring the problem drinker into conflict with outside authorities (for example, an employer or the police). Women are less likely to work outside the home and some studies have shown that they tend to drink at home and alone or with family members; also, women who do come into conflict with 
the police or other authoritles over alcohol-related problems may be handled differently from men (Cahalan, et al, 1969; Corrigan, 1974; Gomberg, 1976). More research 1s needed to clarify these issues and to develop alcohol consumption and alcohol-related problem measures specifically for women. 4. Correlates of Problem Drink1ng Among Women Women who experience alcohol-related problems are not a homogeneous group; that is, the proportion of women reporting alcoholrelated problems is higher in some subgroups than in others. Armor et al (1977) found that more young women report alcohol-related problems; however, there is a higher incldence of problem drinking reported in the age group 35 to 64 years than in efther the younger or older groups. It should be noted that this higher incidence of problem drinking is found in women well past the peak chlldbearing years when heavy maternal alcohol consumption during pregnancy may be a risk factor for the unborn child.

A higher proportion of separated and divorced women report alcohol-related problems than do.the single, widowed, or married women. More employed women report problem drinking than those not in the labor force. In the Technical Support Document (1978), combinatIons of these correlates of women's drinking patterns are examined; however, the findings are based on very small numbers of women in some categories and must be interpreted with caution. There is some evidence to indlcate that more married employed women experience alcohol-related problems than do those who do not work outside the home, regardless of socio-economic status (Technical Support Document, 1978). Once again, 
this is based on small numbers of women in the survey. In the Technical Support Document, however, an attempt is made to explore these findings through a review of literature of the changes in women's lifestyles, sex roles and drinking patterns (including studies of women in treatment for alcohollsm). It must be pointed out that, in fact, very little is known about the social correlates and consequences of alcoholrelated problems among women and consider ble research is necessary before conciustons can be reached.

There is an additional problem that findings from studies of women in treatment for alcoholism cannot be generalized to all women who drink alcohol. Some of the correlates of problem drinking among women are of a physiological or metabolic nature. The research in these areas includes studies of alcoholic women seeking or receiving some kind of treatment for alcoholism or other problems; for example, women inpatients with a history of problem drinking in psychiatric hospitals or women enrolled in treatment programs for alcoholism in outpatient clinics. Alcoholic women compared to non-alcoholics report higher rates for obstetrical-gynecological problems (infertility, miscarriage, hysterectomy) and menstrual irregularities. Some research has postulated a relationshlp between physiological functioning (menstruation, childbirth, and the menopause) and alcoholism; however, whether premenstrual tension or postpartum depression, for example, are causal factors in problem drinking or whether an increase in physiological problems is a consequence of problem drinking has not been established (Bourne, 1979; Gomberg, 1976; Wilsnack, 1976; Blume, 1976).

In a review of the literature regarding physical morbidity 
and its relationship to alcohol abuse, Bourne (1979) concludes that compared to men, women may be differentially at risk. Women may experience an accelerated rate in the development of morbldity for a number of diseases. Alcohollc women were found to have higher rates than men alcoholics for some alcohol-related diseases, including peptic ulcer, cirrhosis of the liver, and pancreatitils. Higher mortality rates from alcoholic cirrhosis and alcoholic hepatitis have also been found among women in some other studies (ibid). On the other hand, aggressive: or violent behavior associated with problem drinking is far more likely to be manifested by men than by women. Most violent acts assoclated with problem drinking -homficides, other crimes, motor vehicle crashes, and suicides -- are comaitted by men; but men are more likely to engage in such behavior generally (Bourne, 1979; Haberman and Baden, 1978; U.S. Department of Health, Education and Welfare, Alcohol and Health, 1974; Aarons et $a 1,1978)$. 


\section{REFERENCES}

1. Aarons et al.: Alcohol, Casualties and Crime, M. Aarons et al, California Research Group, School of Public Health, University of California, 1978.

2. Armor, D.; Johnson, P.; Polich, S.; and Stambul, H.: Trends in U.S. Adult Drinking Practices: Summary Report. Working note prepared for National Institute on Alcohol Abuse and Alcoholism. Santa Mon 1 ca: Rand Corporation, 1977.

3. Beckman, I.: Women alcoholics: A review of social and psychological studies. Journal of Studies on Alcoho1. 36:797-824, 1975.

4. Blume, S.: Diagnosis, casefinding, and treatment of alcohol problems in wolien. Alcohol Health and Research World. 3:10-22, 1978.

5. Bourne, P.: "Alcohol problems in blacks and women," in (eds.) $\mathrm{J}$. Mendelson and N. Mello. The Diagnosis and Treatment of Alcoholism. pp. 93-123. McGraw-Hill Book Co., 1979.

6. Cahalan, D. Problem Drinkers: A National Survey. San Francisco: Jersey Bass. 1970.

7. Cahalan, C.; Cissin, I.; Crossley, H.: American Drinking Practices. College and University Press, 1969.

8. Corrigan, E.: Women and problem drinking: Notes on beliefs and facts. Addictive Diseases. 1:215-222, 1974.

9. Fillmore, K.M.: Relationships between specific drinking problems in early adulthood and middle age: An exploratory 20 year follow-up study. Journal of Studies on Alcohol. 36:882-907. 1975.

10. Gomberg, E. "The female alcoholic," in (eds.) R. Tarter and A. Sugerman. Alcoholism: Interdisciplinary Appraoches to an Enduring Problem. pp. 603-636. Addison-Wesley Publishing Co., 1976.

11. Gomberg, E. "Women with alcohol problems," in (eds.) N. Estes and M. Helnemann. Alcoholism: Development, Consequences and Interventions. pp. 174-185. St. Louis: C.V. Mosby Co., 1977.

12. Haberman, P. and Baden, M. Alcohol, Other Drugs and Violent Death. Oxford University Press, $197 \overline{8 .}$

13. Johnson, P. Sex Differences in Drinking Practices. Working note prepared for National Institute on Alcohol Abuse and Alcoholism. Santa Monica: Rand Corporation. 1978.

14. Little, R.; Schultz, F.; and Mandell, W.: Drinking during pregnancy. Joumal of Studies on Alcohol. 37:375-379. 1976. 
15. Mulford, H.: Drinking and deviant drinking, U.S.A., 1963. Quarterly Journal of Studies on Alcohol. 25:634-650, 1964.

16. Riley, J. and Marden, C. The social pattern of alcoholic drinking. Quarterly Journal of Studies on Alcohol. 8:265-273. 1947.

17. Rosett, H.; Oulette, E.; Weiner, L. ; and Owens, E. Therapy of heavy drinking during pregnancy. Obstetrics and Gynecology. 51:41-46. 1978 .

18. Schuckit, $M$. The alcoholic women: A literature review. Psychiatry in Medicine. 3:37-43. 1972.

19. Schuckit, M. and Morrissey, E. "Alcoholism in women: Some clinical and social perspectives with an emphasis on possibie subtypes," in M. Greenblatt and M. Schuckit (eds.). pp.5-35. Alcoholism Problems in Women and Children. Grune and Stratton. 1976.

20. Technical Support Document, 3rd Speclal Report to Congress on Alcohol and Health, PHS, NIAAA, ADAMHA. June, 1978.

21. U.S. Department of Health, Education and Welfare. Second Special Report to the U.S. Congress on Alcohol and Health from the Secretary of Health, Education and Welfare. DHEW Pub1. No. HSM, 72-9899. Washington, D.C., U.S. Government Printing Office. 1974.

22. Wilsnack, S.: Prevention of alcohol problems in women: current status. Alcohol Health and Research World. 3:23-31. 1978. 
Assessment of Statistics on Alcohol-Related Problems

VI. Alcohol-Related Casualties

Prepared by Eric Josephson and Paul W. Haberman, Division of Sociomedical Sciences, Columbia University School of Public Health 
Heavy alcohol use, in general, has been found to increase the risk of death, 11lness, accidents and violence. In attempting to assess a1cohol use as elther a direct or indirect cause of death (or of related problems), data are usually not available. Even when such data are avallable, moreover, such as for motor vehicle accidents and liver cirrhosis mortality, they do not necessarily provide a reliable basis for estimating the number of casualties which may be related to alcohol.

\section{Cirrhosis of the Liver Mortality}

Alcohol-specific conditions and causes of death are the traditional starting place for studies of alcohol-related casualties. Liver cirrhosis is a significant cause of death in the United States and is alcoholrelated in most cases of persons over 35 years of age (Technical Support Document, Third Special Report to U.S. Congress on Alcohol and Health, 1978; Schmidt, 1977). The death rate in the United States from Iiver cirrhosis in 1977 was 14.3 per 100,000 population; however, the U.S. death rates for major cardiovascular diseases and malignancies that year were respectively 444.5 and 178.7 per 100,000 population (U.S. Bureau of Census, 1979). Among persons under medical care, it should be noted, cirrhosis is somewhat less often related to alcoholism tian among medicallyunattended cases (Haberman and Baden, 1978).

The relationship between alcohol consumption and mortality from liver cirrhosis was considered by Jellinek as sufficiently constant to develop his formula for estimating the number of alcoholics in large communities. Alcoholism prevalence rates prior to 1960 were derived primarily by the Jellinek Formula (Jolliffe and Jellinek, 1942; Popham, 1956 and 1970). 
This formula, however, has been storngly criticized more recently as no longer belng applicable for current estimates (Agnew and Miller, 1976); in fact, Jellinck had previously refuted his own formula for current alcohol estimations (Jellinek, 1959). More recently, population surveys have been used to measure the prevalence of alcoholism in large communities (Bailey et al, 1965; Promisel, 1978). However, national prevalence rates still rely heavily on alcohol-related mortality, principally deaths caused directly by cirrhosis of the 1iver.

Age-adjusted Iiver cirrhosis mortality rates in the U.S. showed a steady increase between 1960 and 1970. followed by a leveling in the early 1970's and a decrease from 1973 to 1975 , as noted by NIAAA (Technical Support Document, 3rd Special Report to U.S. Congress on Alcohol and Healtt, 1978). The decrease, which started in 1974, apparently reflects a major shift since this trend of lower liver cirrhosis rates has continued in 1976 and 1977 (Kaelber et al, 1980).

It is uncertain, however, whether or not the recent decrease in liver cirrhosis mortality reflects a similar decrease in alcoholism, alcohol abuse or problem drinking. The decrease in cirrhosis mortality has been reported as being consistent with decreases in the total death rate and the death rate from cardiovascular disease (Technical Support Document; op. cit., 1978). The total death rate, however, has been lower for a ten-year perlod, whlle liver cirrhosis mortallty has just been lower over the last four years of this decade, but with a greater rate of decrease (Kaelber et al, 1980). Furthermore, the proportion of all alcoholics who develop Ilver cirrhosis and the proportion of these with such complirations who die of liver clrrhosis have probably also decreased. 
Shortly after Jellinek developed his formula, Improvements in overall nutritional status and in medical treatment were suggested as perhaps bringing about some reduction in these two proportions (and consequently In rates of liver cirrhosis mortality) (Keller, 1962). Other possible reasons for this relatively large rate decrease in liver cirrhosis mortality include a reduction in more harmful types of drinking and improved prevention programs (Kaelber et al., 1980.

Apparent increases in cirrhosis mortality rates over a 20-year period have also been attributed primarily to improved reporting in both overal cirrhosis mortality (Keller, 1962) and in cirrhosis mortality with mention of alcoholism (Technical Support Document, op. cit., 1978) without any substantial rise in the actual rates of alcoholism. However, cirrhosis of the liver as the underlying cause of death, in particular with mention of alcoholism, is undoubted1y understated because of reluctance by physicians to certify as the cause of death a stigmatizing condition associated with alcoholism. In addition, the standard U.S. death certificate itself has no specific provision to indicate contributory alcoholism, which is thus infrequently and inconsistently mentioned (Haberman and Baden, 1978). Perhaps also due in part to present death certificate reporting, most mortality tabulations are based on the single diagnostic entry selected as the underlying cause of death (Haberman, 1969).

Cirrhosis of the liver is more completely reported as the underlylng cause of death among autopsied cases and when the certifying physiclan was not previously known by the decedent. Thus, there is more 
complete reporting of liver cirrhosis among urban and younger decedents, who are more often autopsied, and among lower class and nonwhite decedents, who less often have personal physicians (Popham, 1970; Metropolitan Life Insurance Company, 1967; Pearl et al, 1962; LIpscomb and Sulka, 1961). In addition, "alcoholism" and "alcohol psychosis" death rates, although considerably smaller than the cirrhosis death rate are largely interchangeable. All three causes should thus be treated as one statistical unit (Technical Support Document, op. cit., 1978).

Fine11y, changes in 1iver cirrhosis mortality data should not imediately reflect changes in alcoholism prevalence because of the time lag between onset of excessive drinking and death from cirrhosis. The first evidence of liver damage in chronic alcoholics is usually preceded by fifteen (15) years of steady drinking (Sherlock, 1968). That alcoholism is reflected in mortality from liver cirrhosis, however, is beyond dispuce (Keller, 1902; schmid, 1977), Jine essostaIlon between the two has been splidly establishad fory yaars ago (JoIIiffe and Jellinek, 1940) and is in agreement with clinical experience wherever inebriety is observed (Keller, 1962; Schmidt, 1977). In view of the extensive use of trends and rates in liver cirrhosis mortality in order to extrapolate trends and rates of alcoholism prevalence and ultimately numbers of alcoholics or problem drinkers, some caveats are in order.

First, although mention of alcoholisin as a percentage of all Eirrhosis deaths has been increasing (to $41 \%$ in 1975), most 11 ver cirrhosis deaths of persons 35 years or older when not attributed to another medicaliy-attended disease or condition, are alcohol-related (Technical Support Document, op. cit., 1978; see also Baden, 1972). 
Thus, the distinction between liver cirrhosis with or without mention of alcoholism is unnecessarily confusing. The same criticism applies to the distinction between liver cirrhosis, alcoholism, and alcohol psychosis as causes od death. Second, in extrapolating from cirrhosis mortality to alcoholism prevalence, some adjustment must be made for the Iong time lag between onset of alcohol abuse and death directly related to alcoholism. In conclusion, until mortality from alcuhol-related disorders is uniformly, completely reported and takes into account contributory alcoholism, overall and subgroup rates and trends of liver cirrhosis mortality are not completely rellable (Agnew and Miller, 1976). Consequently, rates or trends of alcoholism prevalence derived to some extent from liver cirrhosis mortality data must be subject to the same criticism and may actually be lower or higher than reported.

\section{Excess Mortality of Alcoholics}

Studies have consistently shown that alcoholics, problem drinkers and even high frequency drinkers have a higher mortality rate than do people in the general population; the combination of heavy drinking and heavy smoking further increases the risk of excess mortality (Day, 1976). However, Schmidt and Delint (1972) have noted with regard to the excess mortality rate for diabetes among alcoholics that "alcoholism may only accelerate the course of the disease and thus increase mortality rather than influence its incldence;" this may be true for other causes of death as well. Schmidt and Delint (1972) also observed that the excess mortality among alcoholics from cancers of selected sites and some kinds of heart disease may be attributable to the alcoholics' cigarette smoking per se. However, alcoholics tend to be heavy smokers, so that a preclse assessment of the etlologlcal role of excessive drinking in these diseases would require a hard-to- 
The specific cause of death, e.g., head trauma, infectious disease, etc., is often easier to determine than the mode or manner of death, 1.e., natural, accident, suicide, or homiclde (Aarons et al, 1978; Haberman and Baden, 1978). A major problem is to determine whether violent deaths were accidental or suicida1. Thus, the mode or manner of deaths for alcoholics depends upon these determinations and will vary over time and in different jurisdictions. Moreover, if incomplete health department data rather than completed medical examiner records are used, suicide in particular is apt to be underreported, with more cases in some indeterminate categcry (Haberman and Baden, 1978).

Alcohol, it should be noted, usually is not indicated as a contributing factor on death certificates in homicides and suicides, or in those resulting from the use of alcohol in combination with other drugs (Haberman and Baden, 1978). However, persons classified as both alcoholics and narcotics addicts almost always are primarily the latter.

\section{Traffic Fatalities}

Traffic crashes are the greatest cause of violent death in the U.S., causing more fatalities each year than any other type of accident and almost as many as fiomicide and suicide combined. NIAAA states that one-third of the inijuries and one-half of the deaths resulting from motor vehicle accidents are alcuhol-related (Technical Support Document, op. cit., 1978). Tius, it is r.ot surprising that there is a huge amount of research liserature in this field. 
Most of these studies are event-centered, i.e., focusing on the role of blood alcohol concentration (BAC) of persons involved in traffic crashes. Wost of the event-centered studies are only descriptive and not controlled, reporting only on the extent to which alcohol is present in crash events. Controlled studiss attempt to control for time, place and demographics of traffic accidents to ascertain alcohol's contribution to the increased risk of crash. Person-centered studies focus on the drinking patterns and practices among drivers involved in crashes, the proportion of alcoholics among persons involved in accidents, and the frequency of crashes among alcoholics (Cameron, 1978).

Methodological constraints with regard to event-centered research follow. Data on alcohol use are only obtalned and reported for a portion of accident-involved persons; unknown biases in the selection prozess cast doubts on the representativeness of published data on alcohol involvement. Accurate BAC measurements can only be obtalned for a limited time perlod after an accident, aithough this pertod vartes across studies from one to 24 hours. Thus, persons surviving a longer time are excluded. Second, only a proportion of persons in both fatal and non-fatal accidents are tested for BAC. Information on non-tested persons involved in accidents is rarely reported. Pollce reports of drinking are much less conststent than those which rely on BAC tests.

There are many more non-fatal accidents, but more studies on fatalities; and positive BAC's are directly related to the seriousness of the eveat (particularly to fatal crashes). Thus, conclu- 
sions can be misleading unless one remembers that less than one in 20 traffic accidents result in a fatality, but that fatal accidents are much more often reported and studied (Cameron, 1978).

With regard to the role of "alcohol involvement in highway deaths," Zylman (1974) has stated that widely believed and officially stated figures overestimate the extent of the problem. Some of his reasons are applicable to non-fatal motor vehicle accidents and/or to other alcohol-related causes of death; the most relevant ones follow: Firs, there are no nationally published figures on how many drivers or passengers, drunk or sober, die in traffic accidents. Furthermore, the drinker is not always at fault in an accident, although he is more likely to be labelled as responsible; sometimes a sober driver or pedestrian is at fault. There also often may be other contrtbutory factors in traffic accidents, e.g., poor conditions of the road or absence of safety features in the motor vehicle (Room, 1977).

Second, if all traffic fatalities were tested, the proportion who had blood alcohol concentration (BAC) levels which usually result in impairment or intoxication $(0.10 \%)$ would be lower. BAC tests are done selectively, 1.e., more often on persons who have been or are likely to have been drinking.

Third, figures used to support the official position on drinking and traffic fatalities are often inflated. Percents are consistently rounded up and the top of estimated ranges is the more often cited percent. The differences between official and actual figures 
may be small; however, the cumulative effect can result in a considerable overstatement of the problem. NIAAA in its 1978 Technical Support Document (op. clt.), for example, prefaces most percents on traffic accidents with "as many as" or "up to."

Fourth, a concluding observation is that with representative data, the proportion of traffic deaths causally related to alcohol may be in the order of 30 percent rather than 50 percent (Zylman, 1974).

With regard to person-centered studies, research has clearly indicated that alcohol plays a substantial role in trafilc problems, although there is a considerable variation in the reported relationship between drinking patterns and accidents or traffic violations (Cameron, 1978). The range of estimates of the involvement of problem drinkers or alcoholics in traffic problems and the variation in definitional criteria used to identify such persons are so great that the actual degree of involvement is almost impossible to assess (Cameron, 1978; Technical Support Document, 오. cit., 1978).

NIAAA (Technical Support Document, op. cit., 1978) states that for the role of alcoholics and problem drinkers in traffic accidents to be assessed, more detailed definitional criteria used to Identify them and standardized indicators of problem drinking are required. Several studies report that known alcoholics have signiffcantly more traffic accidents and violations than other drivers. However, accident involvement for alcoholics and others apparently is a complex phenomenon that should not be attributed solely to the effects of alcohol (Cameron, 1978; Technical Support Document, op.cit., 1978). Traffic 
accidents also bring some alcoholics into treatment, thus tending to Inflate the number of known alcoholics with records of traffic crashes and violations (ibid).

\section{Concluding Observations}

Alcohol-related problems are conceptualized as existing in every concelvable body organ and every possible behavior, e.g., physical, psychological, social, economic. Thus, there has been considerable doubt about what criteria to use as a measure of alcoholism (Agnew and Miller, 1976). With regard to the use of alcohol as an explanation for serious events, BAC tests, alcoholism, drunkenness, congener content, drinking, and long-term consumption practices have all been studied (Room, 1977; Aarons et al, 1978). Controlled studies, however, are the exception other than in mortality and accident research, perhaps because no comprehensive reporting system has been developed and/or their being inappropriate in other alcohol-related areas. According to NIAAA (Technical Support Document, op. cit., 1978; Aarons et al, 1978), child abuse, neglect and molestirg; and marital violence, for example, are st111 neglected areas of research, with little systematic data on alcohol involvement available now. Finally, there is a tremendous range of alcohol involvement reporced in studies of accldents, casualties and crime; and as previously observed, the higher estimates are more often used as the official figures. 
M. Aarons et al., "Introduction" in Alcohol, Casualties and Crime, M. Aarons et al, Cal. Social Research Group, School of Public Health, University of California, 1978.

N. Agnew \& G.H. Miller, "An Epidemiological Paradigm for Alcohol Studies," Drug Forum: 5:5-37, 1975-76.

M.B. Bailey et al., "The Epidemiology of Alcohollsm in an Urban Residential Area," Q uarterly Journal of Studies on Alcohol, 26: 19-40, 1965.

J. Cameron, "Alcohol and Traffic," in Alcohol, Casualties and Crime, op. cit.

N. Day, Alcohol and Mortality, Paper prepared for NIAAA under Contract NIA-76-10(P), Jan. 1977 .

P.W. Haberman, "Tr.e Reliability and Valldity of the Data," in Poverty and Health: A Soclological Analysis, J. Kosa et al., eds., Cambridge, Mass.: Harvard Unfversity Press, 1969.

P.W. Haberman \& M.M. Baden, Alcohol, Other Drugs and Violent Death, New York C1ty. Oxford University Press, 1978.

E.M. Jellinek, "Estimating the Prevalence of Alcoholism: Modified Values in the Jellinek Formula and an Alternative Approach," Quarterly Journal of Studies on Alcohol 20:261-269, 1959.

C. Kaelber et al., "Recent Trends in Reported Cirrhosis Mortality," Paper presented at 11th Annual NCA/AMSA/RSA Medical-Scientific Conference of National Alcoholism Forum, Seattle, May 1980.

N. Jollife \& E.M. Jellinek, "Cirrhosis of the Liver" in Effects of Alcohol on the Individual. Vo1. 1, E.M. Jellinek, ed., New Haven: Yale University Press, 1942.

M. Re1ler, "The Definition of Alcoholism and the Estimation of Its Prevalence," in Society, Culture and Drinking Practices, D.J. Pittman and C.R. Snyder, eds. New York City: John Wiley, 1962.

W.R. Lipscomb \& E. Sulka, "Some Factors Affecting the Geographic Comparison of Alcoholism Prevalence Rates, Quarterly Journal of Studies on Alcohol, $22: 558-596,1961$.

Metropolitan Life Insurance Co., "Alcoholism: A Growing MedicalSocial Problem," Statistical Bulletin 48: April, 1967.

Monthly Vital Statistics Report, Final Mortality Statistics, Advance Report 1977 and 1978, Vols. 27 and 28, 1978 and 1979.

R.E. Popham, "The Jellinek Alcoholism Est1mation Formula and 1ts App1ication to Canadian Data," Quarterly Journal of Studies on Alcohol 17: $559-593,1956$. 
R.E. Popham, "Indirect Methods of Alcoholism Prevalence Estimation: A Critlcal Evaluation," in Alcohol and Alcoholism, R.E. Popham, ed., Toronto: Toronto University Press.

A. Pearl et al., "Cirrhosls Mortality in Three Cities: Implications for Alcoholism and Intercity Comparisons," in: Society, Culture and Drinking Problems, op. cit.

D.M. Promisel, "Application of Synthetic Estimates to Alcoholism and Problem Drinking," in Synthetic Estimates for Small Areas NIDA Research Moncgraph 24, ADAMHA, PHS, Feb. 1979.

R. Room, in Research Prlorities on Alcohol, Proceelings of Symposium, M. Keller, ed., Journal of Studies on Alcono1, Supplement 8, Nov. 1978.

W. Schmidt \& L. Delint, "Causes of Death of Alcoholics," Quarterly Journal of St dies on Alcohol 33: 171-185, 1972.

W. Schmldt, "Cirrhosis and Alcohol Consumption: an Epidemiological Perspective," in G. Edwards and M. Grant, eds., Alcoholism: New Knowledge and New Responses, London: Great Britain, Groan Heln Ltd., 1977.

S. Sherlock, Diseases of the Liver and Biliary System, Philadelphia: F.A. Davis, 4 th ed., 1968.

Technical Support Document, 3rd Special Report to Congress on Alcohol. and Health, PHS, NIAAA, ADAMHA, PHS. June, 1978.

U.S. Bureau of Census, Statistical Abstract of the United States, 1979 (100th edition). Washington, D.C., 1979. p.76.

R. Zylman, "A liritical Evaluation of the Literature on 'Alcohol Involvement' in Highway neaths, Accident Analysis and Prevalence 6: 163-204, 1974. 


\section{Assessment of Statistics on Alcohol-Related Problems}

VII. Measuring the Costs of Alcohol Abuse

Prepared by Thomas G. McGulre, Department of Economics, Buston University 


\section{Introduction}

In $a=\in$ port to the National Institute on Alcohol Abuse and Alcoholism (NIAAA), Ralph Berry and his colleagues have estimated the costs of alcohol abuse to the American economy to have been $\$ 42.75$ billion in 1975. The major components of these costs are lost production of goods and services ( $\$ 19.64$ billion), extra health care costs for alcohol abusers ( $\$ 12.74$ billion) and motor vehicle crashes $(\$ 5.14$ bll110n). All. components of the estimated costs are presented in Table 1.

Be-ry's numbers are sure to play a prominent role in the renewed debate on alcohol policy, as his earlier estimates have in past debates. Unfortunately, if history is a reliable guide, the billion dollar cost escimates will be trotted out for their scare-value, loaded with the insinuation that an active anti-alcohol pnIfcy now will save these wasted billions. Berry's work deserves a better fate. In any case, it is certainly appropriate at this time to review the method by which these estimates were produced and to assess the usefulness of such estimates for alcohol policy. These are the purposes of this paper.

It would not be fruitful to judge Berry and Boland's work against ideal standards of method and estimation, standards which are unattainabie largely because of limitations of the data available. What I try to do is judge their work against the standard which they set for themselves - that their estimates should be "conservative" estimates of the cost of alcohol abuse. Berry and Boland point out that although we cannot know with certainty the costs of alcohol abuse 
VII-2

TABLE 1

Estimated Costs of Alcohol Abuse, U.S., 1975 (billions of dollars)

Sources of cost due to alcohol'

1. Lost production

19.64

among males 21-59

among the military

15.46

premature mortality

.41

3.77

2. Health care costs

12.74

3. Motor vehicle crashes

5.14

4. Fire losses

.43

5. Social responses

1.94

social welfare system

alcohol programs

highway safety

fire protection

criminal justice

(non-violent crime)

1.27

.08

.03

.39

.17

Sources of cost associated with alcohol

6. Violent crimie

cost of violent crime criminal justice system

(violent crime)

Source: Berry and Boland 1979. 
using current information, 1 is useful nonetheless to know the cost of alcohol abuse is at least a certain amount (1977, p. 193). Set against the standard of a conservative approach to estimating cost, I find two major faults in Berry and Boland's method: First, as regards alcohol as a consumer good. Berry and Boland minimize the scope for intelligent consumer decision-making in alcohol purchase by assuming no adverse effects of alcohol are foreseen anc taken into account by users. The costs of alcohol which are offset by benefits to consumers are assumed to be limited to the money price of the beverage. This extreme assumption leads to overstatement of the social costs of alcohol abuse. Second, as regards causaltty. Berry and Boland consistently interpret a statistical association between alcohol and social costs, such as use of health resources, as indicating a causal relation. Improving specification of the relation between alcohol and social costs would tend to reduce the estimated impact of alcohol abuse.

For both reasons, Berry and Boland's cost estimate tends to overstate the true cost. These important topics are addressed in Sections 2 and 3 resfectively. There are other reasons why Berry and Boland's $\$ 42.75$ billion estimate would tend to understate the true cost of alcohol abuse. The primary ones are, first, that Berry and Boland do not attempt to value the "intangible" costs of alcohol abuse due to pain and sufferlng; second, that the "value of a life" is understated; and third, that the inventory of cost items is (inevitably) incomplete. These points are recognized by Berry and Boland and we deal with them only briefly in Section 4, containing comments on the specific methods 
behind the estimates of the components of cost in Table 1 .

A final important conclusion has to do with the general usefulness of these cost estimates. The conclusion is that studies of the total cost of alcohol abuse should not be used in formulation of public policy. For policy we need to know how costs change with respect to policy decisions regardless of the level of total cost. This is discussed in Section 5 which concludes the paper.

This review will emphasize the shortcomings rather than the contributions of Berry and Boland's work. Without attempting to do justice to those contributions, it is important to recognize them as being substantial. Berry and Boland have probably dore more to raise the standard of cost studies in the alcohol, drug abuse and mental health field than any other authors. They were the first to rigorous1y face up to the difficulties of statistical inference with the sketchy data avallable. They were the first to clearly focus attention on social cost rather than simple money flows associated with 11lness and abuse. For the rest of this paper we focus on Berry and Boland's The Economic Cost of Alcohol Abuse, which contains the most thorough discussion of thetr approach.

Berry and Boland attempt to break no ground with respect to the definttion of alcoholism or alcohol abuse. In counting the costs of lost productivity and extra health care due to alcohol abuse and alcoholism, Berry and Boland study the behavior of alcoholic or abuser populations defined by other researchers. When studying costs of 
crime, accldents and fires, their definition of costs of abuse broaden to include costs imposed by anyone from abusive drinking. Thus the costs of motor vehicle accidents, for example, attributable to alcohol abuse are not just the accidents caused by alcoholics whose driving is impalred but the accldents caused by alcohol abuse by any driver.

\section{Alcohol as a Consumer Good}

The costs and benefits of alcohol consumption go partly to the direct user (or abuser) of the alcohol and partly to others in society. Some of the henefits, such as satisfying taste and relaxing effect, and some of the cests, such as purchase price of the beverage, fall on the direct user of the alcohol. These private benefits and costs are completely analogous to the benefits and costs from any other commodity In the economy - softdrinks, shirts, washing machines, and so on. Berry and Boland are not concerned with these. Benefits and costs of alcohol are exclucied from their study as long as they are taken into account In the decision to buy the alcohol. Thus, benefits and costs qualify for inclusion in Berry and Boland's study of social costs if they meet one of two criterla: 1) they are external to the user, falling on some other member of society; or 2) they fall directly on the user but they are not, because of 1gnorance or irrationality, taken into account by the user in his decision to use alcohol.

The reason that private costs, such as the purchase price of the alcohol, should not be part of an accounting of the soclal cost of alcohol abuse, is that because we know they are more than offset by 
the private benefits of consuming alcohol (Berry and Boland have a good discussion of this on p. 11) In 1977 Americans spent $\$ 28.2$ billion on alcoholic beverages. The $\$ 28.2$ billion is not counted as part of the social cost, even though real resources worth approximately $\$ 28.2$ b111ion (actually somewhat less because of the high taxes levied on this industry) are used to produce the alcohol, because this cost is offset by the value of alcohol as a consumption good. The reasoning is that since consumers chose to spend the $\$ 28.2$ billion, the benefits must have been at least worth $\$ 28.2$ billion, otherwise consumers would not have freely chosen to spend the money. If there were no externalities in consumpilon of alcohol or irrationality in choices, it would be clear cut, using this reasoning, that the benefits to alcohol must exceed the costs.* It is true, in any case, for the part of the costs taken Into account by users, the benefits must exceed those costs or the alcohol would not have been purchased.

This leads to the issue I want to address in this section. How much of the "costs" of alcohol use and abuse are taken into account by the users? Berry and Boland assume the only ccst of alcohol consumption taken into account by the user is the purchase price.

* Part of Berry and Boland's discussion of this is misleading. They incorrectly state on p, 12 that net benefits to users; total benefits less price paid, must be some fraction of the amount pald for the product. This is not so. Net benefits can be any arount greater than amount paid. Without information on the value of all purchases (which could be estimated if we knew the "demand curve" for alcohol), we cannot infer net benefit. It is therefore not true, as Berry and Boland assert on $p .13$ that it is unlikely that net benefits to users outwelgh the costs 1mposed. We have no basis for fudging net benefits and therefore no basis for comparison. 
All other costs are assumed to be irrationally ignored, qualifying them therefore for inclusion in the "social cost" category. If they are not ignored by the user we can use the reasoning just outlined to say that any cost taken into account - money or otherwise - is known to be more than offset by benefits. Any cost considered by the user should therefore, using Berry and Boland's reasoning, not be included in the social accounting.

I think it is unreasonable to assume that the only cost of alcohol use recognized by the user is the money cost, and to assume that all other unfortunate effects are irrationally ignored. Users of alcohol are often able to foresee the adverse consequences of their drinking. Many of us make consclous decisions, presumably in a rational way, about how much we are going to drink on some occasion, perhaps golng as far as limiting ourselves to one drink after dinner, for example, so as not to be seriously impalred while driving home. We may fully realize when we make this decision that even one drink may diminish our driving skilis and that by drinking we are putting ourselves at some additional risk of an accldent. Realizing this we may still decide to have the drink because for whatever reason the enjoyment we get from it exceeds in our mind the cost of the extra risk of an accident. Is this decision 1rrational? Along the same line, many of us realize that even moderate drinking can have some adverse consequences for health. We choose to drink anyway. Is this irrational?

One could argue that many of the personal consequences of alcohol are well-known, and that drinkers generally take them into account, 
weighing unfortunate consequences such as possible accidents and illness against the pleasures from drinking. This argument would most convincingly apply to the majority of drinkers who are not alcoholics and for whom drinking represents a free choice. Under this argument any unfortunate consequence of drinking that affects tha drinker would be regarded as being more than balanced off by the private benefits of drinking. Many of Berry and Boland's cost items would be dropped: all health costs borne by the drinker, all costs of accidents which fall on the drinker, all work days lost from drinking by non-alcoholics and so on.

Full acceptance of this argument, that non-alcoholic drinkers are fully informed about the effects of alcohol and rational in their decision to use alcohol is unlikely outside of economists of the "Chicago School". It is an extreme position that I would not advocate; but it is an extreme position of the other side, to say that none of the adverse consequences of alcohol are foreseen by drinkers. Th1s other extreme position is the one taken by Berry and Boland. This is no more justifiable than it is to state that drinkers take all costs into account. The truth is somewhere in between. Some of the adverse consequences of alcohol use are foreseen and taken into account by tusers. To assum 2 none, beyond the money cost, are taken into account is to assume a wide scope for irrationality in alcohol purchase and to adopt a "liberal" definition of effects that can be included in a study of social cost. 
VII-9

\section{The Issue of Causality}

Another way that Berry and Boland are liberal in measurement of the costs of alcohol abuse is by consistently interpreting unfortunate effects, such as work days lost and higher health care costs, associated with alcohol abuse as being caused by alcohol abuse.

Correlation (or association) does not necessarily imply causation as we all know. In general, the true or causal effect of alcohol abuse on the various measures of cost may be larger or smaller than the simple association. To make the argument that Berry and Boland overestimate the effects of alcohol we must say more than they interpret association as causality. After fllustrating Berry and Boland's use of association, I will go on to argue that the statistical circumstances in which simple association will overstate causality are very likely to be present in attempts to estimate the effects of alcohol abuse.

Alcohol abuse is not an "accident"; i.t may be caused by some other problem, such as mental disorder or stress. In a typical simple comparison of alcohol abusers and non-abusers, the abuser population has more problems of many sorts than the non-abuser population. To interprat the effects of all these problems as being caused by alcohol, to say that the abuser population would be the same as the nonabuser population if only they wouldn't drink so much, is to overstate the importance of alcohol. 
Berry and Boland's method and why it likely leads to overstatement of the effects of alcohol abuse can be 1llustrated by considering how Berry and soland estimate the lost productivity due to alcohol abuse, the most 1mportant cost category of Table 1. Other coments about this estimate are given in the next section. Hare I focus on the inference from the incomes of families with and without a male abuser present (abuser defined in this context on p. 44) about how much income is lost due to alcohol abuse.

The data for this part of the computation cost come from a national sample of 1561 households in 1968 conducted by the Social Research Group of the UnIversity of California at Berkeley. 285 households (18.3\%) had an alcohol-abusing male present aged 21-59. A crude measure of the effect of alcohol abuse on household income Is the difference in the average income of households with and without an alcohol abusing male present. The computation of the income loss using this "crude" method is shown in Table 2. The difference in income in the two types of households is interpreted as the income loss caused by the presence of the alcohol abusing male. If the male were not an alcohol abuser, it is assumed in this approach that the household income would be the same as the average for households where no abuser was present. The total cost of alcohol abuse for this group of households is thus the number of households experiencing the income loss times the average income loss, $\$ 559,740$.

The vulnerable part of this logic is the part which says that If we took away the alcohol, the abusing households would be the same 


\section{TABLE 2}

Crude Measure of Income Loss due to Alcohol Abuse

\begin{tabular}{llll} 
& \multicolumn{3}{c}{$\begin{array}{c}\text { Average Annual Income } \\
\text { foe. Houseliolds with }\end{array}$} \\
& $\begin{array}{l}\text { No Abuser } \\
\text { Present }\end{array}$ & $\begin{array}{c}\text { Abuser } \\
\text { Present }\end{array}$ & Difference \\
$\begin{array}{l}\text { Average Income } \\
\text { (no. of househoids) }\end{array}$ & $\begin{array}{l}\$ 10689 \\
(1276)\end{array}$ & $\begin{array}{c}\$ 8725 \\
(285)\end{array}$ & $\$ 1964$
\end{tabular}

Cost Computation:

$285 \times \$ 1964=\$ 559,740$ extra income would hive been earned had there been no abusers

Source: Adapted from Berry and Boland 1977, Table 2-2. 
as the non-abusing households. Alcohol abuse is not a random event that befalls some households and not others unrelated to other factors. Without taking into account these other factors, including work force and other social experfences, education, personal characteristics, mental state, and family stability - which may themselves have an independent effect on income - the simple crude comparison of the incomes of the abusing and non-abusing households will not be a good estimate of the effect caused by alcohol abuse.

The 1968 household survey allows Berry and Boland to directly take into account one other factor; age. As the survey shows, older households have higher income on average than younger iouseholds. Older households are also less likely to have an abuser present. This means that in the crude estimate of the effect of alcohol abuse In Table 2, younger households are "overrepresented" in the "abuser present" households category. The "no abuser present" and "abuser present" categories are not the same except for the drinking. Some of the crude differences in incomes between the two categories is due to the different ages of the households, not to alcohol abuse. Berry and Boland correct for this by showing differences in income between abuser and non-abuser households within each age category. This is shown here in Table 3 .

For all age groups but 40-49 years, the difference in income between the abuser and the nonabuser households is less than the gross difference between the abuser and nonabuser household 3 not controlling for the effects of income. Suming the average difference for the 
TABLE 3

Income Loss due to Alcohol Abuse Adjusted for Age

\begin{tabular}{|c|c|c|c|}
\hline & (numb & $\begin{array}{l}\text { e Annual } \\
\text { ouseholds } \\
\text { seholds }\end{array}$ & theses) \\
\hline & $\begin{array}{c}\text { No abuser } \\
\text { Present }\end{array}$ & $\begin{array}{l}\text { Abuser } \\
\text { Present }\end{array}$ & Difference \\
\hline Age & & & \\
\hline $27-29$ & $\begin{array}{r}9692 \\
(284)\end{array}$ & $\begin{array}{r}\$ 7875 \\
(108)\end{array}$ & $\$ 1817$ \\
\hline $30-39$ & $\begin{array}{l}11252 \\
(330)\end{array}$ & $\begin{array}{l}9303 \\
(66)\end{array}$ & 1949 \\
\hline $40-49$ & $\begin{array}{l}11118 \\
(331)\end{array}$ & $\begin{array}{l}8983 \\
(59)\end{array}$ & 2135 \\
\hline $50-59$ & $\begin{array}{l}10556 \\
(337)\end{array}$ & $\begin{array}{l}9462 \\
(52)\end{array}$ & 1094 \\
\hline
\end{tabular}

Cost Coranutation

$108 \times \$ 1817=\$ 196236$

$66 \times 1949=128634$

$59 \times 2135=125965$

$52 \times 1.094=\underline{56888}$

$\$ 507723$

Source: Berry and Boland 1977, Table 2-2. 
285 abusing households from Table 3 yields a revised estimate of income loss of $\$ 507,723,9.3 \%$ less than the first estimate.

Age is of course not the only other factor that influences income. Education, class-position, motivation, work-force experience and other factors have all been shown repeatedly to influence earnings. How would the estimate of the effect on earnings of alcohol abuse have been affected if these additional factors had been considered? Adding another variable to explain income w11l reduce the estimated effect of alcohol abuse if the variable is correlated with income in opposite sign to its correlation to alcohol abuse. This was the case with age. Older workers had higher income and were less likely to be abusers. Age was positively correlated with income and negatively correlated with alcohol abuse.

I believe it is reasonable to expect that most other variables known to be important in explaining income will be positively correlated with earnings and negatively correlated with alcohol abuse. I would expect education, motivation, and work force experience, to take some important examples, to be positively related to income and negatively related to alcohol abuse. If this is true, then when these variables are omitted the simple association of alcohol abuse and low income overstates the effect of abuse.

Berry and Boland acknowledge this problem and try to deal with it. They rely on Luft's (1975) estimate of the interaction effect of general "ill health" and age, education, family structure and region 
of the country to adjust downwards the estimates on the effect of alcohol abuse coning from Table 2. According to Luft's work, these four sets of variables account for $23.9 \%$ of the total asscciation of 111 health and low income. Presuming that alcoholism is similar to general ill health in this regard, Berry and Boland reduce the original estimate of $\$ 559,740$ downward by $23.9 \%$.

Even granting the assumption that alcoholism and general 111 health are sufficiently similar so that using Luft's estimate of the interaction among independent variables makes sense, there is still the issue of the many factors omitted from consideration and their effect on the estimate of the impact of alcohol abuse. To stress the importance of these omissions, suppose for a minute we knew something extra about the people in this survey: whether or not the male in the household has had "favorable" or "unfavorable" experiences in the work force.* This will serve to illustrate the need to know why alcohol 1.s being abused and whether the reason it is being abused has any influence itself on the apparent costs of alcohol abuse.

Thcse who have had favorable work experlences are likely to have higher income. It is also reasonable to think that although causality probably runs in both directions, unfavorable work experiences may sometimes contribute to alcoholism. Revised by the presence of these "facts" - the positive correlation of favorable work experiences with earnin̨̧ and negative correlation of favorable work experiences with alcohul abuse - the Berry and Boland data might look like that In

* The interaction of this factor with alcohol is studied by Calahan (1970). 
Income Loss due to Alcohol Abuse Adjusting for Age and Work-Force Experience

\begin{tabular}{|c|c|c|c|c|}
\hline Age & $\begin{array}{l}\text { Work-force } \\
\text { experience }\end{array}$ & Non-Abuser & Abuser & Difference \\
\hline \multirow[t]{2}{*}{$21-29$} & unfavorable & $\begin{array}{r}9400 \\
(113.6)\end{array}$ & $\begin{array}{r}7650 \\
(86.4)\end{array}$ & 1750 \\
\hline & favorable & $\begin{array}{r}9887 \\
(170.4)\end{array}$ & $\begin{array}{r}8775 \\
(21.6)\end{array}$ & 1112 \\
\hline \multirow[t]{2}{*}{$30-39$} & unfavorable & $\begin{array}{l}10913 \\
(132)\end{array}$ & $\begin{array}{r}9037 \\
(52.8)\end{array}$ & 1876 \\
\hline & favorable & $\begin{array}{l}11478 \\
(193)\end{array}$ & $\begin{array}{l}10366 \\
(13.2)\end{array}$ & 1112 \\
\hline \multirow[t]{2}{*}{$40-49$} & unfavorable & $\begin{array}{r}10783 \\
(132.4)\end{array}$ & $\begin{array}{r}8726 \\
(47.2)\end{array}$ & 2057 \\
\hline & favorable & $\begin{array}{r}11341 \\
(198.6)\end{array}$ & $\begin{array}{r}10010 \\
(11.8)\end{array}$ & 1331 \\
\hline \multirow[t]{2}{*}{$50-59$} & unfavorable & $\begin{array}{r}10238 \\
(132.4)\end{array}$ & $\begin{array}{r}9192 \\
(41.6)\end{array}$ & 1046 \\
\hline & favorable & $\begin{array}{r}10768 \\
(198.6)\end{array}$ & $\begin{array}{r}10544 \\
(10.4)\end{array}$ & 224 \\
\hline
\end{tabular}

$86.4 \times 1750=151200$.

$21.6 \times 1112=24019.2$

$52.8 \times 1876=99052.8$

$13.2 \times 1112=14678.4$

$47.2 \times 2057=97090.4$

$11.8 \times 1331=15705.8$

$41.6 \times 1046=43513.6$

$10.4 \times 224=2329.6$

447589.8

Source: hypothetical data consistent with Berry and Boland 1977, Table 2-2. 
Table 4. (We have assumed specifically that $40 \%$ of the non-abusers have had unfavorable work experience and $80 \%$ of the abusers have had unfavorable work experlence.) These data as displayed are fully consistent with Berry and Boland's data in Table 3. Adding workers with favorable and unfavorable experlence in each category yields the total number and correct averages as shown in Table 3 . 3y including consideration of work experience in our 11lustrative analysis, we can see again how the estimated effect of alcohol abuse is further reduced. With thes? "reasonable" sets of numbers, the lost income is estimated to be only $\$ 444,590$, down $12 \%$ from the estimate in Table 3 .

Berry and Boland could not, of course, correct for work-experience or any other influence on income that may have had important interaction effects with the impact of alcohol abuse. All that can be asked of researchers 1s that they recognize that in the absence of these corrections, simple association of alcohol withother income or other unfortunate effects will likely overstate the influence of alcohol.

\section{Components of Cost}

This section is made up of a series of brief comments on Berry and Boland's method not already covered in Sections 2 and 3 .

\section{4a. The Economic Cost of Lost Production}

\section{Causality: add1tlonal comment}

As we stressed in Section 3, if alcohol abusers are often beset by a range of protlems, the simple association of alcuhol and low pro- 
ductivity overstates the causal relation. Berry and Boland themselves cite good evidence on this (page 36), a study by Winslow (1966) that showed lower productivity characterized "problem workers whether or not they also were drinkers."

Lower wages as a measure of the impact of alcoholism

Berry and Boland have a very good discussion (p. 42-43) of the conditions under which lower productivity due to alcohol abuse will be reflected in lower wages of abusers. If employers imperfectly perceive productlvity differences, the costs of lower productivity will in part be shazed by all workers (who must accept a lower average wage) rather than being borne entirely by abusers. By assuming all 1ost productivity costs are borne by abusers, Berry and Boland conservatively measure abusers' Impact.

\section{Classification error}

The basic method to identify productivity differences involves a first step of classsifying workers into abuser and non-abuser categories. To the extent this is done imperfectly (some workers are wrongly classified) the magnitude of the difference in productivity between the groups is understated.

This comment applies to all forms of cost comparisons in addition to productivity.

Prevalence

Berry and Boland revlew the 11terature on the prevalence of al- 
cohol abuse among workers, reporting estimates as 10 as $1 \%$ of the work force (p.37-38). In making their own estimate of costs, they choose the highest prevalence rate reported, $18 \%$ of adult males from the Berkeley group survey.

\section{Incomplete estimates}

Lost production of women and in non-market sectors is not included. This represents a major underestriation of costs.

The vilue of a $11 \mathrm{fe}$

The cost of a lost worker from death due to alcohol abuse is estimated to be only the present value of lost wages. No good method exists for otherwise estimating the value of a life. Common sense and recent theoretical work in economics (Conley, 1976) coincide to suggest that the full value of a life to society (including to the worker) exceeds the wages that would have been earned.

\section{Unemployment and labor markets}

In an economy characterized by Involuntaxy unemployment, rehab1litation of an alcoholic may increase the labor force, but if total employment is determined by total demand for labor only, the number of employed may not rise at all. Only the unemployment rate would be affected. This very simplistic model of labor marke;s has little value. An appropriate "correction" for involuntary unemployment would be to assume rehabilitated alcohol abusers are involuntarily unemployed with the sarne (or slightly higher) frequency as the average worker. This would represent a small correction on estimates of lost productivity. 


\section{4b. Health Care Costs}

\section{Causal1ty}

In estimating lost productivity due to alcohol abuse, Berry and Boland showed an awareness of the problem of inferring causality from simple assoctations, and attempted to correct where they could for influence of other factors, such as age, that are associated with alcohol abuse and influence productivity. In developing estimates of the health care costs, there is no attempt to go beyond the cruder comparison of use of health servlces by alcoholic and non-alcoholic populations, the type of comparison in Table 2 above.

The major problem in this section, tending to overstate costs of: alcohol abuse, is the disregard of other factors, such as mental illness and disorder, which are positively associated with alcohol abuse and may also be the cause of extra health costs.

\section{Reliability of estimates}

Good data are avallable to estimate the crude difference in use of hospltal services by alcoholics and non-alcoholics (p.84-85). Berry and Boland handle this data well, checking one source against another for aggregate conststency. The data on differences in utilization is not good for all services outside of hospitals.

\section{Expert opinion}

Experts at alcoholism treatment centers may tend to overstate use of health services by alcoholics (p. 81-82). 


\section{Training costs}

Costs of training (p. 73) should not be added in except to the extent training is not pald for by the trainee. Trainee's costs will be reflected in wages of professionals. To include these would then be double-counting, the same as counting in construction costs of hospitals and full hospital day price including an amount to pay off construction bonds.

\section{Dmitted costs}

The cost of treating alcohol abuse in a number of parts of the health sector are omitted, especially from the mental health sector, for example, in Community Mental Health Centers. Also, employee assistance plans, now fairly widespread in industry, have a primary orientation to alcohol and drug abuse counseling. A more comprehensive accounting of costs would raise estimates.

\section{4c. Motor Vehicle Accidents}

\section{Causality}

Berry and Boland are sensitive to the problem of inferring causality from assoctation (p. 107):

When an accident occurs that involves a young, relatively inexperlenced driver who was exceeding the speed limit on a wet road at 2 am and who was found to have BAC in excess of .05 percent, it is one thing to determine that alcohol was present; it is still another to determine the net causal role of alcohol abuse.

In spite of this statement, Berry and Boland make no attempt to correct for influences of age, experfence, time of day, personal 
recklessness or other factors in accidents. Nor do they recognize that omitting these factors (which is necessary in the absence of data) is likely to lead to an overstatement of the effect of alcohol on accidents.

\section{Intangible costs}

Berry and Boland consider the "intangible" cost of accidents pain and suffering - but decline to value it in dollars. This may be the right strategy; it is clearly conservative and, as they recognize, tends to understate total costs.

\section{Data reliability}

The data are good for estimating crude differences in accident rates by drinkers and non-drinkers. Berry and Boland handle the data in a creative fashion.

\section{Value of a life}

By valuing a life only at lost production, total costs are understated.

\section{4d. Fires}

Data for this section are very "soft". These estimates are highly unreliable and further relate only to the association between drinking and losses due to fire. Double-counting is anticipated and handled adequately.

4e. Crime

Berry and Boland distingulsh these estimates from others pre- 
sented in the book. The cost of crimes are those found to be associated with alcohol rather than caused by alcohol. While the problem of Inferring causality troubles all estimates presented, Berry and Boland apparently judge the problem to be so severe in this category of costs that no statement on causality is justified. They admit (p. 147), "Existing research is simply Inadequate to assess the extent to wintch the costs of crime may be due to alcohol abuse".

\section{Value of a life and intanglble costs}

Valuing a life only at lost productivity and neglecting fear, pain and suffering lead to a vast understatement of costs of violent crime assoclated with alcohol.

\section{Property crime as "transfer"}

The value of property stolen has traditionally not been counted as part of the cost of crime because the property is not destroyed, it is simply "transferred" to a new owner. However, since the new owner refused to buy the property at 1 ts market price and was only willing to do so at the "black market" pilce, the new (post crime) allocation of property is inefficient. A legitimate cost equal to the difference in wlllingness to pay between the old and new owners times the quantity of merchandise transferred should be added to the cost of crine.

\section{4e. Soctal Responses}

These costs are all quite legitimately included in an accountIng of social costs and are rewonably estimated. Berry and Boland 
have only included the most obvious of these social responses. A more comprehensive list would add to the estlmated total cost. Much of the response to alcohol abuse is pald for out of private, not public, budgets. Some part of home fire prevention equipment, burglar alarms, safety features in automobiles and many other private expenditures are also social responses to alcohol abuse.

\section{Summary anc Conclusions}

Berry and Boland's $\$ 42.75$ b1llion is an estimate of the total cost of alcohol abuse. It cannot be defended as a conservative estimate. The major reasons that the estimate tends to overstate costs are: 1) other than purchase price, no other costs of abuse are assumed to be offset by benefits, and 2) the causal relation between alcohol and costs is overstated by association. But on the other hand, it cannot be accused of being 1itueral. The reason the estimate tends to understate costs are: 1) undervaluing loss of lives; 2) neglect of intangible costs; and 3) incomplete accounting of all costs. It is 1mpossible to know whether the "true" costs are greater or less than $\$ 42.75$ billion.

It must be emphasized that the $\$ 42.75$ billion estimate is highly imprecise. A truly conservative estimate of the costs - countIng only costs "beyond a reasonable doubt" that could be attributed to alcohol abuse - would be very low. None of the costs in the major categories -- lost productivity, health care or motor vehicle accidents -- can be, with exisitng empirical work, attributed beyond a reasonable doubt to alcohol abuse. A generous or liberal estimate of costs would 
be much larger than $\$ 42.75$ billion. It would include a "best guess" about the costs due to lost productivity, health, accidents and so on (which is not the same as costs attributable beyond a reasonable doubt). It would also include - and here is where the total can be made almost arbitrarlly higher - dollar values for lost lives and pain and suffering. Berry and Boland are extremely conservative in this realm. It would be easy to argue for higher total costs emphasizing these effects of alcohol abuse.

It involves major logical error to conclude from any estimate of the total cost of alcohol abuse (however well-prepared) that there should be a more (or less) active program to prevent alcohol abuse. High total costs do not justify action. We must know that the costs are responsive to action to proceed. Studies of the total cost tell us nothing about how total costs would change with respect to any policy action. In economists! terms, we should be interested in marginal costs, not total costs.

Consider a particular policy say, establishment of additional detoxification clinics. While this might decrease some elements of total cost such as lost productivity, health costs and others, it will raise other elements of total costs; the "soclal response" costs. The 1ssue of whether this program makes sense has to do with whether the total costs go up or down by taking this action. The absolute level of total costs is, in fact, frrelevent. What we need to know are costs of additional action and the benefits (reductions in cost elsewhere) that result from that action. 
Studies of total cost are not designed to provide this information. What all this comes down to is a judgment that except in helping to develop methodology, and possibly in helping to point out areas where new programs might be consldered, studies of total cost are not very useful.

Future research should focus on the costs and benefits of particular programs and policles, not on social totals.

This review also makes clear that alcohol pollcy will be on shaky ground until the relation between alcohol and other factors is better understood. Alcohol may not be the problem at all; discrimination, stress or mental illness may be much more important. If alcohol abuse is not the root cause of the trouble, reducing alcohol abuse through social policy may lead to no social gains, only in costs appearIng in some other sector of the economy and being attributed to some other proximate cause. Research on the $r$ sons for drinking and the complex behavior of which drinking is a part need to be studied to make progress on alcohol polfcy. 


\section{REFERENCES}

Barry, Ralph E. Jr. and Boland, James P., The Economtc Cost of Alcohol Abuse, The Free Press, 1977.

Berry, Ralph E. Jr., Boland, James P., Smart, Charles $N$. and Kanak, James R., "The Economic Cost of Alcohol Abuse, 1975", for NIAAA, DHEW, Final Report, ADM 281-76-0016, August, 15, 1977.

Cahalan, Don, Problem Drinkers: A National Survey, Jussey-Bass, San Francisco, 1970.

Conley, Brian C., "The Value of Human Life in the Demand for Safety", American Economic Review, 66:?, March 1976, Pp. 45-55.

Luft, H. S., "The Impact of Poor Health or Earnings", The Review of Economics and Statistics, 57, Feb. 1975, pp. 43-j7.

Pell, Sidney and D'Alonzo, C. A., "A Five-year Mortality Study of Alcoholic Persons", Alcohol Health and Research World, winter 1974/75, pp. 21-26.

Wins of Environmental Health, vol. 13, (1966), pp. 213-219. 
$9 \cdot 1$

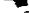

$3+$ 